\title{
IMPACTS OF A VARIABLE SPEED LIMIT SYSTEM ON DRIVER SPEED CHOICE AND CRASH CHARACTERISTICS DURING LOW VISIBILITY CONDITIONS
}

\author{
A Thesis \\ Presented to \\ The faculty of the School of Engineering and Applied Sciences \\ University of Virginia
}

In Partial Fulfillment

Of the requirements for the Degree

Master of Science (Civil Engineering)

Daniela E. Gonzales Hidalgo

November 2017 


\begin{abstract}
APPROVAL SHEET
This thesis is submitted in partial fulfillment of the

Requirements for the degree of

Master of Science (Civil Engineering)

Daniela E. Gonzales Hidalgo
\end{abstract}

This thesis has been read and approved by the Examining Committee:

Dr. Michael D. Fontaine

Thesis Advisor

Dr. Brian L. Smith

Dr. T. Donna Chen

Accepted for the School of Engineering and Applied Sciences:

Dean, School of Engineering and Applied Sciences 


\section{ACKNOWLEDGEMENTS}

It has been profound honor and privilege to have been able to pursue my graduate studies at the University of Virginia. I have been blessed to have met many wonderful people who have supported, encouraged, and pushed me beyond what I thought I was capable of achieving.

First and foremost, I would like express my utmost appreciation and respect for my advisor, Dr. Michael D. Fontaine. I was fortunate enough to be placed with a most excellent advisor, mentor, and professor who not only instructed me in courses, guided me along the entirety of this thesis, and spent countless hours helping me refine my work but was and is simply an exemplary model of the kind of professional I hope one day to be.

I am very grateful for the excellent professors and faculty that have instructed me, particularly Dr. T. Donna Chen and Dr. Brian L. Smith for serving in my committee and providing support and advice. I am especially thankful for Simona Babiceanu, Dr. Emily Parkany, Professor Jose Gomez, and Dr. Brian L. Smith, all who I met as an undergrad and were influential in my decision to not only continue my studies but continue them at this wonderful University.

I would also like to thank Katie McCann, Mike McPherson, and Tim Martin from the Virginia Department of Transportation for their assistance, support, and insights in the process of this research. Their work and assistance was the foundation of this thesis.

Lastly, I would like to thank my family and friends, who encouraged and supported me the entire process, especially my parents who made innumerable sacrifices for me to pursue my education. Support and encouragement came from many different forms yet in the end this achievement has been made possible by grace alone, to God be all the glory. 


\section{ABSTRACT}

Low visibility conditions can inhibit a driver's ability to perceive appropriate operating speeds, particularly during foggy conditions where the characteristics of the fog can vary spatiotemporally. By reducing visibility and contrast in the visual field, fog obscures crucial driving cues essential for perceiving depth and speed. Studies have shown that fog-related crashes tend to involve more vehicles and more severe injuries. Numerous agencies have installed countermeasures like weather advisory systems and variable speed limits (VSLs) to mitigate these conditions, but not many studies have quantitatively analyzed the results of these projects. In October 2016, the Virginia Department of Transportation (VDOT) activated a VSL system on a 12-mile section of Interstate 77 that runs through mountainous terrain in southwestern Virginia known to experience severe, recurring fog events with the objective of to reducing the quantity and severity of crashes in the corridor. This thesis assesses how the I-77 fog VSL system in Fancy Gap, Virginia affected driver speed choice and crash characteristics since its activation in October 2016. Prior to the installation of the VSL, drivers frequently drove much faster than the safe speed based on the stopping sight distance during fog. The VSL system sought to get drivers to travel closer to the safe speed based on available visibility by posting appropriate reduced speed limits.

The analysis examines the effect of the VSL system on driver speeds both before and after at a single site and across the corridor in the after period. Effects on crashes for the entire corridor are also examined. The results showed statistically significant reductions in mean speeds and variances after the VSL was activated, and drivers drove closer to the safe speed based on available visibility. Models developed to understand how the VSL system affected 
speed as a function of visibility showed that speeds are reduced by a statistically significant amount when VSLS are active. Trends in speed by posted speed limit were examined across the corridor, and it was found that compliance generally improved once drivers encountered reduced visibilities. Speeds did not change as much in transition areas leading into the area where the fog was present, however. Crash analysis revealed only two fog-related crashes in the after period, yielding reduced crash rates during low visibility conditions and indicating improved safety. The results of this VSL implementation may be used to further refine current VSL control algorithm to improve compliance even further and could serve as a reference for other agencies contemplating alternatives to improve safety at fog-prone areas given the indications that the countermeasure did have a positive effect. 
TABLE OF CONTENTS

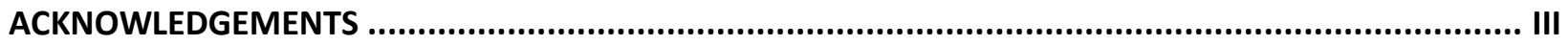

ABSTRACT

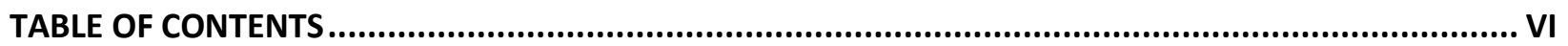

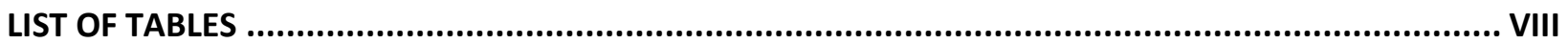

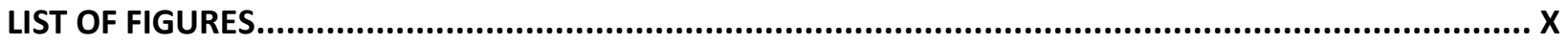

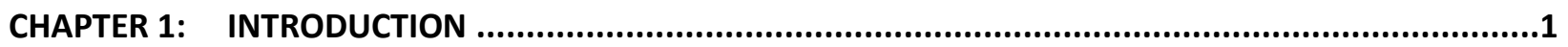

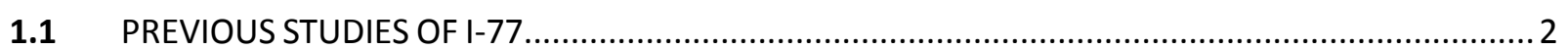

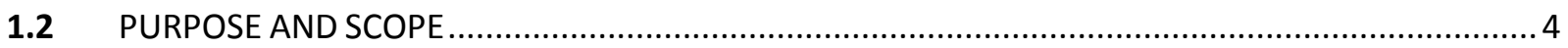

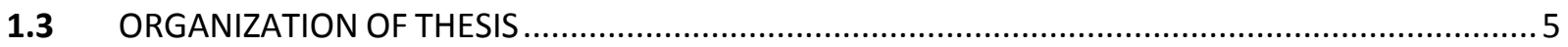

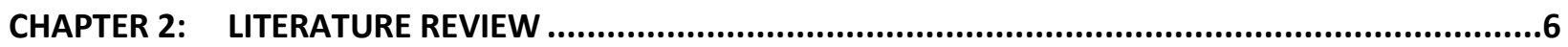

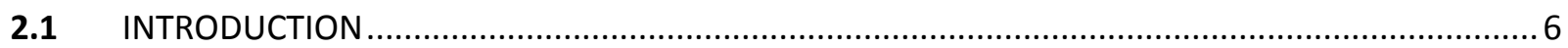

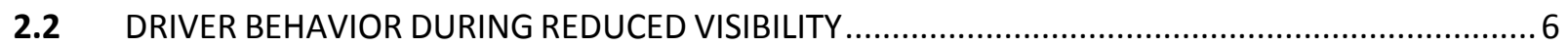

2.3 FIELD DEPLOYMENTS OF COUNTERMEASURES TO ADDRESS LIMITED VISIBILITY....................... 8

2.3.1 ADVISORY VISIBILITY WARNING SYSTEMS ............................................................ 9

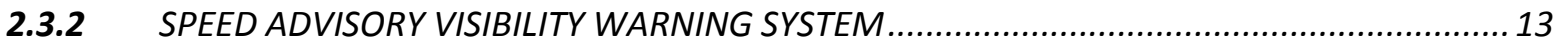

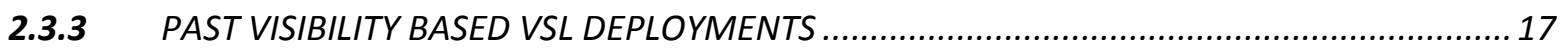

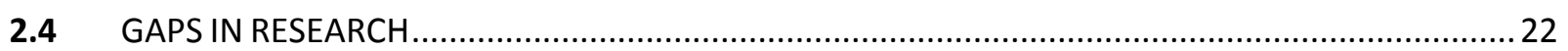

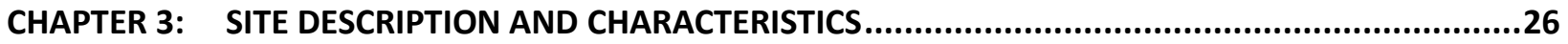

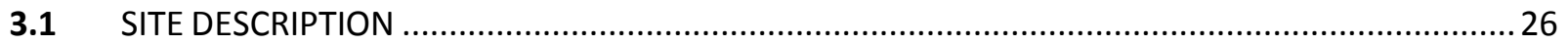

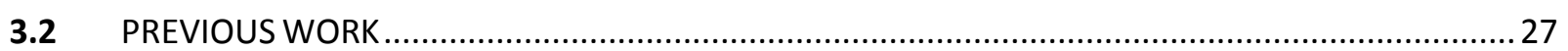

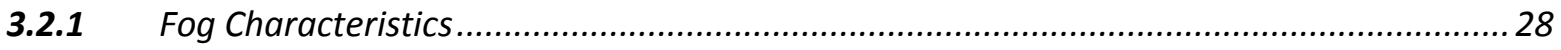

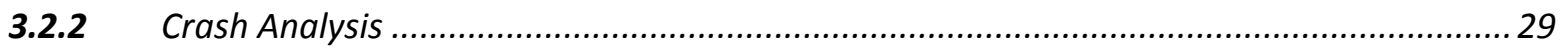

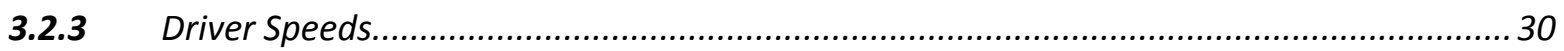

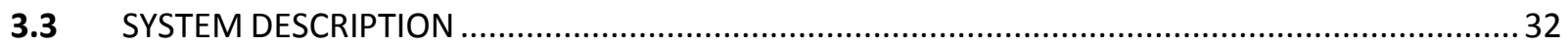

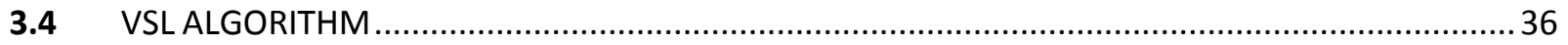

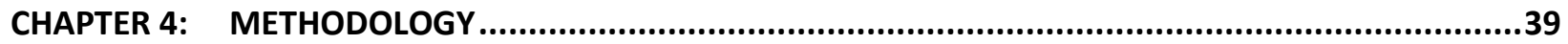

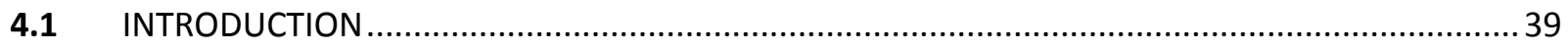

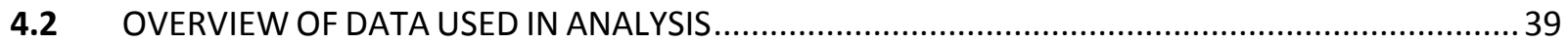

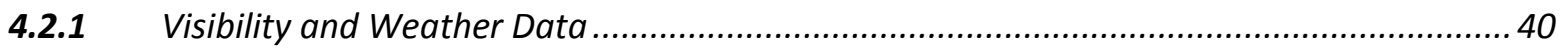

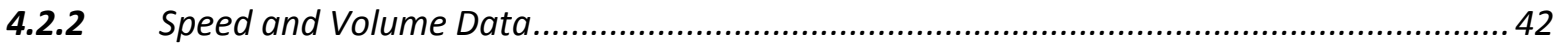

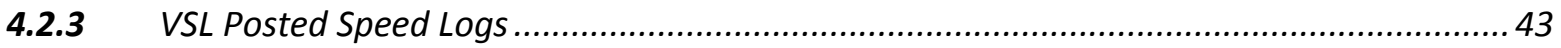

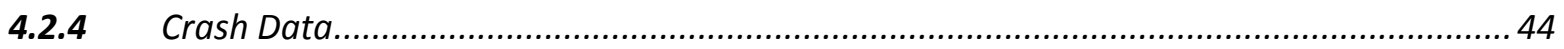

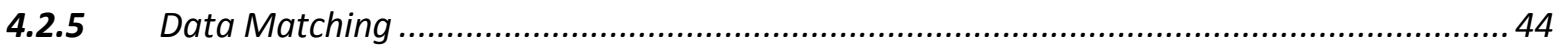

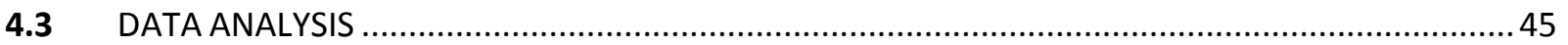

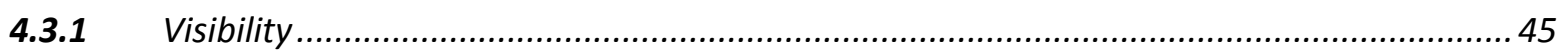

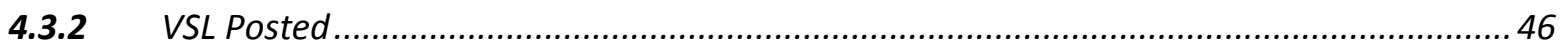

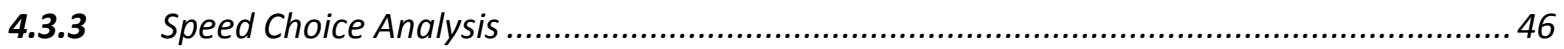

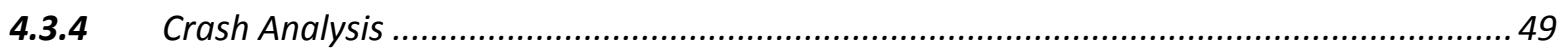




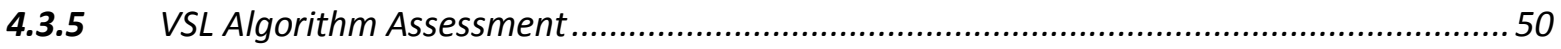

CHAPTER 5: $\quad$ RESULTS

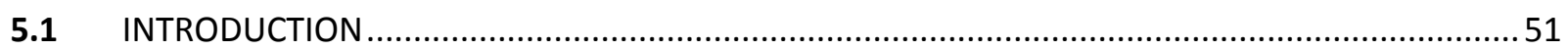

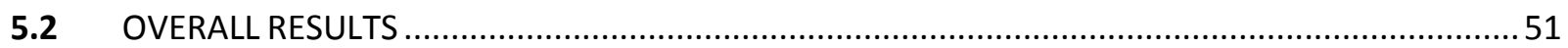

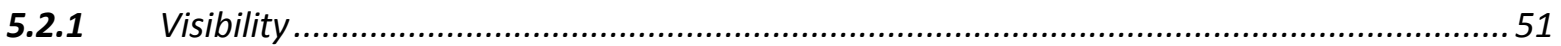

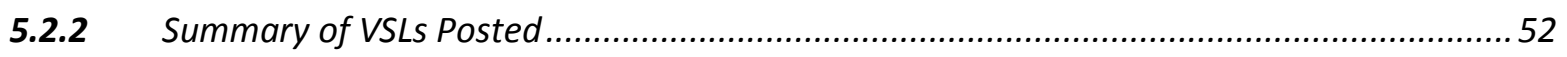

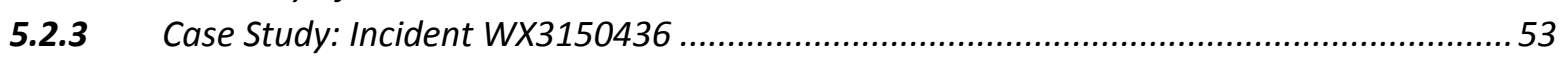

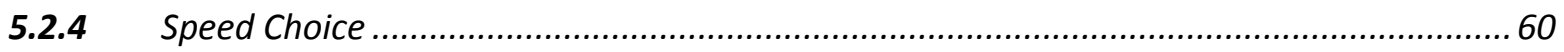

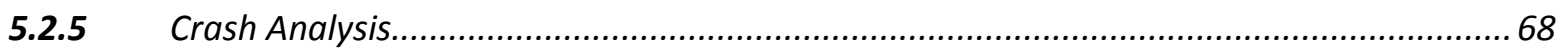

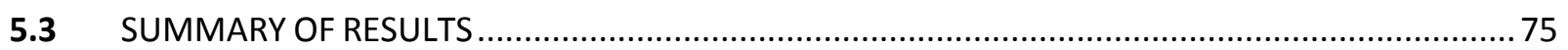

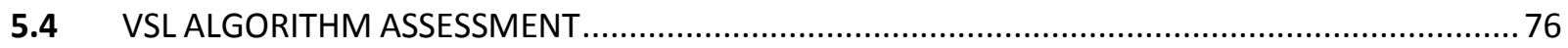

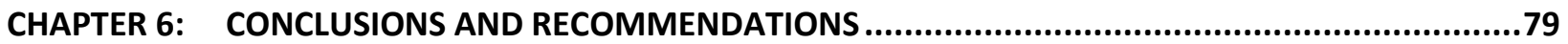

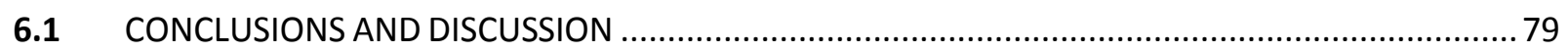

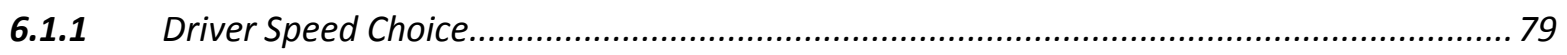

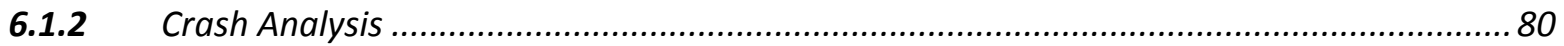

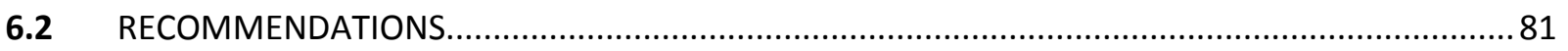

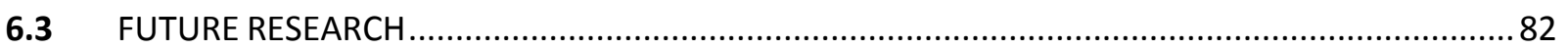

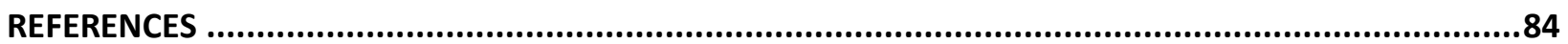

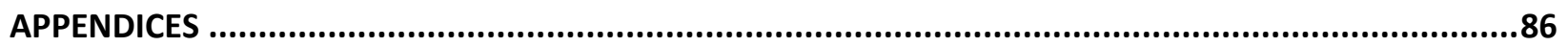

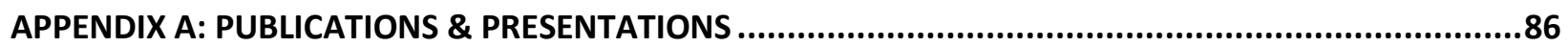

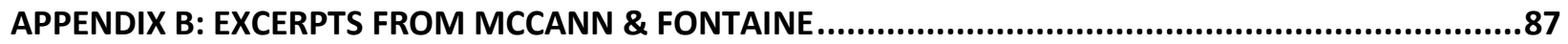

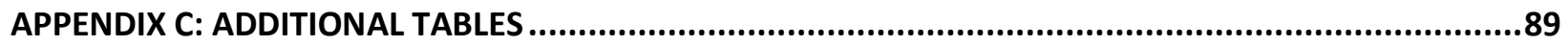




\section{LIST OF TABLES}

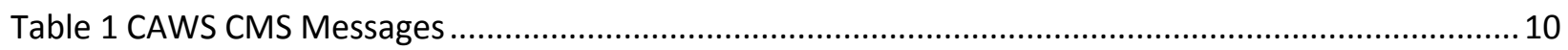

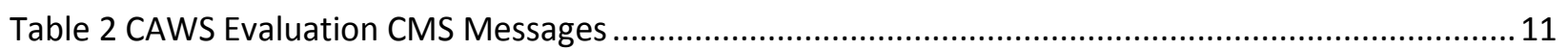

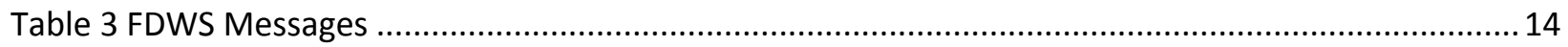

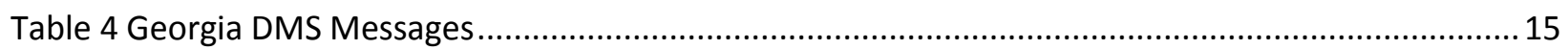

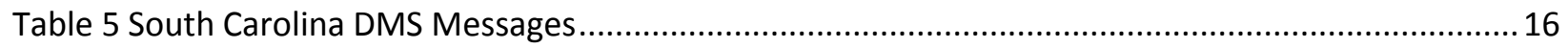

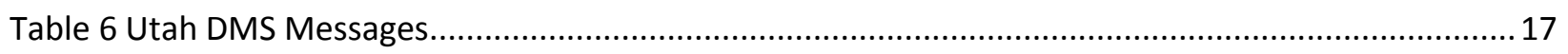

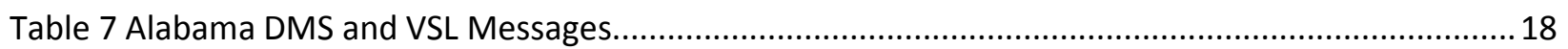

Table 8 Oregon a) Grip Factor and b) Chain Conditions Lookup Tables for Weather Subsystem (23)....... 19

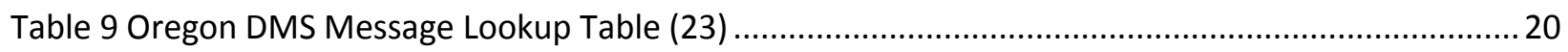

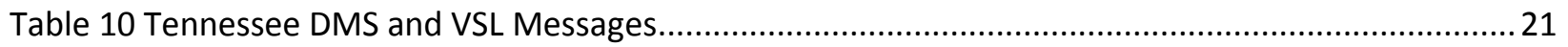

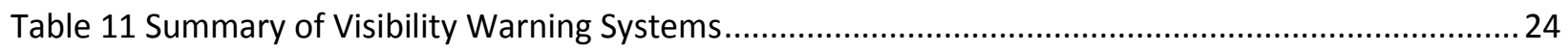

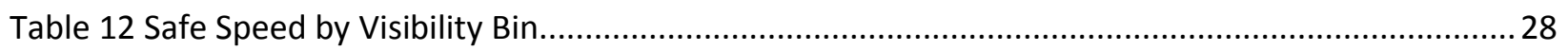

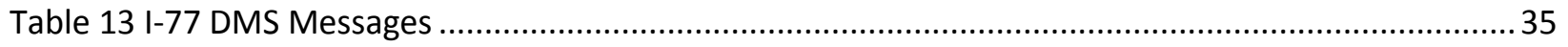

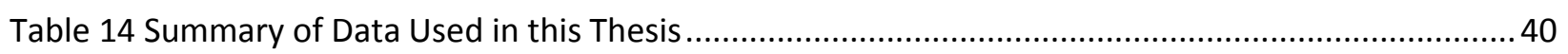

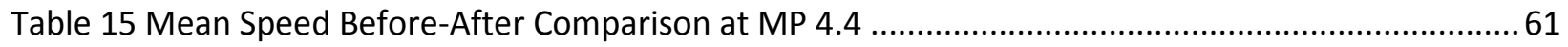

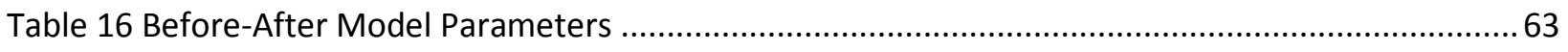

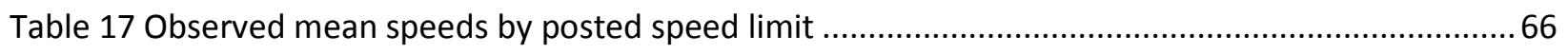

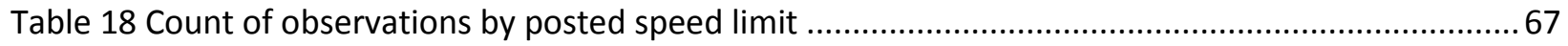

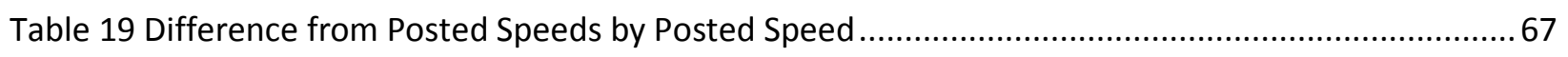

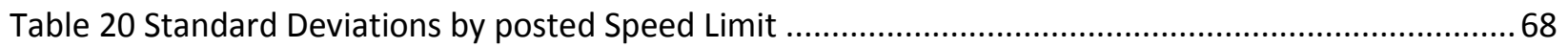

Table 21 Crash Severity by Visibility Bin, updated to with 2015, 2010-2015 ....................................... 70

Table 22 Crash Severity by Visibility Bin, October 2016-August 2017 .................................................. 70

Table 23 Number of Vehicles Involved by Visibility Bin, updated with 2015, 2010-2015 ....................... 70

Table 24 Number of Vehicles Involved by Visibility Bin, October 2016- August 2017 ............................ 71

Table 25 Crash Type by Visibility Bin, updated to include 2015, 2010-2015 .......................................... 71

Table 26 Crash Type by Visibility Bin, October 2016- August 2017 ...................................................... 71

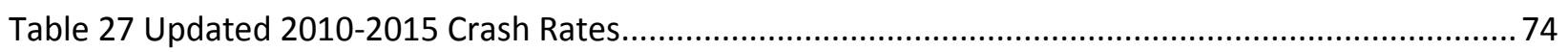




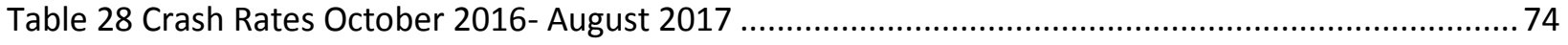

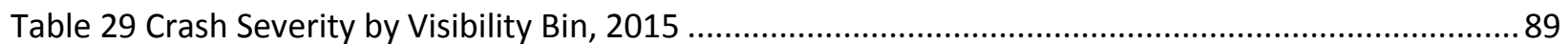

Table 30 Number of Vehicles Involved by Visibility Bin, 2015 ............................................................ 90

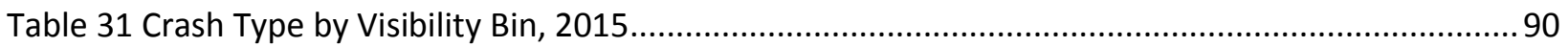

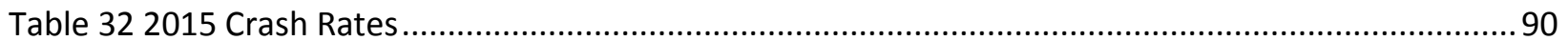




\section{LIST OF FIGURES}

Figure 1 Diagram of CAWS System at one CMS location (12) ........................................................... 11

Figure 2 Idaho Storm Warning System Device Layout (15) .............................................................. 12

Figure 3 Georgia Speed Advisory Nomograph (Robinson, 2000) ....................................................... 15

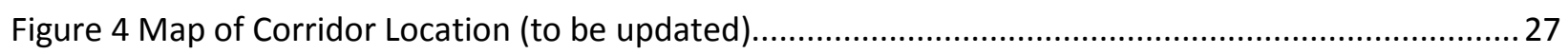

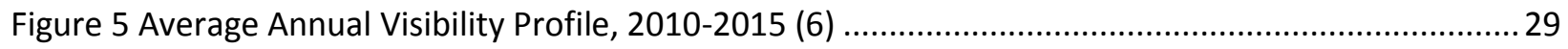

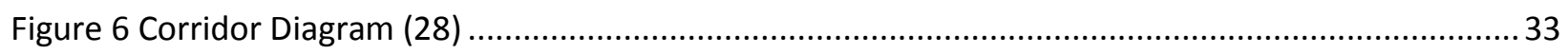

Figure 7 VSL System Devices. a) Full Matrix DMS VSL Display, b) Speed Limit Signs with dynamic VSL cutout, c) RWIS Station, and d) traffic sensor, CCTV, and signing at the northern end of the corridor.

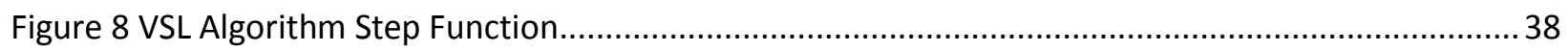

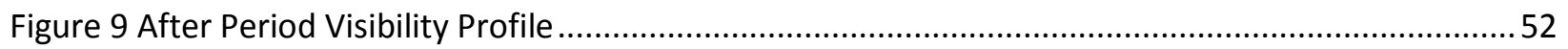

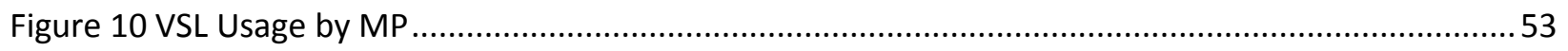

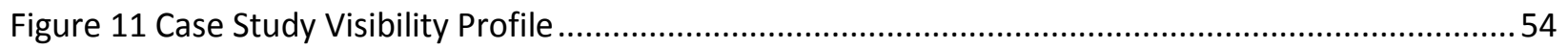

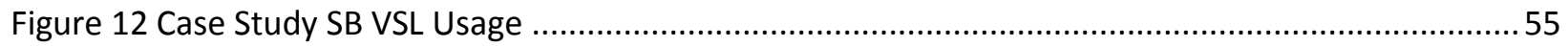

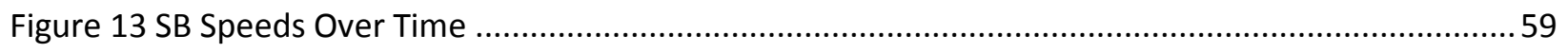

Figure 14 Observed mean speeds a) before and b) after VSL activation at MP 4.4. c) After Speeds Model

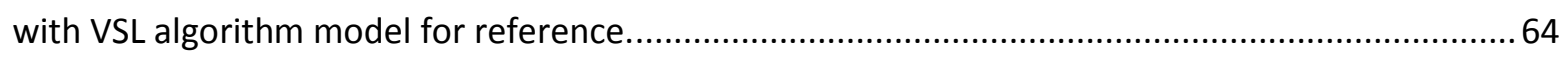

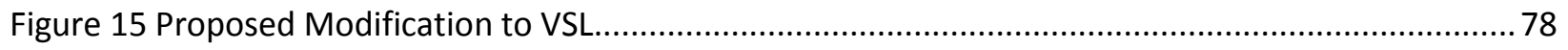

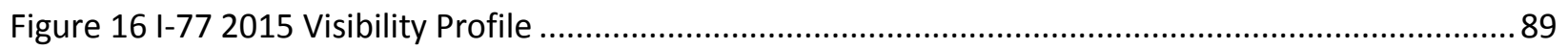




\section{CHAPTER 1: INTRODUCTION}

Driving in fog can pose additional challenges to the driving task. Fog reduces visibility and contrast in the visual field, which are helpful for perceiving depth and speed (1). When these crucial driving cues are obscured, a driver's ability to judge appropriate operating speeds may be hindered. Some studies indicate that motorists seem to compensate for these losses by changing following distances to ensure that the taillights of a lead vehicle remain visible (1). Drivers do not tend to reduce speed when driving in fog until they feel their lane keeping ability is compromised, thus they often maintain operating speeds too great for the close following distances and limited visibilities present under fog conditions (1). These driving behaviors in fog conditions can increase the potential for crashes of greater severity and involving more vehicles (2).

To mitigate safety concerns, agencies sometimes install countermeasures like weather advisory systems and variable speeds limits (VSLs) in areas where fog events are common. Weather advisory systems that include dynamic message signs (DMSs) to relay weather information, speed advisories, and VSLs have been installed in several US states and in other countries. However, not many quantitative evaluations of these systems have been performed.

A 12-mile section of Interstate 77 that runs through mountainous terrain in southwestern Virginia has been known to experience severe, recurring fog events. In the past 20 years, several major fog-related multi-vehicle chain reaction crashes have occurred on this corridor. On Valentine's Day 1997 when visibilities had dropped due to fog, a chain reaction crash involved 56 vehicles, incurring 12 injuries (3). Another fog-related series of crashes in September 2005 involved 50 vehicles, causing 25 injuries (4). On November 16, 2010, visibilities 
were under $100 \mathrm{ft}$. when 70+ vehicles were involved in 10 separate crashes which resulted in 2 fatalities and 16 injuries and closed the highway for nearly 10 hours (5). One of the most severe fog events to date happened on Easter Sunday 2013. When fog had limited visibilities to $167 \mathrm{ft}$. at the worst locations, a chain of 17 crashes involving 96 vehicles resulted in 3 fatalities and 25 injuries, and took almost 11 hours to clear (4).

In 2002, a report on reducing fog-related crashes on I-77 suggested seeking authorization for experimental use of VSLs (3). Other less expensive countermeasures were employed over the years including rumble strips, delineator signs, wider pavement markings, chevrons, and other enhanced signs (4). In 2014, the Virginia Department of Transportation (VDOT) awarded a \$7.5 million contract to build an Active Traffic and Safety Management System (ATSMS) along 12 miles of I-77 in Fancy Gap. The system was activated in October 2016 and has experienced a full year of operations since. Now that VDOT has gained experience with the system, there is a need to quantify its effect on traffic and safety.

\subsection{PREVIOUS STUDIES OF I-77}

Several safety studies have been conducted on this section of I-77 between 1995 and 2015. These studies assessed the relative safety of the corridor by quantifying the traffic incident frequency and severity of fog-related incidents. The 2002 Crash Analysis Study observed data from 1995-1998; the 2007 Crash Analysis and Speed Study analyzed the years 2001-2005; the 2012 Safety Analysis Update and Verification studied the years 2006-2010; and McCann's 2016 study examined the years 2010-2015. The later studies verified/expanded upon the trends first identified in the 2002 study (5) (6). 
The 2002 study found that 14 out of 139 total incidents between the mileposts 2 and 9 in a four-year period were attributable to fog, accounting for $10 \%$ of total crashes. However, these crashes accounted for nearly $44 \%$ of all vehicles involved in crashes, averaging nearly 11.21 vehicles per crash event and 2.64 injuries per event (3). The 2007 and 2012 studies had a broader scope and analyzed the corridor from milepost 0 to 32.5 . The 2007 study found a total of 1009 individual crashes involving 1611 vehicles, and the 2012 study identified 1118 individual crashes involving 1718 vehicles (5). The proportion and frequency of fog-related crashes decreased from 68 crashes (6.7\% of total crashes) between $2001-2005$ to 52 crashes (4.7\% of total crashes) between 2006-2010. These reductions may be due to some of the enhanced warning and lane departure counter measures implemented following the 2002 study, or possibly due to the fact that traffic and fog exposure was not taken into account.

The most recent study in 2016, examined crash characteristics considering exposure, and also examined driver speed choice under foggy conditions to reflect further safety surrogate measures and aid in the development of the VSL algorithm (6). Crash analysis of police crash reports between milepost 0 and 15 showed 524 total crashes, 58 of which occurred under low visibility conditions. An overwhelming $84 \%$ of the fog-related crashes occurred in the southbound direction. Five of these crashes resulted in fatalities and 23 in injuries. Although fog-related crashes only accounted for $11 \%$ of total crashes, they accounted for $19 \%$ of fatal and injury crashes. More than $90 \%$ of fog-related crashes involved 2 or more vehicles while this proportion was only $47 \%$ during clear conditions. Crash rates during fog were calculated to be about 580 crashes per 100 million vehicle miles traveled, nearly 8.5 times greater than in clear conditions. 
Another important outcome of the 2016 study reaffirmed the notion that the area between mile posts 2 and 9 most commonly experienced severe fog events. Visibility profiles confirmed that fog varied spatiotemporally and was concentrated most heavily near milepost 5.3 and 6.6. Speed analysis revealed that drivers traveled much faster than the stopping sight distance (SSD) safe speed based on available visibilities. Although speed reductions were observed during dense fog, at some of the worst visibilities mean speeds were still $25 \mathrm{mph}$ or more higher than SSD safe speeds. Increasing standard deviations of speed were also observed as visibilities worsened.

This study also developed a model of driver speeds that explained the variation of speed due to visibility, day/night conditions, and mile marker along corridor. This model has subsequently been used as a base in the development of the control algorithm for the I-77 VSL system. Now that the VSL system has been activated, data from October 2016 to September 2017 is available to assess how the system has impacted driver speeds and crash characteristics.

\subsection{PURPOSE AND SCOPE}

The two primary goals of the I-77 VSL system are to reduce the quantity and severity of crashes in the corridor. The I-77 ATSMS Concept of Operations proposed reductions in total, fatal, property damage, and injury crashes as measures of effectiveness along with changes in speed limit compliance (5).

The purpose of this thesis is to evaluate the effectiveness of the I-77 VSL system during its first year of operations. The specific objectives of this paper are to: 
1. Determine the effect of the VSLs on driver speeds and compliance throughout the corridor,

2. Determine changes in crash characteristics following VSL activation

The work detailed in this paper uses data collected from crash reports and weather and traffic stations across the corridor. This scope of this paper is limited:

1. Spatially to the $\mathbf{I - 7 7}$ corridor from mile post zero to mile post 12 and

2. Temporally to the first year after VSL system activation.

This work builds on previous safety evaluations of the site to assess if system has had the desired effect. While prior work by McCann (6) established safety and driver behavior trends before VSL activation, this thesis focuses on assessing whether the system created positive changes in safety on the corridor.

\subsection{ORGANIZATION OF THESIS}

The rest of this thesis is organized as follows:

- Chapter 2: Reviews the literature on driver behavior in fog/low visibility conditions and past visibility based warning systems and VSL deployments.

- Chapter 3: Provides an overview of site, system, and previous work on the I-77 VSL system.

- Chapter 4: Discusses the methodology for the evaluation of the I-77 VSL system

- Chapter 5: Presents the results of the analysis

- Chapter 6: Discusses the conclusions and recommendations of this research 


\section{CHAPTER 2: LITERATURE REVIEW}

\subsection{INTRODUCTION}

A literature review was done to understand driver response to fog/low visibility conditions and countermeasures to improve safety in such conditions. This chapter examines past visibility based warning systems and VSL deployments to discuss results and gaps in research.

\subsection{DRIVER BEHAVIOR DURING REDUCED VISIBILITY}

A driver's ability to determine appropriate operating speeds relies greatly on the driver's visual perception. Reductions in visibility can impair drivers' judgment and negatively impact safety. Early research in driving in fog had focused on identifying perceptual changes that influenced speed, often modeling fog as a uniform reduction in contrast. These studies have considered both simulated and test-track data to understand the effects of visibility on driver behavior and safety.

In a virtual-environment driving simulation, Snowden et al (7) found that drivers' sense of speed decreases in fog, as drivers tend to drive faster as fog becomes more dense. Simulating fog by blending a partially transparent polygon over each pixel, RGB values where recalculated at a $15 \mathrm{~Hz}$ rate decreasing the contrast at three separate levels to represent "clear", "misty", and "foggy" conditions. First, the test subjects were shown two scenes that moved at the same speed, one with "clear" conditions, another with "clear", "misty", or "foggy" conditions. Foggier scenes were perceived as slower moving. In the second part of the experiment, drivers were asked to match a certain operating speed in the different simulated 
conditions. In foggier scenes, subjects drove at faster speeds, causing the study to conclude that perceived speed depends on level of contrast, with lower contrast yielding higher speeds. However, these results consider fog as a contrast reduction evenly dispersed across the whole visual field.

A couple of years later, a similar study using a test track concluded that drivers overestimate their actual speeds in foggy conditions (8). This study also considered fog as a uniform contrast reduction, simulating it with plastic filters covering the windshields and windows. When drivers in this study were asked to match a given speed, drivers' speeds were consistently lower than the speeds they were asked to match. While these studies had conflicting results, neither Snowden, et al. nor Brooks, et al. addressed driving behavior which would help to explain how drivers would actually perform in real world conditions.

A more recent study by Brooks et al (8) used driver simulator data that more accurately coded fog as a distance dependent contrast reduction to give insight into driver behavior under reduced visibility. The study measured the ability of participants to stay in their lane and maintain speed. In the study, participants were assigned into one of six groups classified by a combination of a factors including: presence or absence of auditory speed indicators, ability to maintain speed task priorities, and speedometer availability. Participants were first given practice sessions to get acquainted with driving in the simulator before running through six fog scenarios. Results showed that throughout each of the groups, drivers did not appear to significantly decrease speed as visibility decreased. In fact, results suggested that as long as drivers were able to maintain vehicular control they would maintain high speeds while driving in fog. The finding of the Brooks et al study, however, are limited due to small sample sizes 
within the groups. Since the sample consisted only of college students, the results may also not accurately represent the overall population of drivers on road.

Case studies of actual traffic data have also been performed to have a better understanding of real world driving in low visibility conditions. In a case study of the effects of visibility and other environmental factors on driver speed by Liang et al (9), researchers studied the speed-visibility relationship on a rural Idaho freeway prior to the installation of a storm warning system. The data used in this study was collected from an operational test of weather and visibility sensing systems at a spot site between December 1995 to April 1996, during which 21 days experienced extreme weather conditions. In this period where no external information or warning signs were shown to the drivers, mean speed reductions of $8.0 \mathrm{~km} / \mathrm{hr}$. during fog events were observed, however this was accompanied by a doubling in the variation in speeds. In this study, it was unable to be determined if trends in speed reductions were sufficient to ensure adequate sight distances given no periods of visibility were below 528 feet.

\subsection{FIELD DEPLOYMENTS OF COUNTERMEASURES TO ADDRESS LIMITED VISIBILITY}

Transportation agencies have deployed countermeasures to mitigate safety concerns of fog and low visibility conditions. Road weather management countermeasures have ranged from simply adding enhanced signage to larger scale intelligent transportation system deployments.

In this section, field deployments of three different levels of advisory and control strategies are presented. The individual field deployment discussions include site and system descriptions along with implementation results. The first set of field deployments presented are advisory visibility warning systems which relay weather information and display advisory messages but offer no control strategy. The second set of deployments discussed, speed advisory visibility 
warning systems, are like the first but do provide speed advisories as part of the warning messages. The last set of deployments discussed are visibility based VSL deployments that set both advisory and regulatory speed limits in response to low visibility conditions.

\subsubsection{ADVISORY VISIBILITY WARNING SYSTEMS}

This section details visibility based warning system countermeasures and their effects on driver behavior and safety, if any.

\subsubsection{California Automated Warning System}

The California Department of Transportation (Caltrans) activated the Caltrans Automated Warning System (CAWS) on southbound Interstate 5 and westbound State Route 120 in 1996 (10). In this corridor, visibility reductions due to wind-blown dust during the summer and stationary, dense fog during the winter seasons pose safety concerns, as many chain-reaction crashes have been experienced in this region (11). The system was deployed to improve safety along the corridor and warn drivers of potential driving hazards. CAWS consists of three primary subsystems: weather monitoring stations, traffic monitoring stations, and changeable message signs (CMSs). Nine weather monitoring stations were deployed that measured atmospheric conditions and visibility with a dual axis atmospheric visibility sensor. Thirty-six loop-pairs spaced approximately at half mile intervals were installed to collect traffic count and speed data at 15-minute intervals. Nine CMS locations corresponding with weather station locations were also installed.

The weather station and loop detector data fed into the CMS control computer which automatically selected warning messages to display based on traffic speed, visibility, and wind speed. Operators can also override the system and enter messages manually. Table 1 lists the 
automatic messages that were initially used for given observed conditions. When visibilities fall below $200 \mathrm{ft}$., the system is supplemented with vehicle guidance operations by California Highway Patrol (CHP), which uses patrol cars to put traffic intro platoons and lead traffic at a safe pace, typically $50 \mathrm{mph}(11)$.

Table 1 CAWS CMS Messages

\begin{tabular}{|l|l|}
\hline \multicolumn{1}{|c|}{ Condition } & \multicolumn{1}{c|}{ Message Displayed } \\
\hline Speeds 11-25 mph & "Slow Traffic Ahead" \\
\hline Speeds $<11 \mathrm{mph}$ & "Stopped Traffic Ahead" \\
\hline Visibility $200-500 \mathrm{ft}$. & "Foggy Conditions Ahead" \\
\hline Visibility <200 ft. & "Dense Fog Ahead" \\
\hline Wind speed $>35 \mathrm{mph}$ & "High Wind Warning" \\
\hline
\end{tabular}

Sometime between initial activation in 1996 and 2003, the automatic messages were changed to those seen in Table 2 (12). A study in 2006 assessed the influence of CAWS on driver behavior using data from traffic monitoring stations upstream and downstream of the first CMS shown in Figure 1. Data from the 2003-2004 and 2004-2005 fog seasons showed an additional $1.1 \mathrm{mph}$ speed reduction in fog conditions after encountering the CMS. This study also looked at differences in potential collision speed before and after encountering the CMS and found that these speeds actually increased by $8 \mathrm{mph}$. Crash analysis compared crash data from 19921996 to $1997-2003$ in 3 study areas against 5 control areas (13). Collisions during fog were normalized to the number of collisions per 100 heavy fog days in either the before or after period. That analysis found that for 2 of the 3 study sites reductions in rates were seen, but one site had a crash rate that increased by $242 \%$. Further analysis into secondary fog related crashes found that all study areas encountered an increase in fog related crashes with 6 related crashes in the before period and 13 in the after period. However, due to small number of 
crashes and the random nature of crashes, the safety effectiveness of this system is not definitive.

Table 2 CAWS Evaluation CMS Messages

\begin{tabular}{|l|l|c|}
\hline \multicolumn{1}{|c|}{ Visibility } & $\begin{array}{c}\text { 2003-2004 Fog Season Message } \\
\text { Displayed }\end{array}$ & $\begin{array}{c}\text { 2004-2005 Fog Season Message } \\
\text { Displayed }\end{array}$ \\
\hline $200-500 \mathrm{ft}$. & "Dense Fog Ahead, Advise $45 \mathrm{mph}$ & \multirow{2}{*}{ “Dense Fog Ahead, Advise 45} \\
$\mathrm{mph}$
\end{tabular}

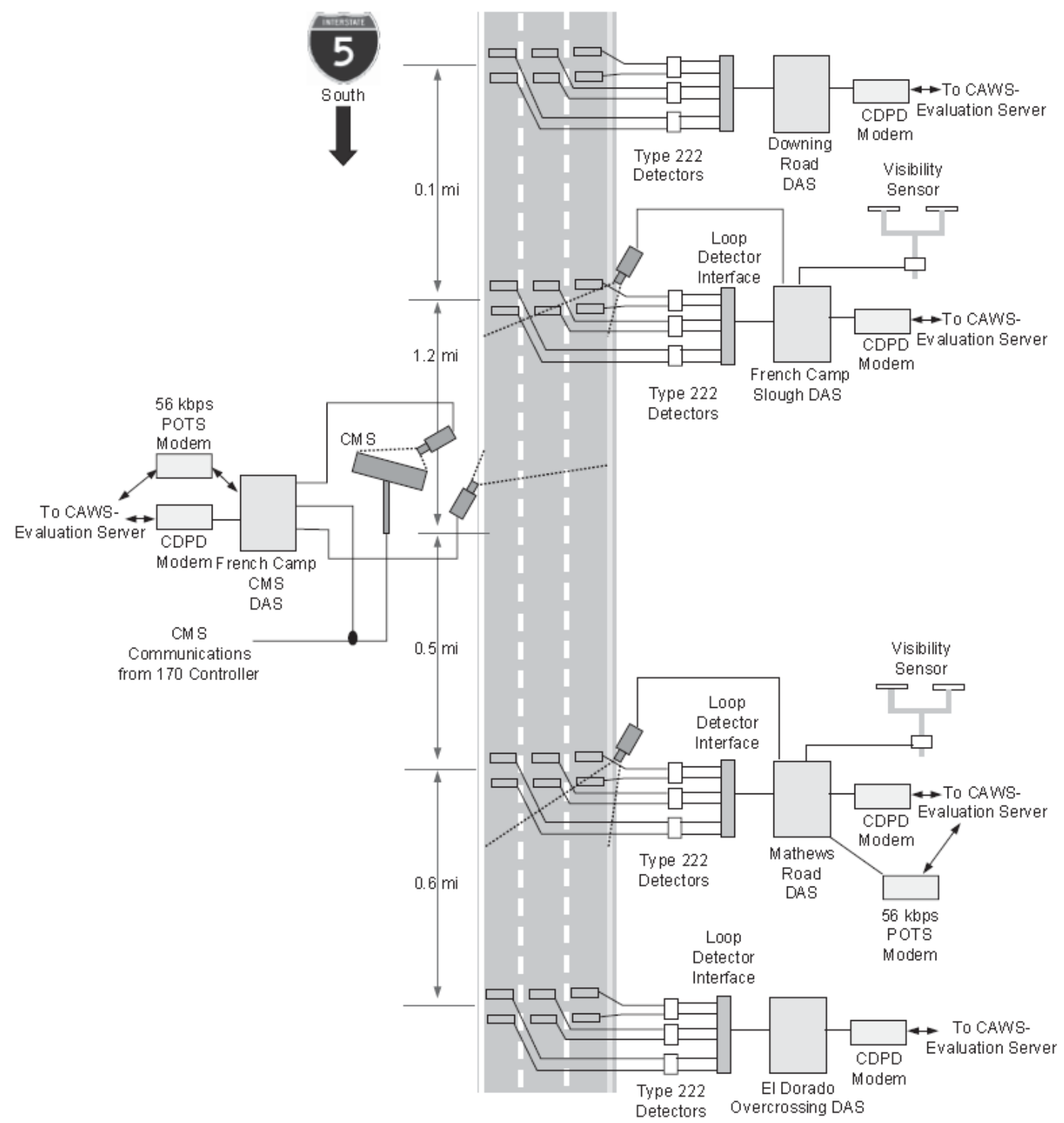

Figure 1 Diagram of CAWS System at one CMS location (12) 


\subsubsection{Idaho Storm Warning System}

In 1993, the Idaho Department of Transportation deployed the $\$ 1.2$ million Idaho Storm Warning System along a 100-mile section of Interstate 84 in response to the numerous multivehicle crashes this corridor had seen in the previous 5 years (14). The system consisted of environmental sensor stations to detect pavement conditions and collect weather data, visibility sensors that measured visibility distance with forward-scatter detection sensors, loop detectors for traffic data, and DMSs to display advisories. These sensors communicated sensor data with a central computer in five minute intervals, and the computer alerted traffic managers when visibility conditions have fallen below a 0.23-mile threshold. This allowed TMC staff to decide on messages and manually activate DMSs. The sensor locations are shown in Figure 2 (15).

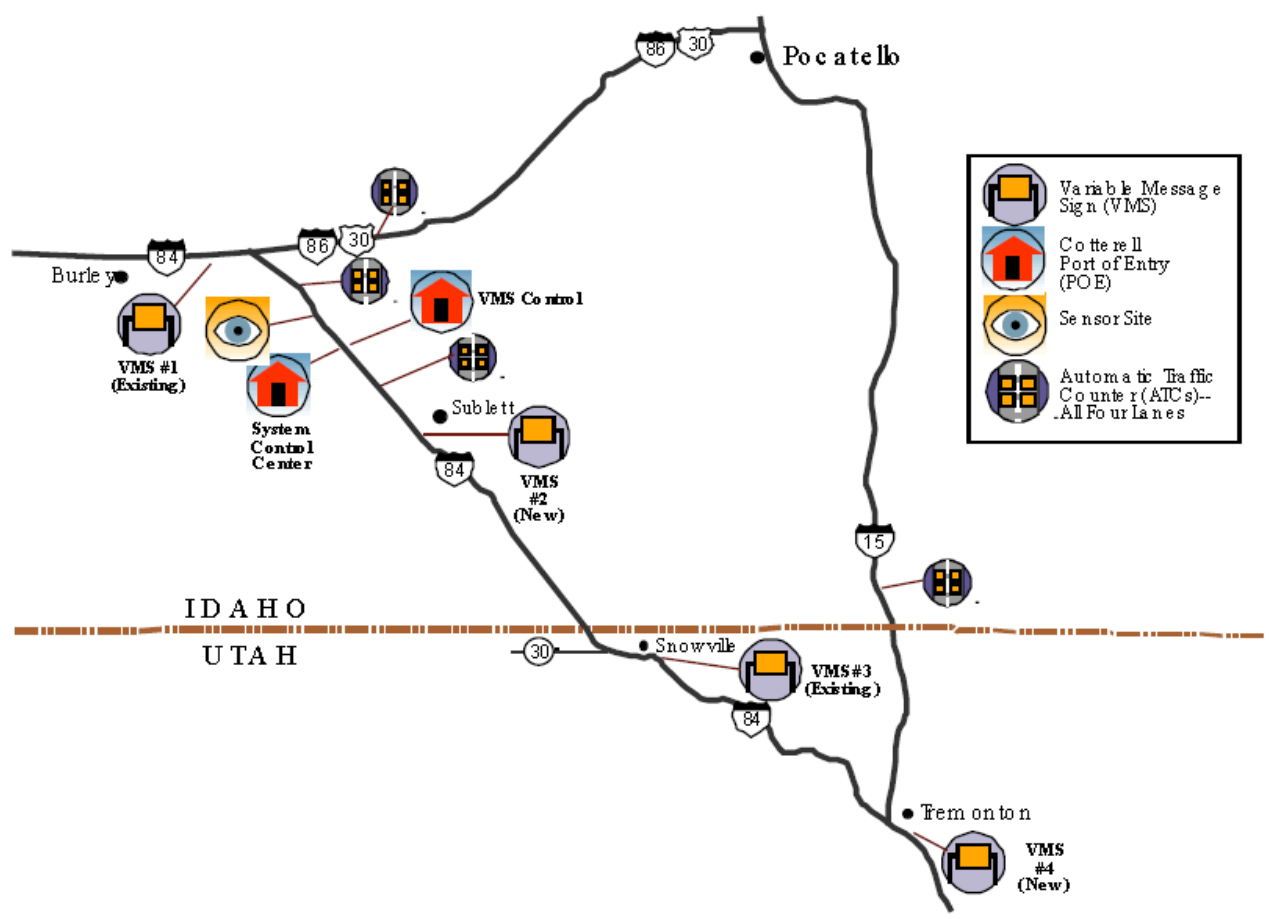


An evaluation of the system over the course of the first 8 years of deployment considered the influence of the DMS messages on driver behavior by comparing traffic speeds with and without the presence of advisories (11). An initial study in this corridor was performed by looking at data from December 1995 to April 1996 to understand the effects of environmental conditions on driver speeds (9). However, speed limits were increased in April 1996, rendering the results of the earlier study unsuitable for comparison (15). Since the system relied on the judgement of the operators to choose both the content and when the messages would be the displayed on the DMSs, there were 19 occasions in the evaluation period were visibilities were greater than 0.23 miles and other adverse weather conditions were present that operators did not utilize DMSs. Driving behaviors during these events were considered baseline conditions. The report shows no indication as to the content of the messages, but results showed that during high winds, high winds and moderate to heavy precipitation, and snow/high wind events when DMSs were utilized to display weather conditions, speed reductions of $23 \%, 12 \%$, and $35 \%$ were seen during these types of events, respectively. During poor visibility only periods, there was insufficient data to see if the display of warning messages contributed to speed reductions.

\subsubsection{SPEED ADVISORY VISIBILITY WARNING SYSTEM}

This section reviews visibility based speed advisory systems and their effects on driver behavior and safety, if any.

\subsubsection{California Fog Detection and Warning System (FWDS)}

The FDWS was installed along a 13-mi corridor of Highway 99 in 2009 in a region of California known to experience seasonal fog (16). The system consists of 22 Vaisala PWD-10 
visibility sensors, 41 traffic sensors, 11 CCTVs, 29 CMSs, 4 Full Color CMSs, 6 portable CMSs, and 2 HAR for a total project cost of $\$ 12$ million (17). Forty-percent of the field equipment is run using solar power. Since this corridor runs through a relatively rural area, wireless communications between field devices and TMC were chosen for this system. Should communications with the TMC be broken, local controllers were set in place to continue system operations. The system also included a social media outreach component and eventually would be integrated into the state 511 system. Traffic sensors including both loops and microwave vehicle detection sensors were installed every quarter of a mile, while visibility sensors and CMSs where installed every half mile. This system also offers the option for vehicle guidance operation by CHP when requested by operators. Table 3 summarizes the message sets that were deployed as a function of visibility and traffic conditions. No effectiveness results were available for this system.

Table 3 FDWS Messages

\begin{tabular}{|c|c|c|}
\hline Visibility & Speed Condition & Warning Message \\
\hline $200-800 \mathrm{ft}$. & \multirow[t]{2}{*}{$>=45 \mathrm{mph}$} & "Fog Ahead" \\
\hline $0-200 \mathrm{ft}$. & & "Dense Fog Ahead" \\
\hline- & $>=45 \mathrm{mph} \&$ CHP pace speed $>-45$ & "Dense Fog" / "CHP Pace" / "Do Not Pass" \\
\hline \multirow{5}{*}{$<800 \mathrm{ft}$. } & $35-45 \mathrm{mph}$ & "Fog Ahead" / "Traffic Slows to 40 mph" \\
\hline & $25-35 \mathrm{mph}$ & "Fog Ahead" / "Traffic Slows to 30 mph" \\
\hline & $15-25 \mathrm{mph}$ & "Fog Ahead" / "Traffic Slows to 20 mph" \\
\hline & 5-15 mph & "Fog Ahead" / "Traffic Slows to 10 mph" \\
\hline & $0-5 \mathrm{mph}$ & "Stopped Traffic Ahead" \\
\hline
\end{tabular}

\subsubsection{Georgia Automated Adverse Visibility Warning and Control System}

The Georgia Adverse Visibility Warning and Control System was installed along a 14-mi section of I-75 and became operational in 2001 (18). The system consisted of 19 Vaisala visibility sensors, 5 CCTVs, 4 DMSs, 5 sets of traffic detectors, and a weather station, with total 
project cost of $\$ 2.4$ million (19). The visibility sensors are densely spaced at approximately $1 / 4$ mile apart. Two DMSs are installed in each direction, with the first signs giving advance warning and second set of signs providing updated speed advisories 1 mile upstream of the fog prone area. The system receives speed and visibility data at one minute intervals. A processing unit installed in the middle of the corridor processes visibility and speed information to generate warning messages. The visibility thresholds were determined using stopping sight distances for a 2-second perception reaction time, shown visually through a nomograph in Figure 3. Table 4 shows the displayed messages for these thresholds. In 2004, preliminary studies were still ongoing however, no study of the safety effectiveness of the system was found (20).

Table 4 Georgia DMS Messages

\begin{tabular}{|l|l|}
\hline Visibility Level & \multicolumn{1}{|c|}{ Message Displayed } \\
\hline$>1100 \mathrm{ft}$. & No speed advisory \\
\hline $800-1100 \mathrm{ft}$. & "CAUTION / FOG AHEAD" with "ADVISE $70 \mathrm{MPH}$ \\
\hline $500-800 \mathrm{ft}$. & "CAUTION / FOG AHEAD" with "ADVISE $55 \mathrm{MPH}$ " \\
\hline $300-500 \mathrm{ft}$. & "CAUTION / FOG AHEAD" with "ADVISE $40 \mathrm{MPH}$ \\
\hline$<300 \mathrm{ft}$. & "CAUTION / FOG AHEAD" with "ADVISE 25 MPH" \\
\hline
\end{tabular}

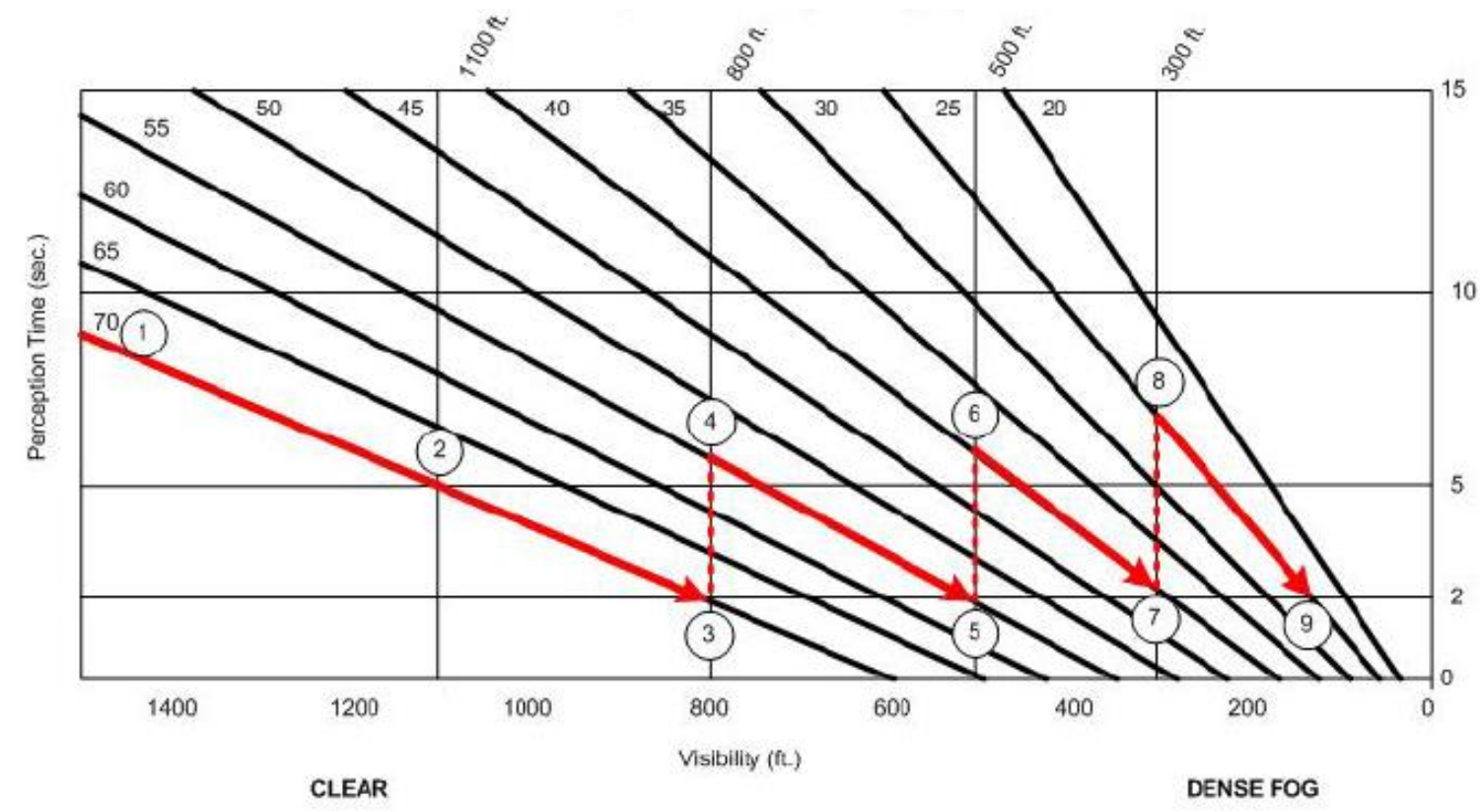

Figure 3 Georgia Speed Advisory Nomograph (Robinson, 2000) 


\subsubsection{South Carolina}

In South Carolina, a \$5 million Low Visibility Warning System was installed in 1992 on a 7-mile section of I-526 (19). It consisted of 1 environmental sensor station, 5 forward scatter visibility sensors, 8 CCTVs, 8 DMSs, and pavement lights installed at $110 \mathrm{ft}$. spacing (11). A central processing unit on site transmits data back to operators in district office. This system had four levels of visibility conditions for which it would deploy an advisory message or speed advisory. The CPU predicts/detects low visibility conditions and alerts operators who would then accept or reject messages to display, as seen in Table 5. From 1992 until 2003, no fogrelated crashes occurred on corridor. No further results were available.

Table 5 South Carolina DMS Messages

\begin{tabular}{|c|l|}
\hline Visibility & \multicolumn{1}{c|}{ Warning Message } \\
\hline $700-900 \mathrm{ft}$. & $\begin{array}{l}\text { "Potential For Fog" / "Light Fog Caution" } \\
\text { "Light Fog Trucks 45 mph" / "Trucks Keep Right" }\end{array}$ \\
\hline 450-700 ft. & $\begin{array}{l}\text { "Fog Caution" / “Fog Reduce Speed" } \\
\text { "Fog Reduce Speed 45 mph"/ "Trucks Keep Right" }\end{array}$ \\
\hline $300-450 \mathrm{ft}$. & $\begin{array}{l}\text { "Fog Caution" } \\
\text { "Fog Reduce Speed 35 mph" / "Trucks Keep Right" }\end{array}$ \\
\hline$>300 \mathrm{ft}$. & $\begin{array}{l}\text { "Dense Fog Reduce Speed 25mph"/ "Trucks Keep Right" } \\
\text { "Prepare to Stop" / "I-526 Bridge Closed Ahead Use I-26/US-17" / "All Traffic Must } \\
\text { Exit" }\end{array}$ \\
\hline
\end{tabular}

\subsubsection{Utah Adverse Visibility Information System and Evaluation}

In 1995, Utah DOT’s Adverse Visibility Information System and Evaluation (ADVISE) was deployed on a two-mile section of I-215 that lies above the Jordan River in Salt Lake City. The system consisted of 4 forward scatter visibility sensors, 6 vehicle detection sites, and 2 DMSs. The warning system displayed warning messages with stopping sight distance based safe speeds based on 4 different levels of visibilities as seen in Table 6 (11). Evaluations of the 
system using data through 2000 showed that average speeds increased and speed variance decreased from 9.5 to $7.4 \mathrm{mph}$. During this study period, however, the posted speed during clear conditions increased from $55 \mathrm{mph}$ to $65 \mathrm{mph}$, an additional lane was added, and construction on I-15 disrupted regular traffic patterns (21). These confounding factors make it difficult to assign these affects to the ADVISE system.

Table 6 Utah DMS Messages

\begin{tabular}{|l|l|}
\hline \multicolumn{1}{|c|}{ Visibility Level } & \multicolumn{1}{c|}{ Message Displayed } \\
\hline$>820 \mathrm{ft}$. & No Speed advisory \\
\hline $656-820 \mathrm{ft}$. & "Fog Ahead" \\
\hline $492-656 \mathrm{ft}$. & "Dense Fog"/ "Advise $50 \mathrm{mph"}$ \\
\hline $328-492 \mathrm{ft}$. & "Dense Fog"/ "Advise $40 \mathrm{mph"}$ \\
\hline $197-328 \mathrm{ft}$. & "Dense Fog"/ "Advise $30 \mathrm{mph"}$ \\
\hline$<197 \mathrm{ft}$. & "Dense Fog"/ "Advise $25 \mathrm{mph"}$ \\
\hline
\end{tabular}

\subsubsection{PAST VISIBILITY BASED VSL DEPLOYMENTS}

This section reviews past visibility based VSL deployments and their effects on driver behavior and safety, if any.

\subsubsection{Alabama Low Visibility Warning System}

Alabama DOT installed a Low Visibility Warning System along a 7-mile bridge on I-10 in Mobile in 2000 (16). The system consists of 6 forward scatter visibility sensors spaced at approximately 1-mile intervals along the bridge, 25 CCTVs, 5 DMSs, and 24 VSL signs. Operators used the CCTVs to observe fog and confirm it with data from sensors. The system has visibility levels with DMSs advisories and corresponding VSLs for each level. Operators manually choose which message set to display. Operators can also request vehicle guidance operations by highway patrol to platoon traffic together and lead at a safe speed for available visibility. Table 
7 shows the DMS and VSL messages recommended for different visibility ranges. The speed limits posted by VSLs are regulatory and system automatically alerts the DOT Division Office, the Highway Patrol, and local law enforcement agencies during system activation (22).

Table 7 Alabama DMS and VSL Messages

\begin{tabular}{|c|c|c|}
\hline Visibility & DMS Advisory & VSLS \\
\hline $660-900 \mathrm{ft}$. & "Fog Warning" & $65 \mathrm{mph}$ \\
\hline $450-660 \mathrm{ft}$. & $\begin{array}{l}\text { "Fog" / "Slow Use Low Beams" } \\
\text { "Trucks Keep Right" }\end{array}$ & $55 \mathrm{mph}$ \\
\hline $280-450 \mathrm{ft}$. & $\begin{array}{l}\text { "Fog" / "Slow Use Low Beams" } \\
\text { "Trucks Keep Right" }\end{array}$ & $45 \mathrm{mph}$ \\
\hline $175-280 \mathrm{ft}$. & $\begin{array}{l}\text { "Dense Fog"/ "Slow Use Low Beams" } \\
\text { "Trucks Keep Right" }\end{array}$ & $35 \mathrm{mph}$ \\
\hline$<175 \mathrm{ft}$. & I-10 Closed, Keep Right, Exit $1 / 2$ mile & Road Closed by Highway Patrol \\
\hline
\end{tabular}

The system was later upgraded in 2008 , to increase the density of radar vehicle detection devices to every $1 / 3$ of a mile and to use visibility sensors that could detect finer gradations of fog (19). Since the installation of the system, Alabama DOT has reported reduced mean speeds but no specific quantitative results are available (16).

\subsubsection{Oregon}

In 2014, Oregon DOT deployed a VSL system on Interstate 5 and US Route 97 to address both weather and congestion on I-5 (22). The system includes pavement monitoring sensors and visibility sensors as well as traffic sensors. VSL signs are placed $1 / 3$ to $1 / 2$ mile apart with DMSs every 1.5 miles. Volume and speed data are collected in 20 second intervals. Three subsystems, one for weather, another for congestion, and a third for operator control, were considered but only weather subsystem has been developed so far (23).

For the weather subsystem, speed limits are selected based on look up tables using available visibility and pavement grip factor and chain conditions if applicable, as shown in 
Table $8 \mathrm{a}$ and $\mathrm{b}$. Visibility and grip factor values are gathered from weather sensors and which then are used to determine the speed limits based on stopping sight distance safe speeds. ODOT's Advanced Traffic Management System (ATMS) or Traffic Operations Center Software (TOCS) determine which vehicles require snow chains based of gross vehicle weight, axle count, and whether they are towing a trailer. If chain conditions are present and vehicles require chains a second lookup table in the weather subsystem is considered to produce a second suggested speed limit. The calculated suggested speeds from the lookup table could then be either be absolute or recommended. If absolute, the speed limits would automatically be displayed on the VSLs. Otherwise, speeds would be compared with suggestions from within and across other subsystems and lowest speed limit would be posted. Additionally, operators can choose to lower the speed limit further or have associated messages displayed shown in Table 9. Currently, VSLs are advisory and no evaluations are yet available.

Table 8 Oregon a) Grip Factor and b) Chain Conditions Lookup Tables for Weather Subsystem (23)

\begin{tabular}{|l|c|c|c|}
\hline Gisibility $\quad$ Grip Factor & $>0.70$ & $0.70>X>0.30$ & $<0.30$ \\
\hline$>\mathbf{5 0 0 ^ { \prime }}$ & Speed Limit & Speed Limit - 10 MPH & Speed Limit - 20 MPH \\
\hline$<500^{\prime}$ & Speed Limit - 10 MPH & Speed Limit - 20 MPH & Minimum Speed \\
\hline
\end{tabular}

(a)

\begin{tabular}{|l|c|c|}
\hline Visibility Chain Condition & B or B1 & C \\
\hline$>\mathbf{5 0 0}$ & $45 \mathrm{MPH}$ & $35 \mathrm{MPH}$ \\
\hline$<\mathbf{5 0 0 ^ { \prime }}$ & $35 \mathrm{MPH}$ & Minimum Speed \\
\hline
\end{tabular}

(b) 
Table 9 Oregon DMS Message Lookup Table (23)

\begin{tabular}{|c|c|c|c|c|c|}
\hline Visibility & $\begin{array}{l}\text { Grip Factor } \\
\text { Classification }\end{array}$ & $>0.70$ & $0.70>x>0.30$ & $<0.30$ & $\begin{array}{c}\text { Chain } \\
\text { Requirement }\end{array}$ \\
\hline \multirow{2}{*}{$>500^{\prime}$} & Moist or Wet & (None) & U: & $\begin{array}{l}\text { US } \\
\text { CAUI }\end{array}$ & (None)* \\
\hline & $\begin{array}{l}\text { Frosty, Snowy, lcy, or } \\
\text { Slushy }\end{array}$ & (None) & $\begin{array}{c}\text { ICE } \\
\text { USE CAUTION }\end{array}$ & $\begin{array}{c}\text { ICE } \\
\text { USE CAUTION }\end{array}$ & (None)* \\
\hline \multirow{2}{*}{$<500^{\prime}$} & Moist or Wet & $\begin{array}{l}\text { LOW VISIBILITY } \\
\text { USE CAUTION }\end{array}$ & CAU: & US & (None)* \\
\hline & $\begin{array}{l}\text { Frosty, Snowy, Icy, or } \\
\text { Slushy }\end{array}$ & $\begin{array}{l}\text { LOW VISIBILITY } \\
\text { USE CAUTION }\end{array}$ & $\begin{array}{c}\text { ICE } \\
\text { USE CAUTION }\end{array}$ & $\begin{array}{c}\text { ICE } \\
\text { JSE CAUTION }\end{array}$ & (None)* \\
\hline
\end{tabular}

*Snow zone chain requirement messages for VMS will come from ATMS/TOCS

\subsubsection{Tennessee Low Visibility Warning System}

A Low Visibility Warning System was also installed along 19 miles of I-75 in Tennessee in 1993 for \$1.2 million (16). The system included 9 forward scatter visibility sensors, 14

microwave radar vehicle detectors, 21 CCTVS, 6 static warning signs, 10 VSL signs, 10 DMSs, and 2 HAR. These systems relay their data via fiber optic cable to a central computer in the Highway Patrol office. The system alerts operators of reduced visibilities and operators manually display the messages based from the advisory messages suggested per visibility conditions as shown in Table 10. Should conditions necessitate closure, ramps gates are closed and highway patrol directs a detour. The continued communications with law enforcement suggest that VSLs are regulatory. The system usually has one activation weekly in the months of October to March displaying speeds of $50 \mathrm{mph} 95 \%$ of the time when activated, $13 \%$ of these activations required further reductions in posted speeds to $35 \mathrm{mph}$ (11). From 1993 to 2012, only 1 fog-related 
accident was recorded with the system active, but this was not normalized relative to exposure and data on before conditions was also not available.

Table 10 Tennessee DMS and VSL Messages

\begin{tabular}{|c|c|c|}
\hline Visibility & Advisory & VSL \\
\hline$>1320 \mathrm{ft}$. (fog detected) & "Caution" / "Fog Ahead Turn on Low Beams" & "Fog" \\
\hline $480-1340 \mathrm{ft}$. & $\begin{array}{l}\text { "Fog Ahead"/ "Advisory Radio Tune to XXXX AM" "Reduce } \\
\text { Speed Turn on Low Beams" or "Speed Limit } 50 \text { mph" }\end{array}$ & $\begin{array}{l}\text { "Fog" } \\
50 \mathrm{mph}\end{array}$ \\
\hline $240-480 \mathrm{ft}$. & $\begin{array}{l}\text { "Fog Ahead"/ "Advisory Radio Tune to XXXX AM" "Reduce } \\
\text { Speed Turn on Low Beams" or "Speed Limit } 35 \text { mph" }\end{array}$ & $35 \mathrm{mph}$ \\
\hline$<240 \mathrm{ft}$. & $\begin{array}{l}\text { "Detour Ahead" / "Reduce Speed Merge Right" or "I-75 } \\
\text { Closed" / "Detour" or "Fog Ahead" / "Advisory Radio Tune to } \\
\text { XXXX AM" }\end{array}$ & "Fog" \\
\hline
\end{tabular}

\subsubsection{Australia}

In Australia, 12 VSL signs were installed in 1993 along $11 \mathrm{~km}$ of the F6 Tollway (24). Each of these signs were connected to vehicle detector loops and visibility sensors. Since the main objective of this system was to reduce rear-end collisions in foggy conditions, the advisory VSL was based on the visibility distance available and the speed of the preceding vehicle (25). No evaluation results from this system were found.

\subsubsection{Netherlands}

In the Netherlands in 1991, a VSL was installed in the urban A16 freeway near Breda (25). The system consisted of 20 visibility sensors and VSL signs every $700-800 \mathrm{~m}$ over $12 \mathrm{~km}$. The system also included automatic incident detection. For visibilities above $140 \mathrm{~m}$ the posted speed would remain $100 \mathrm{~km} / \mathrm{h}$, and once it dropped below $140 \mathrm{~m}$ the speed limit would be reduced to $60 \mathrm{~km} / \mathrm{h}$. When incidents were detected the first upstream sign and followed by 70 
$\mathrm{km} / \mathrm{h}$ on the second one. This system reported mean speed reductions by $8-10 \mathrm{~km} / \mathrm{h}$ during fog conditions.

\subsection{GAPS IN RESEARCH}

Table 11 summarizes the effectiveness of past field deployments. While a variety of systems have been deployed within the past 30 years, there is a general lack of quantitative evaluations on the results of such implementations, and even those that provide evaluations hold several limitations.

Four of the field deployments explored in this section did not provide any performance measure on the effectiveness of the system. Another system qualitatively reported improvements without any quantitative backing to statements. Two deployment evaluations reported low to no fog-related crashes after activation and another reported both reductions and increases in fog-related crashes. Presumably the South Carolina and Tennessee deployments have achieved their objectives, but due to the rarity of the occurrence of crashes, a simple crash frequency before after comparison does not paint a full picture of safety. Neither of these evaluations considered exposure to fog or traffic. It could be possible that the low visibility conditions in the after period were not representative of those in the before period. The California Motorist Warning system evaluation tried to account for fog exposure by considering crashes per 100 heavy fog days. This measure of exposure however arguably could have been more accurate if it used weather data from its 9 weather stations rather than visibility conditions of nearest airport. These results point towards the expected positive impacts but present possible bias. 
Four deployment evaluations reported mean speed reductions during low visibility conditions under the system and one reported mean speed increases. The mean speed reductions in these deployments either considered reductions from clear conditions in the same study period or from low visibility conditions prior to system activation. Classifying both of these conditions within one deployment would more accurately characterize effects.

The aim of this research is to fill in these gaps and provide a full understanding of the problem of how VSLs impact safety in low visibility conditions. 
Table 11 Summary of Visibility Warning Systems

\begin{tabular}{|c|c|c|c|}
\hline System & Type of System & Major Findings & Limitations \\
\hline $\begin{array}{l}\text { Alabama, I-10 } \\
\text { Low Visibility Warning System } \\
\text { (16) }\end{array}$ & $\begin{array}{l}\text { - Regulatory } \\
\text { VSL } \\
\text { - Manual }\end{array}$ & $\begin{array}{l}\text { - Reduced average speeds } \\
\text { - Minimized crash risks in low } \\
\text { visibility conditions }\end{array}$ & $\begin{array}{l}\text { - No specific quantitative } \\
\text { results }\end{array}$ \\
\hline $\begin{array}{l}\text { Australia, F6 Tollway } \\
\text { (25) }\end{array}$ & $\begin{array}{l}\text { - Advisory VSL } \\
\text { - Automated }\end{array}$ & - No reports on results & - No reports on results \\
\hline $\begin{array}{l}\text { California, SB I-5 \& WB CA-120 } \\
\text { Motorist Warning System } \\
\text { (11) }\end{array}$ & $\begin{array}{l}\text { - (Speed) } \\
\text { Advisory } \\
\text { - Automated } \\
\text { (Manual } \\
\text { override } \\
\text { option) }\end{array}$ & $\begin{array}{l}\text { - } 1.1 \text { mph reduction in mean speeds } \\
\text { - } 8.0 \text { increase in potential collision } \\
\text { speed } \\
\text { - One study area experience } 242 \% \\
\text { increase in fog-related crashes }\end{array}$ & $\begin{array}{l}\text { - Control road used for crash } \\
\text { comparison } \\
\text { - Normalized fog crashes by } \\
\text { "heavy fog" days not actual } \\
\text { visibility conditions during } \\
\text { collision }\end{array}$ \\
\hline $\begin{array}{l}\text { California, Hwy } 99 \\
\text { Fog Detection and Warning System } \\
\text { (16) (17) }\end{array}$ & $\begin{array}{l}\text { - Speed } \\
\text { Advisory } \\
\text { - Automated }\end{array}$ & - No reports on results & - No reports on results \\
\hline $\begin{array}{l}\text { Georgia, I-75 } \\
\text { Automated Adverse Visibility Warning } \\
\text { and Control System } \\
(19)(20)(26)\end{array}$ & $\begin{array}{l}\text { - Speed } \\
\text { Advisory } \\
\text { - Automated }\end{array}$ & - No reports on results & - No reports on results \\
\hline $\begin{array}{l}\text { Idaho, I-84 } \\
\text { Storm Warning System } \\
\text { (11) (15) }\end{array}$ & $\begin{array}{l}\text { - Advisory } \\
\text { - Manual }\end{array}$ & $\begin{array}{l}\text { - At visibilities }<0.1 \text { miles and no } \\
\text { DMS, speed reductions } 67.7 \text { to } 58.4 \\
\text { - When DMS used with high winds, } \\
\text { high winds and moderate to heavy } \\
\text { precipitation, and snow/high wind } \\
\text { events, speed reductions of } 23 \% \text {, } \\
12 \% \text {, and } 35 \% \text { respectively }\end{array}$ & $\begin{array}{l}\text { - Insufficient data at low } \\
\text { visibility only conditions to } \\
\text { show effect } \\
\text { - No crash analysis } \\
\text { - No consideration to fog } \\
\text { exposure }\end{array}$ \\
\hline
\end{tabular}




\begin{tabular}{|c|c|c|c|}
\hline System & Type of System & Major Findings & Limitations \\
\hline $\begin{array}{l}\text { Netherlands, A16 } \\
\text { (25) }\end{array}$ & $\begin{array}{l}\text { - VSL } \\
\text { - Automated }\end{array}$ & $\begin{array}{l}\text { - Mean speed reductions during fog } \\
\text { conditions approximately } 8 \text { to } 10 \\
\mathrm{~km} / \mathrm{h} \text { (5-6 mph) }\end{array}$ & $\begin{array}{l}\text { - No crash analysis } \\
\text { - No consideration to fog } \\
\text { exposure }\end{array}$ \\
\hline $\begin{array}{l}\text { Oregon, I-5 US-97 } \\
(27)\end{array}$ & $\begin{array}{l}\text { - Advisory VSL } \\
\text { - Automated }\end{array}$ & - No reports on results & - No reports on results \\
\hline $\begin{array}{l}\text { South Carolina, I-526 } \\
\text { Low Vis Warning System } \\
\text { (11) }\end{array}$ & $\begin{array}{l}\text { - Speed } \\
\text { Advisory } \\
\text { - Semi- } \\
\text { Automated }\end{array}$ & - No crashes 1992-2003 & $\begin{array}{l}\text { - No speed analysis } \\
\text { - No consideration to fog } \\
\text { exposure }\end{array}$ \\
\hline $\begin{array}{l}\text { Tennessee, I-75 } \\
\text { Low Visibility Warning System } \\
\text { (16) }\end{array}$ & $\begin{array}{l}\text { - VSL } \\
\text { - Automated/ } \\
\text { Manual }\end{array}$ & $\begin{array}{l}\text { - Only } 1 \text { fog related incident 1993- } \\
2012 \\
\text { - Effective for general incident } \\
\text { management }\end{array}$ & $\begin{array}{l}\text { - No speed analysis } \\
\text { - No consideration of fog } \\
\text { exposure at large }\end{array}$ \\
\hline $\begin{array}{l}\text { Utah, I-215 } \\
\text { ADVISE } \\
\text { (11) (14) }\end{array}$ & $\begin{array}{l}\text { - Speed } \\
\text { Advisory } \\
\text { - Automated }\end{array}$ & $\begin{array}{l}\text { - } 15 \% \text { increase in speeds } \\
\text { - } 22 \% \text { decrease in standard deviation } \\
\text { of speeds }\end{array}$ & $\begin{array}{l}\text { - No crash analysis } \\
\text { - Speed limit increase } \\
\text { implemented same year as } \\
\text { system } \\
\text { - Road widened before and } \\
\text { after }\end{array}$ \\
\hline
\end{tabular}




\section{CHAPTER 3: $\quad$ SITE DESCRIPTION AND CHARACTERISTICS}

\subsection{SITE DESCRIPTION}

Interstate 77 runs 68 miles through the mountainous southwestern region of Virginia, connecting northbound and southbound traffic between North Carolina and West Virginia. The I-77 ATSMS project is located in the southernmost section of this interstate from mile post zero at the North Carolina border to mile post 12, just south of Route 702 as shown in Figure 4. While grades vary across the site, there is a relatively constant $+4 \%$ grade between the North Carolina state line and approximately milepost 6, with southbound traffic traveling downhill (5). This section of I-77 is a four-lane divided freeway, with an additional truck climbing lane from mile post 0 to 7 in the northbound direction. There are also two runaway truck ramps in the southbound direction. The base posted speed limit during clear conditions is $65 \mathrm{mph}$. As of 2016, average annual daily traffic (AADT) is over 19,000 vehicles in each direction with over $25 \%$ truck traffic. Shoulders widths along the corridor range from 4-6 ft. for left shoulders and 10-12 ft. for right shoulders (4). In addition to steep grades, there are also 11 horizontal curves throughout the site.

Prior to VSL implementation, VDOT had already implemented the following countermeasures (4) (5):

- 5 DMSs

- Safety Service Patrol

- 11 RWIS stations installed by Fall 2009

- Shoulder rumble strips installed in Fall 2012 on majority of the roadway sections 
- Delineation signs added behind guardrail

- Wider 8" pavement markings added

- Chevron signs (MUTCD Sign W1-8) added in all curves

- Enhanced Regulatory and warning signs upgraded to new prismatic sheeting

- Regulatory signs dual indicated

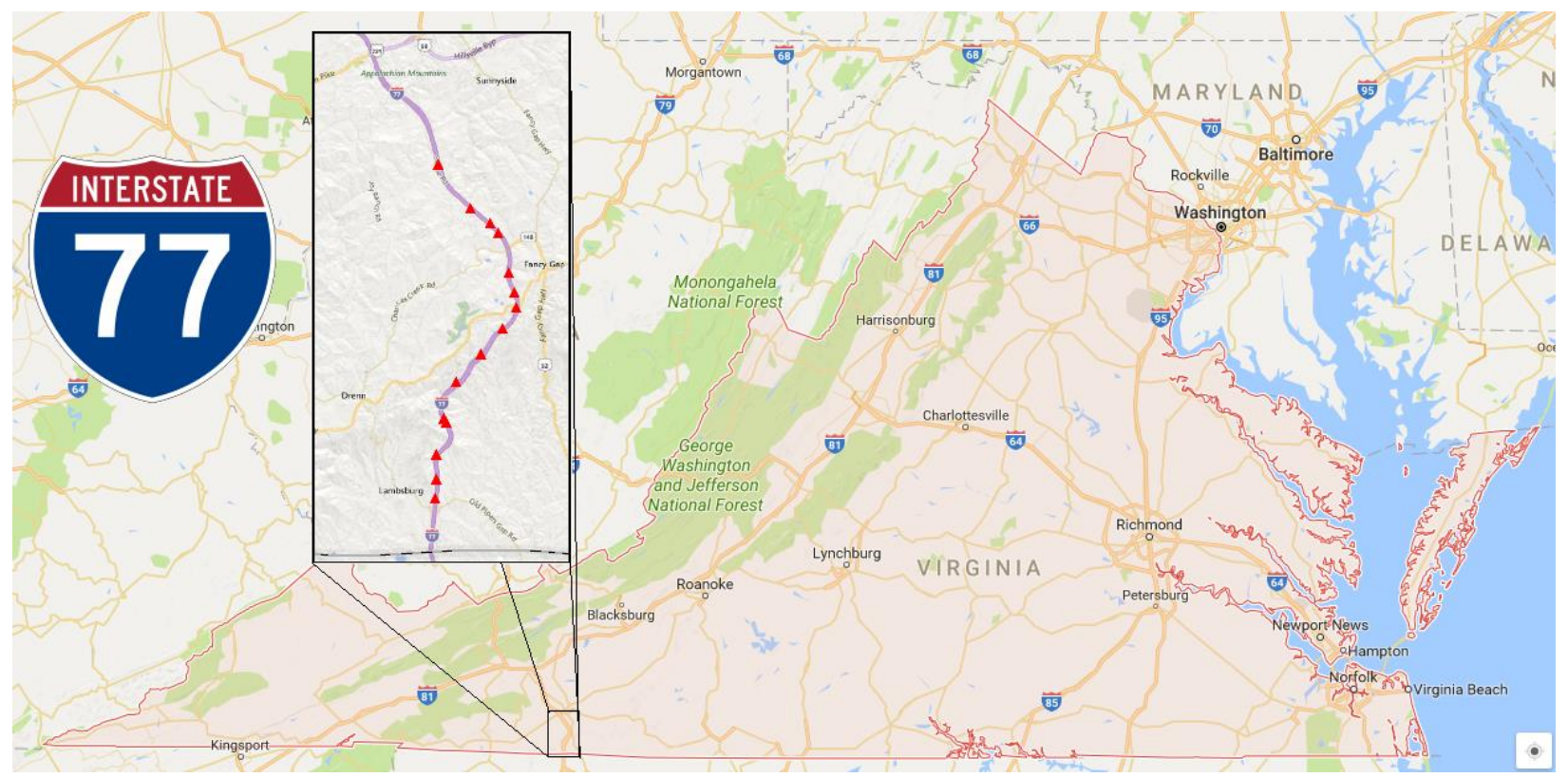

Figure 4 Map of Corridor Location (to be updated)

\subsection{PREVIOUS WORK}

McCann and Fontaine (6) sought to determine the relationship between speed and visibility and other possible environmental factors on I-77 to better understand the conditions prior to VSL activation. Their work provides most of the "before" period analysis that is used as baseline comparisons for the analysis portion of this thesis. This section describes previous analysis performed by McCann and Fontaine with regards to fog characteristics, crash characteristics, and driver speeds, and compliance in the corridor. Additional "before" period 
data analyzed for use as baseline comparisons for this thesis will be discussed in the Methodology section.

\subsubsection{Fog Characteristics}

McCann and Fontaine used a criterion for visibilities based on stopping sight distance (SSD) to better compare actual operating speeds to a theoretical safe speed (6). Using the stopping sight distance equation assuming a flat grade and a 2.5 second reaction time, the maximum safe speed for a given visibility could be determined. Table 12 lists the bins used for analysis.

Table 12 Safe Speed by Visibility Bin

\begin{tabular}{|c|c|c|}
\hline Visibility Bin Range & \multicolumn{2}{|c|}{ Safe Speed } \\
\hline$>645 \mathrm{ft}$ & $65 \mathrm{mph}$ & $\begin{array}{l}\text { Clear } \\
\text { Conditions }\end{array}$ \\
\hline $495-645 \mathrm{ft}$. & $55 \mathrm{mph}$ & \multirow{5}{*}{ Low Visibility } \\
\hline $360-495 \mathrm{ft}$. & $45 \mathrm{mph}$ & \\
\hline $250-360 \mathrm{ft}$. & $35 \mathrm{mph}$ & \\
\hline $155-250 \mathrm{ft}$. & $25 \mathrm{mph}$ & \\
\hline$<155 \mathrm{ft}$ & $<25 \mathrm{mph}$ & \\
\hline
\end{tabular}

Visibility profiles were constructed using available visibility sensor data and confirmed that fog varied spatially. Although there was variability in the amount of fog year to year, the distribution of the fog was fairly consistent with a concentration of recurring low visibility conditions occurring between mile posts 4.4 and 7.3. In the 2010-2015 study years, milepost 6.6 experienced reduced visibility between $4 \%$ to $7 \%$ of the year, making it the location along the corridor experiencing the highest average yearly low visibility conditions. The average annual visibility profile is depicted in Figure 5. 


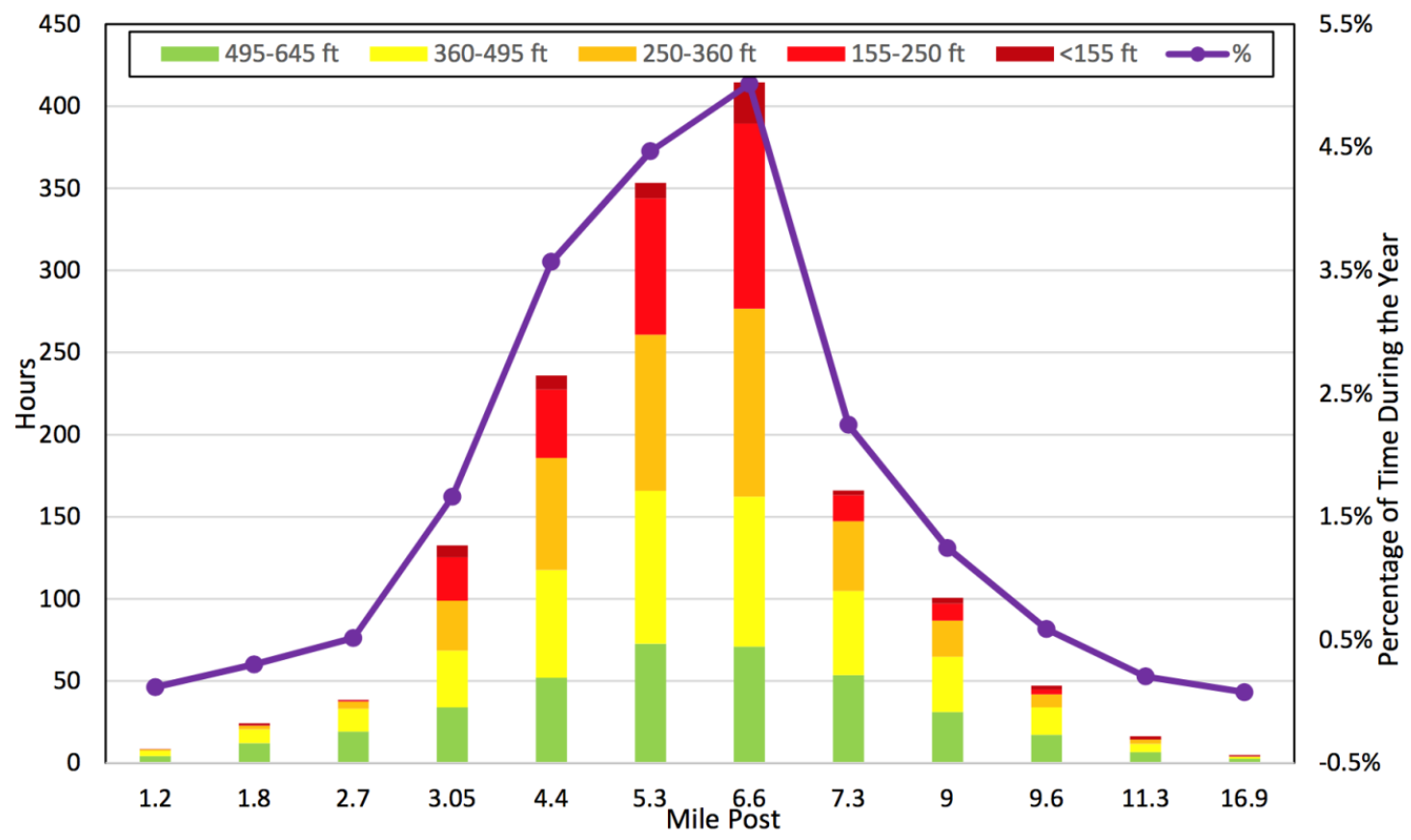

Figure 5 Average Annual Visibility Profile, 2010-2015 (6)

\subsubsection{Crash Analysis}

Prior to McCann and Fontaine, safety studies analyzing the characteristics of fog-related crashes did not account for exposure to low visibility conditions or volume changes and simply considered crash frequency and characteristics (5). Using visibility readings from nearby RWIS stations McCann and Fontaine were able to estimate visibilities present during the crash rather relying simply on crashes coded as "fog" in police crash reports (6). Crashes were then compared by crash type, severity, numbers of vehicles involved, and visibility condition. The research found that low-visibility conditions were correlated with increased crash severity, had more vehicles involved, and were more likely to be rear end crashes than crashes during clear conditions. Crashes during low visibility were much more common in the southbound (downhill) direction. 
McCann and Fontaine also calculated crash rates per 100 million vehicle miles traveled (VMT) by visibility bin (6). This analysis indicated the disparity between crash rates in clear vs. low visibility conditions, with increasing crash rates as visibilities decreased. For clear conditions in the north and southbound directions crash rates were 66.8 and 69.1 crashes per 100 million VMT, respectively. For all low visibility conditions, crash rates worsened to between 175.3 and 1000.5 crashes per 100 million VMT depending on the density of fog. Although this crash rate analysis was limited by a lack of real-time volume and the accuracy of times and locations indicated by police reports, the analysis shows that there is indeed an association between fog and higher crash rates.

\subsubsection{Driver Speeds}

Speed data at three southbound locations were used to summarize driver behavior in terms of mean speeds by visibility bin and speed differentials between lanes by visibility bin. McCann and Fontaine found that although there is an overall trend towards speed reduction with decreasing visibility, the speeds do not decrease to the corresponding SSD safe speeds. Differentials between observed speeds and the SSD safe speed tended to increase as visibilities worsened. Trends in speed differentials between lanes were inconsistent by milepost, but there seemed to be an increase at the lowest visibilities, potentially indicating an increased potential for crashes. Across mile posts, mean speeds and speed differentials between lanes by visibility at MP 6.6 were consistently greater than at MP 5.3 and MP 7.3.

Speed profiles by visibility bin were created for MP 6.6. Coefficients of variation nearly doubled at the lowest visibility from those during clear conditions, another sign of increased 
safety concerns. The percentage of vehicles traveling at speeds above the SSD safe speed increased from 74\% at visibilities between 495 and $645 \mathrm{ft}$. to $99 \%$ at visibilities below $155 \mathrm{ft}$.

A baseline model for driver behavior in fog prior to VSL installation was also developed. McCann and Fontaine found that driver speeds are inversely related to visibility, vary for day and night times, and by mile post. Though some temperature and precipitation data were available, McCann and Fontaine's model did not find those variables statistically significant. The final model shown below yielded an adjusted $R^{2}$ value of 0.451 .

$$
S=64.6-\frac{4204}{V i s}+(1.13 * \text { DayNight })+(6.07 * S B 6)-(2.67 * S B 7)
$$

Where:

$\mathrm{S}=$ Mean speed per 5 minutes $(\mathrm{mph})$

Vis $=$ Visibility distance $(\mathrm{ft}$.

DayNight $=$ Day or night dummy variable, with 1 indicating day and 0 indicating night SB6 = Dummy variable, with 1 indicating site Southbound MP 6.6 SB7 = Dummy variable, with 1 indicating site Southbound MP 7.3

Although the $\mathrm{R}^{2}$ fit was low, the model is useful to explain the overall trend observed. The coefficients for the dummy variables for mile posts suggested that for the same visibilities, driver speeds vary significantly by site with means speeds $6 \mathrm{mph}$ higher at MP 6.6 or $2.67 \mathrm{mph}$ lower at MP than at MP 5.3, raising another concern for driver safety at MP 6.6. The results from McCann and Fontaine's research was crucial to the development of the initial VSL algorithm. 


\subsection{SYSTEM DESCRIPTION}

A \$7.5 million contract to construct the I-77 ATSMS was awarded to G4S Technologies in February 2014. Before construction of the system began, twelve miles of power and 14 miles of fiber optic communications infrastructure was installed beginning in July 2011 to support the system installation (4). The system was initially set to be in operation by the summer of 2015 , but due to construction delays it was not operational until October 2016. When construction was completed, the project added 13 DMSs, 36 full matrix VSL displays, 8 speed limit signs with dynamic VSL cutouts, 25 CCTV cameras, 22 traffic sensors, and 14 road weather information system (RWIS) stations. The locations of these devices are shown in Figure 6. Examples of devices are shown in Figure 7. 


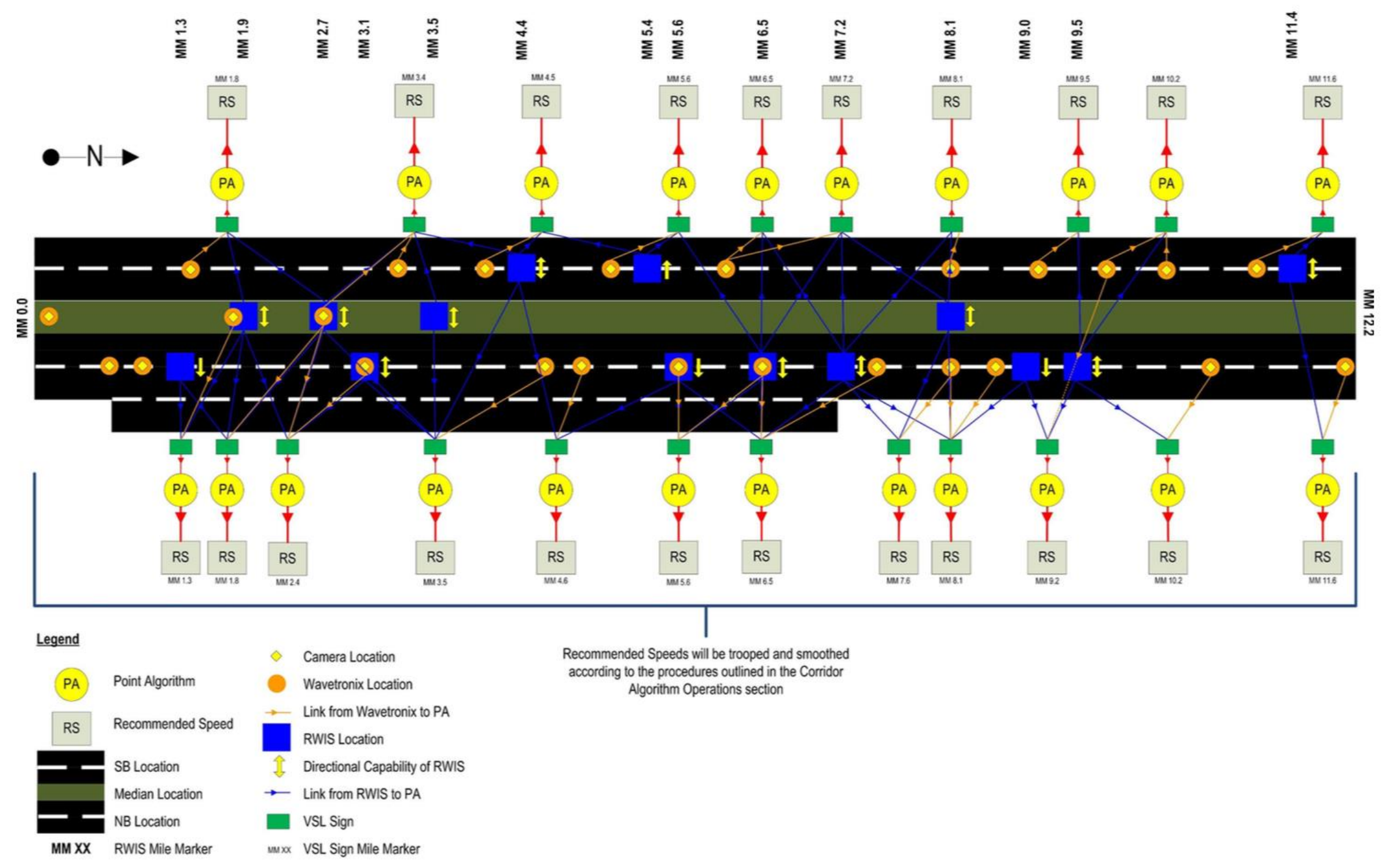

Figure 6 Corridor Diagram (28) 


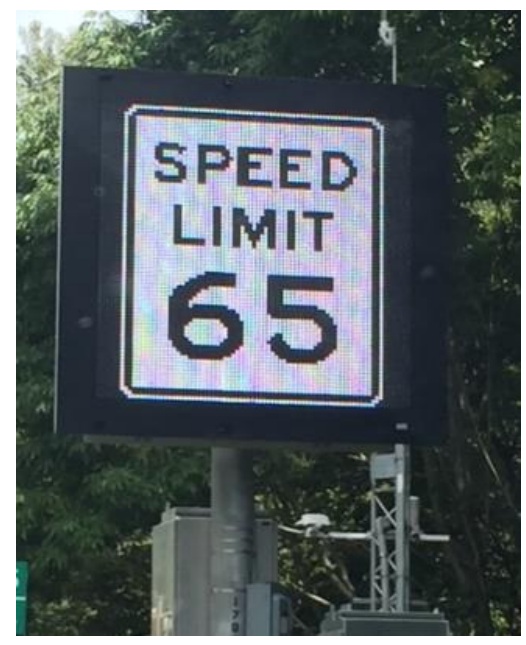

(a)

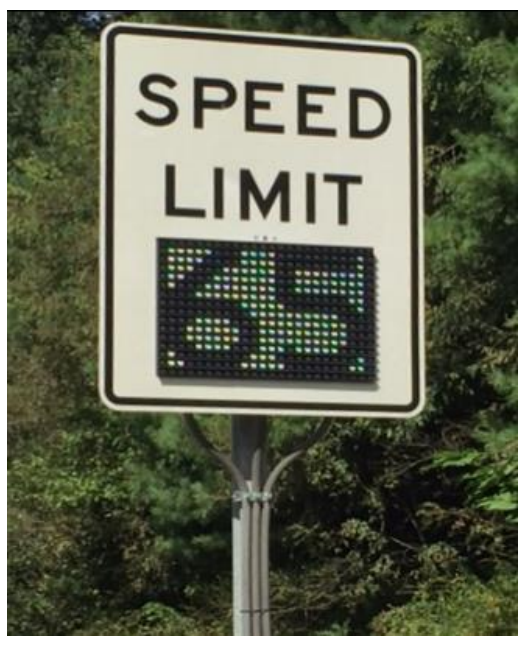

(b)

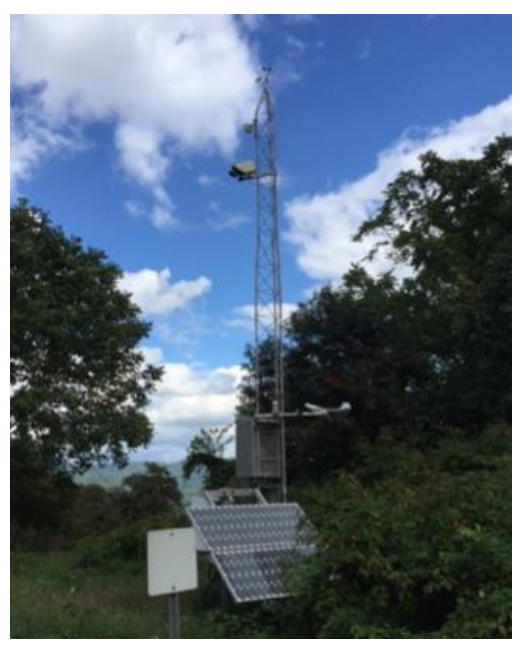

(c)

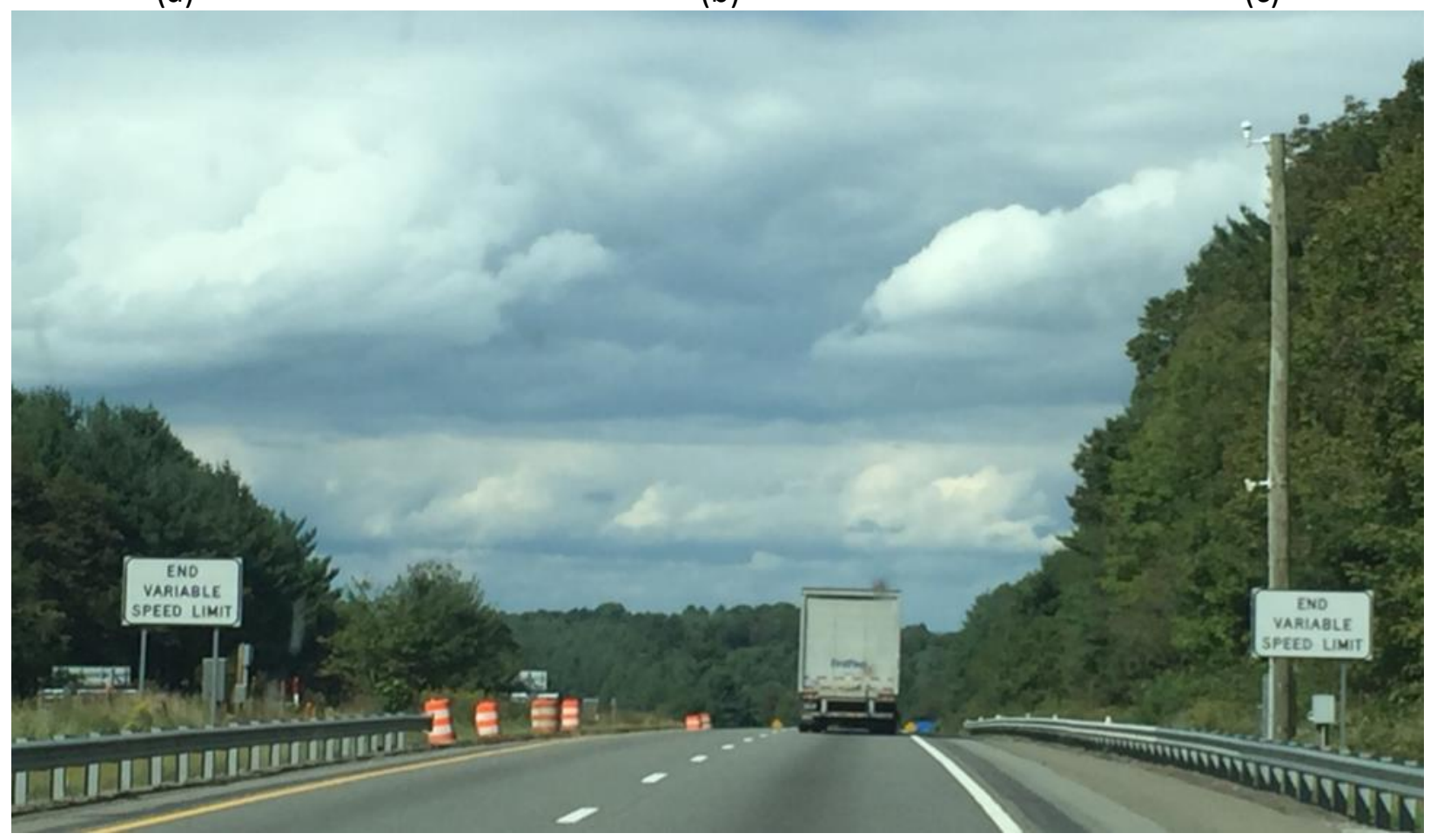

(d)

Figure 7 VSL System Devices. a) Full Matrix DMS VSL Display, b) Speed Limit Signs with dynamic VSL cutout, c) RWIS Station, and d) traffic sensor, CCTV, and signing at the northern end of the corridor.

Prior to entering corridor, static signs reading "Speed Limit May Vary Next 12 Miles"

were posted, along with static warning signs with flashers reading "Reduced Speed When Flashing" that are also scattered throughout the corridor in both directions (28). DMSs were installed at locations at the start of the corridor in both directions and at various intervals throughout the site to warn users of fog conditions ahead and to reduce speeds downstream. 
Depending on conditions throughout the corridor, the DMSs as encountered in NB and SB

directions will display the messages in Table 13. Other weather-related messages may also be posted depending on conditions (27).

\section{Table 13 I-77 DMS Messages}

\begin{tabular}{|c|c|c|c|c|c|}
\hline \multirow{2}{*}{$\begin{array}{c}\text { Fog } \\
\text { Level } \\
\text { (Visibility } \\
\text { in ft.) }\end{array}$} & \multicolumn{5}{|c|}{ Messages Displayed } \\
\hline & $1^{\text {st }} \mathrm{DMS}$ & $2^{\text {nd }} D M S$ & $\begin{array}{c}3^{\text {rd }}, 4^{\text {th }} \text {, and } 5^{\text {th }} \\
\text { DMS }\end{array}$ & $\begin{array}{c}6^{\text {th }} \text { DMS } \\
\text { (exit } \\
\text { condition) }\end{array}$ & DMS at Exit 1 \\
\hline $\begin{array}{l}1 \\
\geq 650 \mathrm{ft} .\end{array}$ & \multicolumn{5}{|c|}{ "Fog On Mountain | Use Caution" } \\
\hline $\begin{array}{l}2 \\
496 \text { to } \\
650 \mathrm{ft} .\end{array}$ & $\begin{array}{l}\text { "Fog Ahead | } \\
\text { Use Caution / } \\
\text { Adjust Speed I } \\
\text { To Conditions" }\end{array}$ & $\begin{array}{c}\text { "Fog Ahead | } \\
\text { Use Caution / } \\
\text { Reduce | } \\
\text { Speed" }\end{array}$ & $\begin{array}{c}\text { "Fog Ahead | } \\
\text { Reduce } \\
\text { Speed" }\end{array}$ & $\begin{array}{l}\text { "Fog Present | } \\
\text { Use Caution" }\end{array}$ & $\begin{array}{l}\text { "Fog Ahead | } \\
\text { Use Caution" }\end{array}$ \\
\hline $\begin{array}{l}3 \\
361 \text { to } \\
496 \mathrm{ft} .\end{array}$ & $\begin{array}{l}\text { "Fog Ahead I } \\
\text { Use Caution / } \\
\text { Adjust Speed I } \\
\text { To Conditions" }\end{array}$ & $\begin{array}{l}\text { "Moderate } \\
\text { Fog | Ahead | } \\
\text { Use Caution / } \\
\text { Reduce | } \\
\text { Speed" }\end{array}$ & $\begin{array}{c}\text { "Moderate } \\
\text { Fog | Ahead | } \\
\text { Reduce } \\
\text { Speed" }\end{array}$ & $\begin{array}{l}\text { "Fog Present | } \\
\text { Use Caution" }\end{array}$ & $\begin{array}{l}\text { "Moderate } \\
\text { Fog | Ahead | } \\
\text { Use Caution" }\end{array}$ \\
\hline $\begin{array}{l}4 \\
<361 \mathrm{ft} .\end{array}$ & $\begin{array}{c}\text { "Dense Fog } \\
\text { Ahead | Use } \\
\text { Caution / } \\
\text { Adjust Speed | } \\
\text { To Conditions" }\end{array}$ & $\begin{array}{c}\text { "Dense Fog I } \\
\text { Ahead | Use } \\
\text { Caution / } \\
\text { Reduce | } \\
\text { Speed" }\end{array}$ & $\begin{array}{c}\text { "Dense Fog | } \\
\text { Ahead | } \\
\text { Reduce } \\
\text { Speed" }\end{array}$ & $\begin{array}{l}\text { "Fog Present | } \\
\text { Use Caution" }\end{array}$ & $\begin{array}{c}\text { "Dense Fog | } \\
\text { Ahead | Use } \\
\text { Caution" }\end{array}$ \\
\hline
\end{tabular}

VSL messages are displayed on the full matrix VSL displays and speed limit signs with dynamic VSL cutouts, shown in Figure 7, all of which are dual mounted in each direction and spaced no more than 1.5 miles apart. During clear conditions, VSLs post the base regulatory speed of $65 \mathrm{mph}$. Speed limits can be posted as low as $30 \mathrm{mph}$ when conditions dictate. VSL speeds are set based off of the visibility data collected from the RWIS stations and traffic data from traffic detection stations. A more detailed description of the VSL algorithm can be found in the following sections. 
Vaisala RWIS stations are spaced within 1.7 miles of each other and more densely within the fog prone area near mile post 6.6. These stations contain equipment to collect pavement temperature and condition, air temperature, humidity, pressure, precipitation type and intensity, wind speed and direction, and visibility. The visibility sensors at each station are mounted $20 \mathrm{ft}$. in the air and use forward scatter techniques to estimate visibility distance. Near each RWIS station there are also corresponding Wavetronix side-fire radar devices to collect traffic data. Although speeds posted by VSLs are regulatory, speed enforcement during low visibility conditions is limited. Automated speed enforcement of speed limits is not legally permitted in Virginia. Due to safety concerns, enforcement by Virginia State Police (VSP) during low visibility conditions is selective, so as to not put enforcement officers at excessive risk during limited visibility conditions.

\subsection{VSL ALGORITHM}

As part of a collaborative effort between VDOT Southwest Region Operations (SWRO), VDOT Traffic Engineering Division, VDOT Operations Division, and the Virginia Transportation Research Council, Kimley-Horn prepared a methodology for operating the I-77 VSLs. In light of the poor compliance to SSD safe speeds revealed by the work performed by McCann and Fontaine, VDOT was concerned that simply posting these speeds would not adequately alter driver behavior and instead would further increase speed variance and interactions between vehicles under low visibilities. Thus, the initial VSL algorithm considered intermediate speeds between the pre-VSL driving behavior model and the SSD safe speed, which resulted in a step function of visibility to determine the posted speed. 
The step function was based off of the driver behavior model. However, the equation used is a modification of the McCann and Fontaine's driver behavior model equation, requiring less parameters as it serves to model of speeds throughout the entire site, both northbound and southbound. This model mean speed was represented by the equation (28):

$$
S=64.6-\frac{4204}{\text { Vis }}+(2.15 * \text { DayNight })
$$

Where:

$$
\begin{aligned}
& \mathrm{S}=\text { Mean speed per } 5 \text { minutes }(\mathrm{mph}) \\
& \text { Vis = Visibility distance }(\mathrm{ft} .) \\
& \text { DayNight = Day or night dummy variable, with } 1 \text { indicating day and } 0 \text { indicating night }
\end{aligned}
$$
The two cut off points for the step functions are when SSD safe speed equals 50 and $40 \mathrm{mph}$. The SSD safe speed is determined directionally due to uphill/downhill grades. When SSD safe speeds are greater than $50 \mathrm{mph}$, the model mean speed was used. When SSD safe speeds were between 40 and $50 \mathrm{mph}$, the model mean speed is reduced by $5 \mathrm{mph}$. When SSD safe speeds were below $40 \mathrm{mph}$, the model mean speed was reduced by $10 \mathrm{mph}$. Additionally the algorithm considers a day/night variable, therefore there are 4 step-functions considered for both day and night with different cutoff points for steps for north and south directions. A graphical representation is shown below in Figure 8 for the southbound direction. At each VSL location, depending on observed average speeds over an interval, the algorithm would determine what the posted VSL should be based on the minimum value of either the observed mean speed or the step-adjusted model fit. VSLs would not post values below $30 \mathrm{mph}$, and an additional smoothing algorithm would adjust VSLs over the corridor to have a smooth transition between posted VSLs as vehicles traveled into and out of fog zones. Speed limits between successive VSL 
signs cannot decrease by more than $15 \mathrm{mph}$, but could return to $65 \mathrm{mph}$ as quickly as possible after exiting the fog zone, provided no additional visibility impacts follow. For example, SB VSL signs approaching fog zone would transition 60 to 45 to $30 \mathrm{mph}$ at the worst fog locations. As soon as drivers exit the fog zone, the next VSL sign could read $65 \mathrm{mph}$ if visibilities were clear in the remained of the corridor. VSL speeds at individual locations were also subject to a step range that would not allow them to vary by more than 15 mph over successive 5 minute intervals.

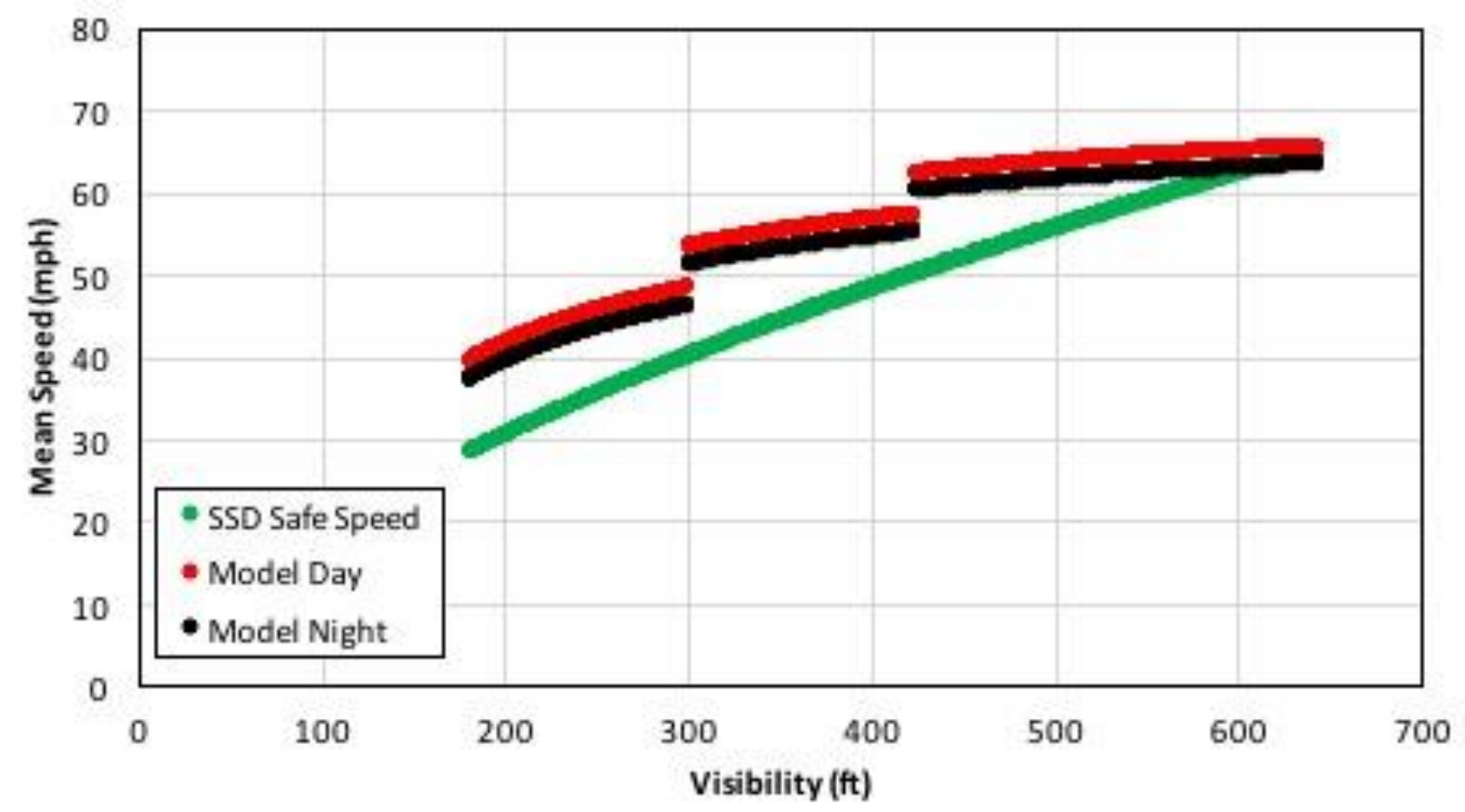

Figure 8 VSL Algorithm Step Function 


\section{CHAPTER 4: METHODOLOGY}

\subsection{INTRODUCTION}

This chapter discusses the data used for this thesis and how that data was analyzed in order to evaluate the effectiveness of the I-77 VSL system. Additional data prior to VSL activation, not available during McCann and Fontaine's study, is also presented here. This additional before period data and new after period data are discussed in this chapter.

\subsection{OVERVIEW OF DATA USED IN ANALYSIS}

Data was available at a limited number of locations along the corridor prior to VSL activation from both permanent and temporary data collection stations. After VSL installation, some stations were relocated and additional permanent data collection sites were installed. Data prior to VSL activation was obtained primarily through querying existing databases. For the after period, SWRO provided logs of speed limits, detected speed, and visibility during fog events. Although data was available for both directions of travel, the after analysis of this thesis focuses on the southbound (downhill) direction given that past work indicated this direction was responsible for the vast majority of safety concerns. Table 14 summarizes the data used in this thesis. Subsequent sections describe the data used in more detail. 
Table 14 Summary of Data Used in this Thesis

\begin{tabular}{|c|c|c|c|c|}
\hline $\begin{array}{l}\text { Data } \\
\text { Type }\end{array}$ & $\begin{array}{l}\text { Data } \\
\text { Source }\end{array}$ & Period & Location & $\begin{array}{l}\text { Aggregation } \\
\text { Interval }\end{array}$ \\
\hline \multirow{2}{*}{ Visibility } & Vaisala & $\begin{array}{l}\text { Jan } 2015-\text { Dec } \\
2015\end{array}$ & $\begin{array}{l}\text { MPs } 1.2,1.8,2.7,3.0,4.4,5.3,6.6 \text {, } \\
7.3,9.0,9.6,11.3 \text {, and } 16.9\end{array}$ & $10 \mathrm{~min}$ \\
\hline & SWRO Logs & $\begin{array}{l}\text { Oct } 2016-\text { Sep } \\
2017\end{array}$ & $\begin{array}{l}\text { MPs } 1.3,1.9,2.7,3.1,3.5,4.4,5.4 \\
5.6,6.5,7.2,8.1,9,9.5 \text {, and } 11.4\end{array}$ & $\sim 6 \min$ \\
\hline Weather & Vaisala & Jan 2015 - Jul 2016 & MP 4.4 and 6.6 & $10 \min$ \\
\hline \multirow[t]{2}{*}{ Speed } & $\begin{array}{l}\text { VDOT } \\
\text { Portable } \\
\text { Speed } \\
\text { Detection }\end{array}$ & Jan 2015 - Jul 2016 & SB 4.4, NB 6.6 & $15 \mathrm{~min}$ \\
\hline & SWRO Logs & $\begin{array}{l}\text { Oct } 2016 \text { - Sep } \\
2017\end{array}$ & $\begin{array}{l}\text { SB } 1.0,3.3,4.3,4.4,5.3,6.2,6.6 \\
7.5,8.1,8.8,9.7,10.2 \text {, and } 11.3\end{array}$ & $\sim 6 \min$ \\
\hline VSLS & SWRO Logs & $\begin{array}{l}\text { Oct } 2016-\text { Sep } \\
2017\end{array}$ & $\begin{array}{l}\text { SB } 1.8,3.4,4.5,5.6,6.5,7.2,8.1 \text {, } \\
9.5,10.2 \text {, and } 11.6\end{array}$ & $\sim 6 \min$ \\
\hline \multirow{2}{*}{ Volume } & $\begin{array}{l}\text { VDOT } \\
\text { Traffic }\end{array}$ & $\begin{array}{l}\text { Jan } 2015 \text { - Aug } \\
2016\end{array}$ & MP $0-15$ & \multirow{2}{*}{$5,15 \mathrm{~min}$} \\
\hline & $\begin{array}{l}\text { Monitoring } \\
\text { System }\end{array}$ & $\begin{array}{l}\text { Oct } 2016 \text { - Aug } \\
2017\end{array}$ & MP $0-12$ & \\
\hline \multirow{2}{*}{ Crash } & $\begin{array}{l}\text { VDOT } \\
\text { Roadway }\end{array}$ & $\begin{array}{l}\text { Jan } 2015-\text { Dec } \\
2015\end{array}$ & MP $0-15$ & \multirow{2}{*}{ N/A } \\
\hline & $\begin{array}{l}\text { Network } \\
\text { System }\end{array}$ & $\begin{array}{l}\text { Oct } 2016 \text { - Aug } \\
2017\end{array}$ & MP $0-12$ & \\
\hline
\end{tabular}

4.2.1 Visibility and Weather Data

Visibility data was collected from Vaisala PWD10/12 visibility sensors at each RWIS station. These sensors use forward scatter technology to measure visibility over a short range and extrapolate it out to estimate visibility in feet. Additional weather data collected at RWIS stations included pavement temperature and condition, air temperature, humidity, pressure, precipitation type and intensity, and wind speed and direction. This data was stored on a Vaisala external website that could be queried. 
Before weather data consisted of two types of information. This visibility data consisted of visibility readings collected every 10 minutes from RWIS stations located at mile posts 1.2 , 1.8, 2.7, 3.0, 4.4, 5.3, 6.6, 7.3, 9.0, 9.6, 11.3, and 16.9 from January 2015 to December 2015. Additional visibility and weather data was retrieved for the RWIS station at MP 4.4 for the period of January 2015 until July 2016 when data was no longer available through the Vaisala external site. This additional data was used to further enhance the before condition model of speed behavior.

For the after period analysis, three additional RWIS stations installed at mile posts 3.5, 5.6, and 8.1 were available, and several stations were relocated. The RWIS station at MP 16.9 was outside scope of study for after period, and thus was not used. The stations used for the after analysis were located at mile posts: $1.3,1.9,2.7,3.1,3.5,4.4,5.4,5.6,6.5,7.2,8.1,9,9.5$, and 11.4. Although RWIS Stations were located either on the NB shoulder, SB shoulder, or in the median, most stations had the ability to provide visibility readings for both directions regardless of location. RWIS stations at MP 4.4, 5.4, and 11.4 were on the SB shoulder; the station at MP 5.4 provided data only for the SB direction. RWIS stations at MP $1.9,2.7,3.5$, and 8.1 were on the median. The remainder of the stations were located on the NB shoulder of which RWIS stations at MP 1.3, 5.6, and 9.0 provided data only for the NB direction. After system activation, visibility data was acquired from SWRO logs for fog events between October 2016 to end of September 2017. These visibility readings were updated at an average rate of every 6.5 minutes. Outside of SWRO logs, no visibility data is available but it is assumed to be clear conditions since low visibilities trigger activation of the system. 
Additionally, sunrise and sunset times for the years 2015-2017 were also acquired from the US Naval Observatory to determine day/nighttime conditions.

\subsubsection{Speed and Volume Data}

Prior to VSL activation, newly available continuous speed data at MP 6.6 NB and 4.4 SB was available from the VDOT Traffic Monitoring System for the period January 2015 to August 2016. The detectors recorded the count of vehicles in $5 \mathrm{mph}$ bins in 15 -minute intervals. The 15-minute volume was taken as the sum of the vehicle counts in each $5 \mathrm{mph}$ bin for the 15minute interval. In order to match speeds to visibility readings, these 15 minute intervals were converted into 10 minute intervals. This conversion involved first evenly splitting 15 minute intervals into 5 minute intervals assuming a linear distribution of data during each 15-minute interval. In this way a \#\#:15 15-minute interval would become \#\#:05, \#\#:10, and \#\#:15 5-minute interval, a \#\#:30 15-minute interval would become \#\#:20, \#\#:25, and \#\#:30 5-minute intervals, and so on. Then these 5-minute intervals would then be recombined to form 10-minute intervals where \#\#:05 and \#\#:10 5-minute intervals would combine to make \#\#:10 10-minute intervals, and \#\#:15 and \#\#:20 5-minute interval would combine to make \#\#:20 10-minute interval, etc. Average speeds for the new 10-minute intervals were calculated assuming all vehicles were traveling at the midpoint of each $5 \mathrm{mph}$ bin and finding the volume weighted average speed.

In the after period, SWRO provided logs with mean observed speeds and the posted speed limit during every fog event for every VSL location. The recording interval averaged approximately 6.5 minutes. Mean observed speeds for each interval were collected by Wavetronix speed detectors at MPs 1.0, 3.3, 4.3, 4.4, 5.3, 6.2, 6.6, 7.5, 8.1, 8.8, 9.7, 10.2, and 
11.3 in the SB direction. Posted speeds were recorded from each VSL sign locations at MPs 1.8, $3.4,4.5,5.6,6.5,7.2,8.1,9.5,10.2$, and 11.6 . Since SWRO logs only provided mean speeds, volume data needed to be retrieved from the VDOT Traffic Monitoring System for the entire after period.

Volume data for the entire corridor was retrieved from VDOT Traffic Monitoring System for the 2015 before period and for the October 2016 to June 2017 after period. In the NB direction, volume data for links MP 0-0.94, MP 0.94-8.57, and MP 14.85-19.03 were retrieved. The link for MP 8.57-14.85 did not have continuous data available, but volumes were estimated as the average of the links directly upstream and downstream of it. In the SB direction, MP 01.07, MP 1.07-8.99, and 15.22-19.53 were retrieved. Similarly, the link for MP 8.99-15.22 did not have any data and was estimated as the average of the links directly upstream and downstream of it. The volume data were recorded in 5- and 15-minute intervals. 15-minute intervals were converted into 5-minute intervals assuming a linear distribution of data during 15-minute intervals. Before data was further converted to 10 -minute data to match visibility data.

\subsubsection{VSL Posted Speed Logs}

VSL signs for the southbound direction were located at MPs: 1.8, 3.4, 4.5, 5.6, 6.5, 7.2, 8.1, 9.5, 10.2, and 11.6. In the after period, posted VSLs at each VSL location were recorded in the SWRO logs at approximate 6.5 minute intervals. Posted speed values were: $30,35,40,45$, $50,55,60$, and $65 \mathrm{mph}$. Periods when VSLs were offline were recorded in SWRO logs as "Blank" and were discarded from analysis. 


\subsubsection{Crash Data}

Police crash reports for 2015 were retrieved from VDOT's Roadway Network System (RNS) to understand crash characteristics and frequencies for the year immediately prior VSL activation. Crash data from October 2016 up until August 2017 (the latest date when crash data were closed out in RNS) were also collected to perform a preliminary crash analysis following VSL activation. For both data sets, crashes coded as fog were then matched with visibility data to confirm low visibility conditions.

\subsubsection{Data Matching}

Data sets came in several different reporting intervals, and data was matched across different sets in a number of ways. For crash rate calculations, visibility and volumes needed to be matched, and crashes and visibilities needed to be matched. For the before data, volume data from the entire corridor was converted to 10-minute bins to match visibility data. For after data, volume data was converted to 5-minute intervals since visibility readings in the after period were roughly 6 minutes to maintain as much granularity as possible. Visibility readings were then matched to 5-minute volume readings by linearly interpolating between visibility readings. Visibility readings for times outside of SWRO logs, were considered as clear conditions. For the post-VSL during activation logs, if intervals between visibility readings were ever more than 30 minutes apart, the 5-minute intervals to be matched in between periods were marked as missing.

To match visibility to crash records, visibilities at the nearest visibility stations and timestamps closest to crash record times were determined. Then visibilities were linearly interpolated between nearest RWIS station and visibility readings. 


\subsection{DATA ANALYSIS}

The following section presents the analysis performed in this thesis. The analysis examines the effect of the VSL system on driver speeds both before and after at a single site and across the corridor in the after period and on crashes for the entire corridor.

\subsubsection{Visibility}

To be consistent with prior work, visibility conditions were categorized into groups corresponding to a range of stopping sight distance safe speeds. Boundaries for each of these visibility bins were calculated by solving for speeds of $65,55,45,35$, and 25 mph using the equation for stopping sight distance below:

$$
S S D=1.468 \times V \times t_{r}+\frac{2.155 \times V^{2}}{2 \times a}
$$

Where:

$$
\begin{aligned}
& \text { SSD = Stopping sight distance }(\mathrm{ft} .) \\
& \mathrm{V}=\text { Speed }(\mathrm{mph}) \\
& \mathrm{t}_{\mathrm{r}}=\text { reaction time }(\mathrm{sec}) \\
& \mathrm{a}=\text { deceleration rate }\left(\mathrm{ft} . / \mathrm{sec}^{2}\right)
\end{aligned}
$$

The SSD was calculated assuming flat grades, a reaction time of $2.5 \mathrm{sec}$, and a deceleration rate of $11.2 \mathrm{ft} . / \mathrm{sec}^{2}$ as specified in the AASHTO Policy on the Geometric Design of Highways and Streets. The SSD calculated from each of the above speeds was rounded up to the nearest multiple of 5 . This resulted in the following visibility bins:

- $\quad>645 \mathrm{ft} .=>65 \mathrm{mph}$

- $495-645 \mathrm{ft} .=55-65 \mathrm{mph}$ 
- $\quad 360-495 \mathrm{ft} .=45-55 \mathrm{mph}$

- $250-360 \mathrm{ft} .=35-45 \mathrm{mph}$

- $\quad 155-250 \mathrm{ft} .=25-35 \mathrm{mph}$

- $\quad<155 \mathrm{ft} .=<25 \mathrm{mph}$

From this a visibility profile of the corridor was created to examine the frequency of reduced visibility across the corridor. The visibility profile served to indicate if fog exposure during both the before and after were representative of each other and to McCann and Fontaine's initial study. This frequency of reduced visibility served to create crash rates.

\subsubsection{VSL Posted}

To present how often the system is posting reduced speeds, VSLs were summarized by how often each PSL was posted at each VSL sign. Average posted speeds per SB VSL sign location were also calculated.

4.3.3 Speed Choice Analysis

\subsubsection{Before-After Evaluation at MP 4.4}

There were only two sites along the corridor that provided continuous speed and visibility data both before and after system activation, those being SB 4.4 and NB 6.6. Since the focus of this thesis is on the SB direction, only SB 4.4 was analyzed before-after to compare changes in driver behavior and compliance. Speed data was summarized into counts, mean speeds, and standard deviations by visibility bin for both periods. Mean speeds and standard deviations by visibility bin were also calculated for both before and after periods. Z tests were used to test if mean speeds in the after period were statistically significantly different from the 
before period. $\mathrm{F}$ tests were also performed to assess if the variance in speeds by visibility changed for the periods tested.

Weather data and VSL data were considered to develop driver speed choice models at the singular comparison site MP 4.4. Several different types of speed choice models were attempted: a before model to compare to McCann's original model/VSL algorithm model, an after model to compare to before model, and a combined before-after model at MP 4.4.

Stepwise linear regression was performed in order to describe speeds as a function of visibility, weather conditions, and/or VSL factors for each of the models considered. For the before model, independent variables considered were:

- Available visibility

- Weather data (pavement temperature and condition, air temperature, humidity, pressure, precipitation type and intensity, and wind speed and direction)

- Day/night conditions

In the after period, the only data available from RWIS stations available was visibility, thus weather data was not considered. In addition to visibility and day/night condition variables, the after period also considered posted speed limits as an independent variable. The before-after model considered the same variables as the after model with the addition of a VSL absence/presence indicator variable which used the value of 0 to indicate the before period or of 1 for the after period.

Transformations and interactions of all these variables within their respective models were also taken into consideration. Periods with visibilities over $645 \mathrm{ft}$. (clear conditions) and of zero feet were discarded from the model. Theoretically, visibilities of $645 \mathrm{ft}$. and above should 
provide adequate SSD for the base speed limit of $65 \mathrm{mph}$. Based on feedback from VDOT, visibility readings of zero feet were taken to be errors and were discarded from the data set. Furthermore, speed data during crash events and their aftermath were ignored as this analysis' intent was to understand speed under undisturbed low visibility conditions and not during congestion. Models were further refined using Cook's Distance value to exclude outlier data points whose values were excessively influencing the models. To check if regression assumptions were satisfied, residual plots and probability-probability (P-P) plots were reviewed. Models accepted showed no curvilinear or systematic trends in residual plots and had errors that were homoscedastic, uncorrelated, and normally distributed. Adjusted $\mathrm{R}^{2}$ values and average absolute error and bias were also checked.

\subsubsection{Speed Changes During Fog Along Corridor}

Although speed data throughout the entire corridor was not available in the before period, it was available in the after period and was used to characterize driver behavior in response to VSLs. To understand speed changes during fog along the corridor, speed data was summarized in several forms: posted speeds by MP, observed speeds for posted speeds by mile post, and speed differentials for posted speeds by mile post.

The frequency of different reduced speeds was mapped by milepost. For periods of activation, average posted speed was also calculated by mileposts. Observed mean speeds and differentials between observed mean speed and posted speeds were summarized by posted speed and mileposts. To analyze the effect of the posted speed on the mean speed, paired ttests were performed on observed speeds to test if means speeds for a set posted speed at a mile post were significantly different than posted speeds. 


\subsubsection{Crash Analysis}

\subsubsection{Crash Frequency and Characteristics}

Crashes matched with low visibilities and coded as fog in police reports were summarized by crash type, severity, and number of vehicles involved. These were summarized also by visibility bin and direction to compare with decreased visibility. All other crashes were considered "clear conditions" and were summarized similarly. For the before period, the newly acquired 2015 data was combined with the crash characteristics previously summarized by McCann and Fontaine to create a crash characteristics of the corridor for the 5 full years immediately prior to VSL activation. Due to the limited amount of crash that has been reported since VSL system has been activated, analysis is discussed more qualitatively although similar summaries are provided.

\subsubsection{Crash Rates}

Crash rates along the corridor were calculated using visibility and crash data during this period. After visibility and volume data had been matched, vehicle miles traveled (VMT) per visibility bin needed to be estimated. First, the corridor was broken into segments according to the number of RWIS stations corresponding to each direction. The NB direction was broken into 13 segments with the midpoints between RWIS station MPs 1.3, 1.9, 2.7, 3.1, 3.5, 4.4, 5.6, 6.5, $7.2,8.1,9,9.5$, and 11.4 as the segment boundaries. Similarly, the SB direction was broken into 11 segments with the midpoints between RWIS stations 1.9, 2.7, 3.1, 3.5, 4.4, 5.4, 6.5, 7.2, 8.1, 9.5, and 11.4 as segment boundaries. For each segment the vehicle miles traveled would be determined by the multiplying segment length and with corresponding link volume. This was 
done for all intervals. The sum of VMT per visibility bin was found and crashes per 100 million VMT per visibility bin were calculated. The crash rate for all combined low visibilities was also calculated. VMT per visibility bin was also summarized into percentages to get a picture of the traffic actually on roads during periods of reduced visibility.

\subsubsection{VSL Algorithm Assessment}

Based on driver responses to the system, modifications to the current VSL algorithm may be warranted to increase system's effectiveness. To assess the VSL algorithm, modifications to different constraints in the algorithm were examined. Modifications to algorithm could entail altering spatial and temporal step ranges or altering the (input) values used in the algorithm to determine the recommended speed. Other alternatives to improve system effectiveness beyond control algorithm itself were also discussed. 


\section{CHAPTER 5: RESULTS}

\subsection{INTRODUCTION}

This section describes the results of the analysis described in the previous chapter beginning with a case study to illustrate system operations. Whenever tables and charts list MPs for the SB direction, they are listed in descending order to reflect the order in which drivers encounter MPs as they enter the corridor from the north at MP 12 and exit at the south at MP 0.

\subsection{OVERALL RESULTS}

\subsubsection{Visibility}

Altogether, there were 106 VSL separate activations from October 2016 to September 2017, which resulted in at least some portion of the corridor having a reduced VSL for a total of 702.5 hours. From the VSL activation logs, visibilities were retrieved to construct the visibility profile for the after period, as shown Figure 9. The figure shows a concentration of low visibility conditions between MP 7.3 and 5.3, consistent with previous findings that this section experiences the most amount of time of reduced visibilities in the corridor yearly. For the after VSL activation period, RWIS stations at MP 6.6 and 5.6 experienced the most reduced visibility with 386 and 275 hours(4.4 and 3.1\% of the time in the after period, respectively) of reduced visibilities of less than 645 feet available. Although this is about $1 \%$ of the time less than the before period shown in Figure 5, visibilities less than $360 \mathrm{ft}$. occur approximately $3.1 \%$ of the total time for both periods at MP 6.6. 
In the after period, 10 stations experienced no more than 3 hours of missing data during activations. Visibility data was only available during VSL activations, and any time outside of those periods available visibility readings are assumed to be clear conditions at all RWIS stations. RWIS stations at MPs 9.6, 7.3, and 1.8 had the most missing hours of data with 34-42 hours of missing data. Since RWIS stations at MPs 9.6 and 1.8 fall outside the worst fog zone area, this missing data likely does not greatly affect the overall visibility profile. At MP 7.3 there is a sudden drop, which can probably attributed to the missing data. Overall, however, the visibility in the corridor for the after period was found to be spatially similar in distribution to the average low visibility conditions summarized by McCann and Fontaine for the 2010-2015 period, with slightly shorter durations of about $1 \%$ less total time in reduced visibilities across all stations.

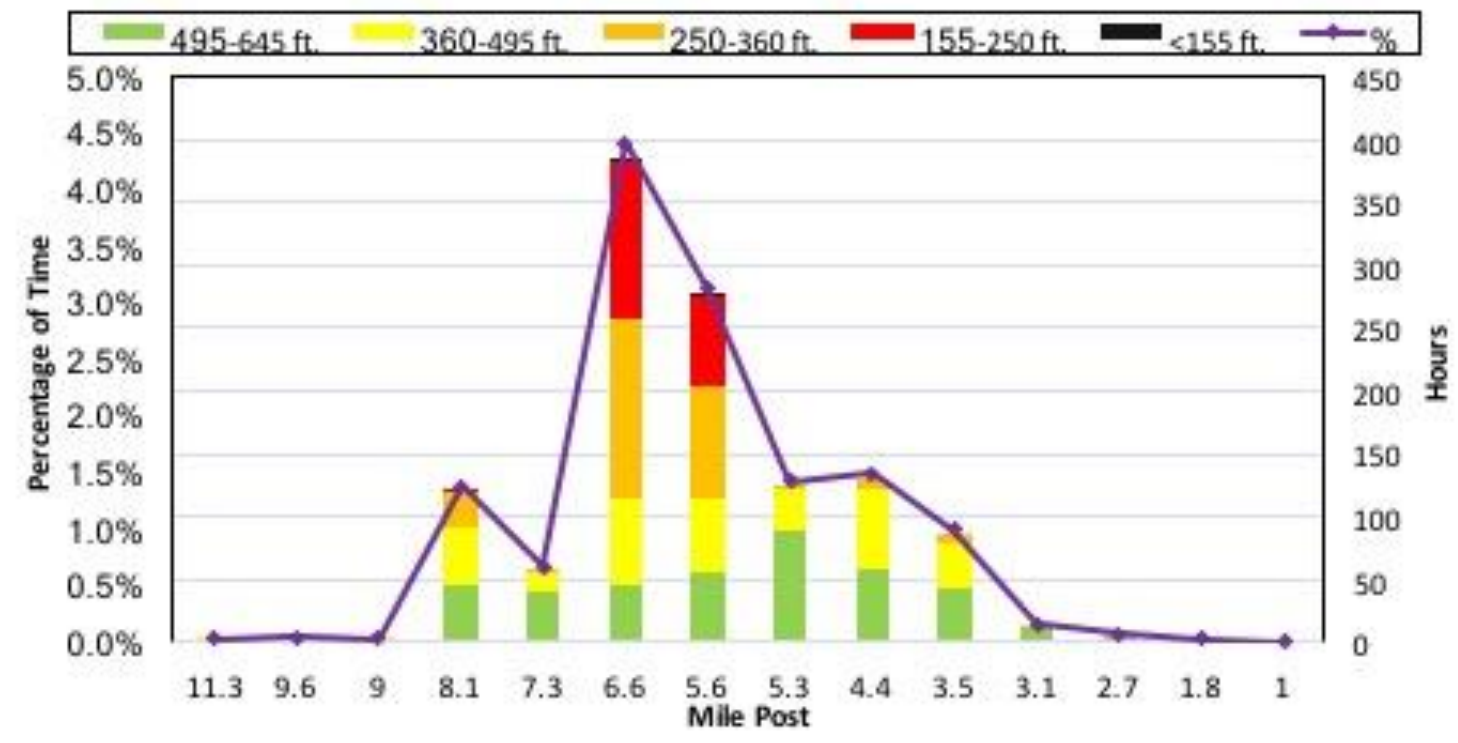

Figure 9 After Period Visibility Profile

\subsubsection{Summary of VSLs Posted}

Figure 10 shows the amount of time and overall percentage of the after period in which reduced speed limits were posted in the southbound direction. This figure parallels the visibility 
profile in Figure 9 showing the most usage of reduced speeds between MPs 7.2 and 5.6 posting reduced speeds for more than $5 \%$ of the after period. In general, this figure displays how during fog events the VSL system will post speeds that gradually reduce as drivers encounter the first VSL sign at 11.6 until the worst fog area between 7.2 and 5.6 where reduced speeds are the lowest. After drivers traversed the worst fog zone, posted speeds quickly increase back up to base speed limit.

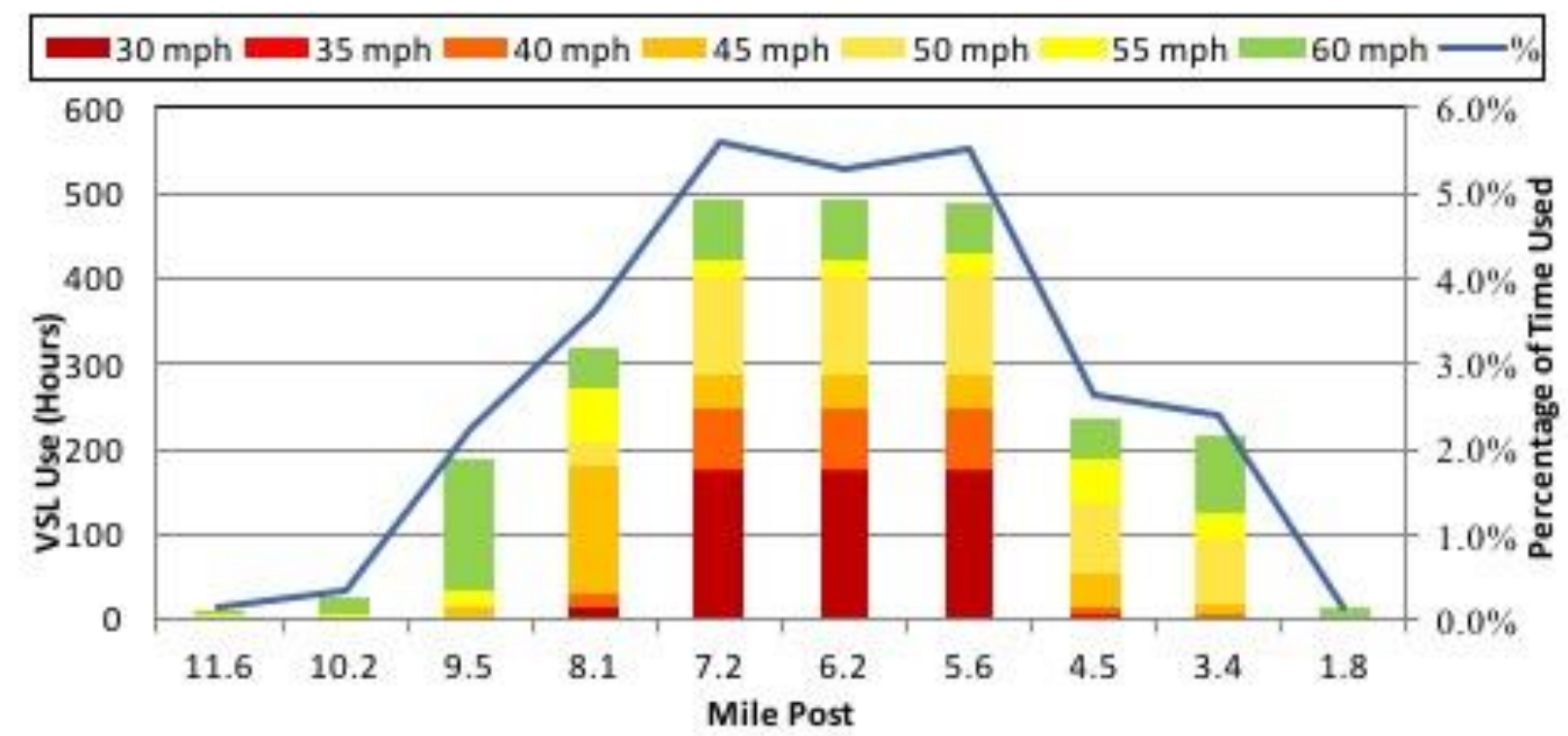

Figure 10 VSL Usage by MP

\subsubsection{Case Study: Incident WX3150436}

Before discussing overall trends in the results, a case study is presented to illustrate how the system works over the course of an event. This allows for a more granular presentation of results, and helps illustrate common performance trends.

Incident number WX3150436 was initiated on 12/17/2016 at 8:38:39 PM and lasted until $12 / 18 / 2016$ at 11:01:46 AM, for a total duration of 14 hours and 23 minutes. During this event, all RWIS stations and VSL signs were operational with no missing data. All SB speed 
sensors were operational with no missing data as well except for those at MPs 8.1, 6.2, and 4.4 which were offline for the entirety of the event. At its most critical point, visibilities were as low as $177 \mathrm{ft}$. at MP 5.6, with reduced visibilities extending from MP 2.7 to 8.1. On average, there was a median spread of fog of 2.2 mile centered about MP 6.6, with a visibility profile as shown in Figure 11. The VSLs were used as shown in Figure 12. From this figure, we can see that the VSLs used at MPs 7.3, 6.6, and 5.6 are almost identical, posting reduced speeds of $30 \mathrm{MPH}$ over $60 \%$ of the event duration. Although visibilities at MP 7.3 fared better than the preceding station at MP 8.1 due to the worsened condition ahead, the trooping in the VSL algorithm caused all speeds in this region to be equal, and VSLs at 8.1 were posted at $45 \mathrm{mph}$ a majority of the time.

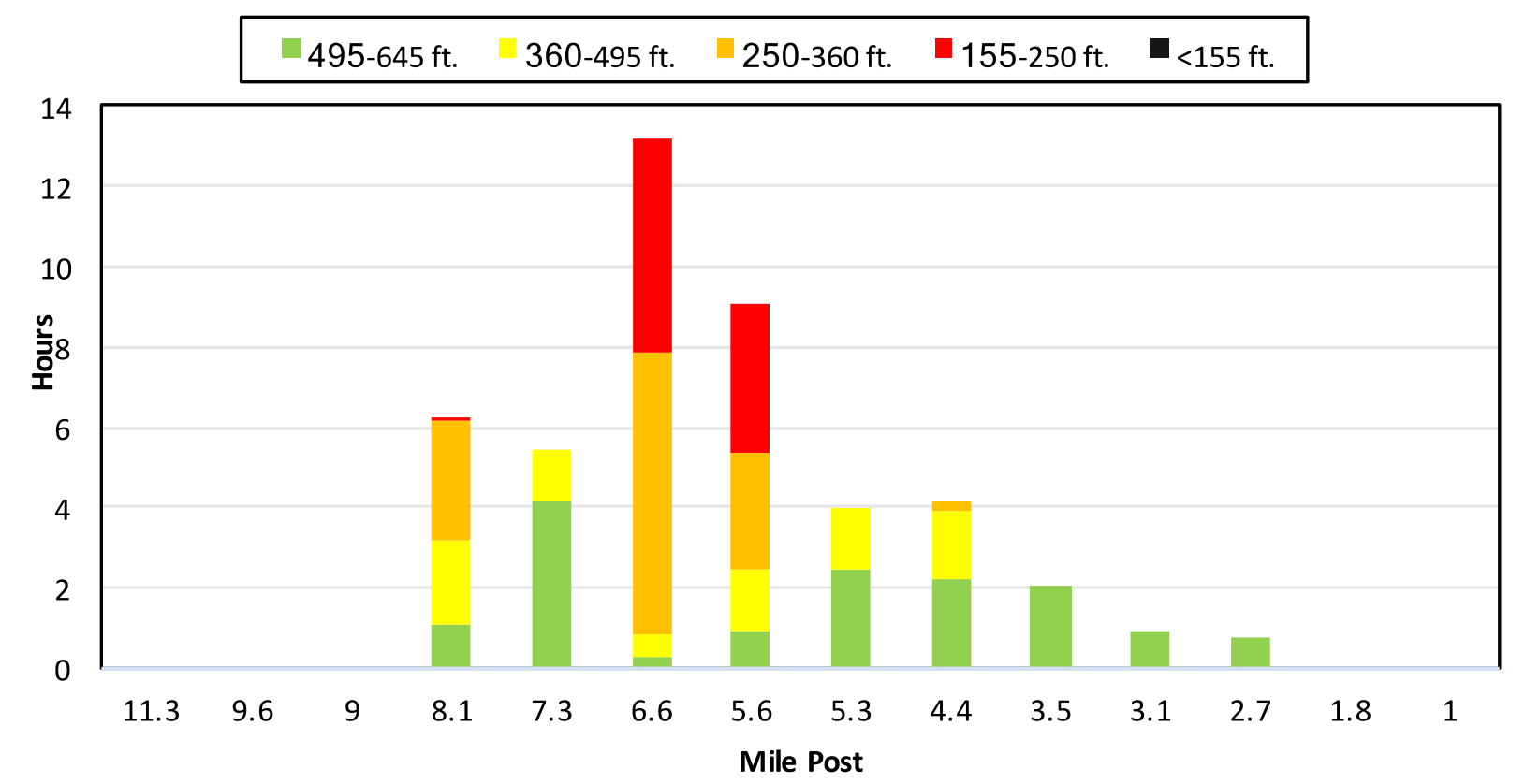

Figure 11 Case Study Visibility Profile 


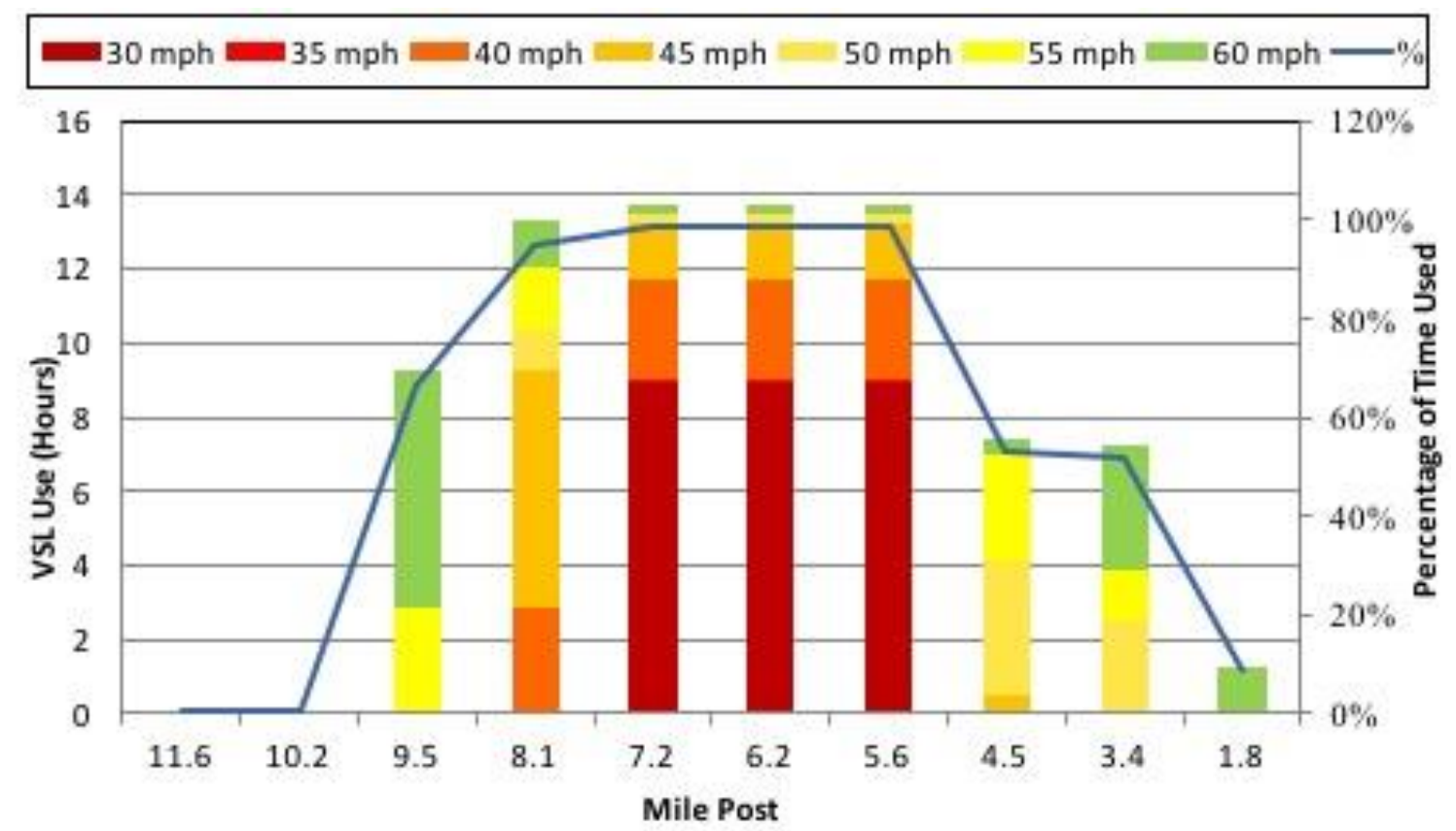

Figure 12 Case Study SB VSL Usage

Figure 13 shows how speeds and visibilities vary over time at successive MPs for this event. Only visibilities less than $1000 \mathrm{ft}$. are graphed. From this, it can be seen that upon entering the corridor observed speeds closely follow the posted speeds that for almost $99 \%$ of the time remained at $65 \mathrm{mph}$. When drivers approach the first reduced speed limits at MP 9.5, observed speeds still remain about the posted speeds $+5 \mathrm{mph}$ or so. The lowest posted speeds are first seen at MP 7.2, and downstream speeds are first recorded at MP 6.6 where the most severe fog was concentrated. Here we see the greatest differentials between posted speeds and observed speeds. Posted speeds over time at this location fluctuate between $45 \mathrm{mph}$ and $30 \mathrm{mph}$, but as time progresses the vehicles passing through this section maintain speeds in the 50s. Speeds remain far above posted speeds until drivers encounter the VSL at MP 4.5, where there are even instances where average speeds are below the posted speeds. Here the delayed reaction to VSLs after the fog is seen most prominently. 
This delayed effect that causes an increase of compliances at MP 4.4 may suggest that the before-after site analysis at this location may be the best-case scenario/location to conduct a before-after study, thus effects at this location cannot be generalized over the entire corridor but perhaps only to the locations downstream MP 4.4. 


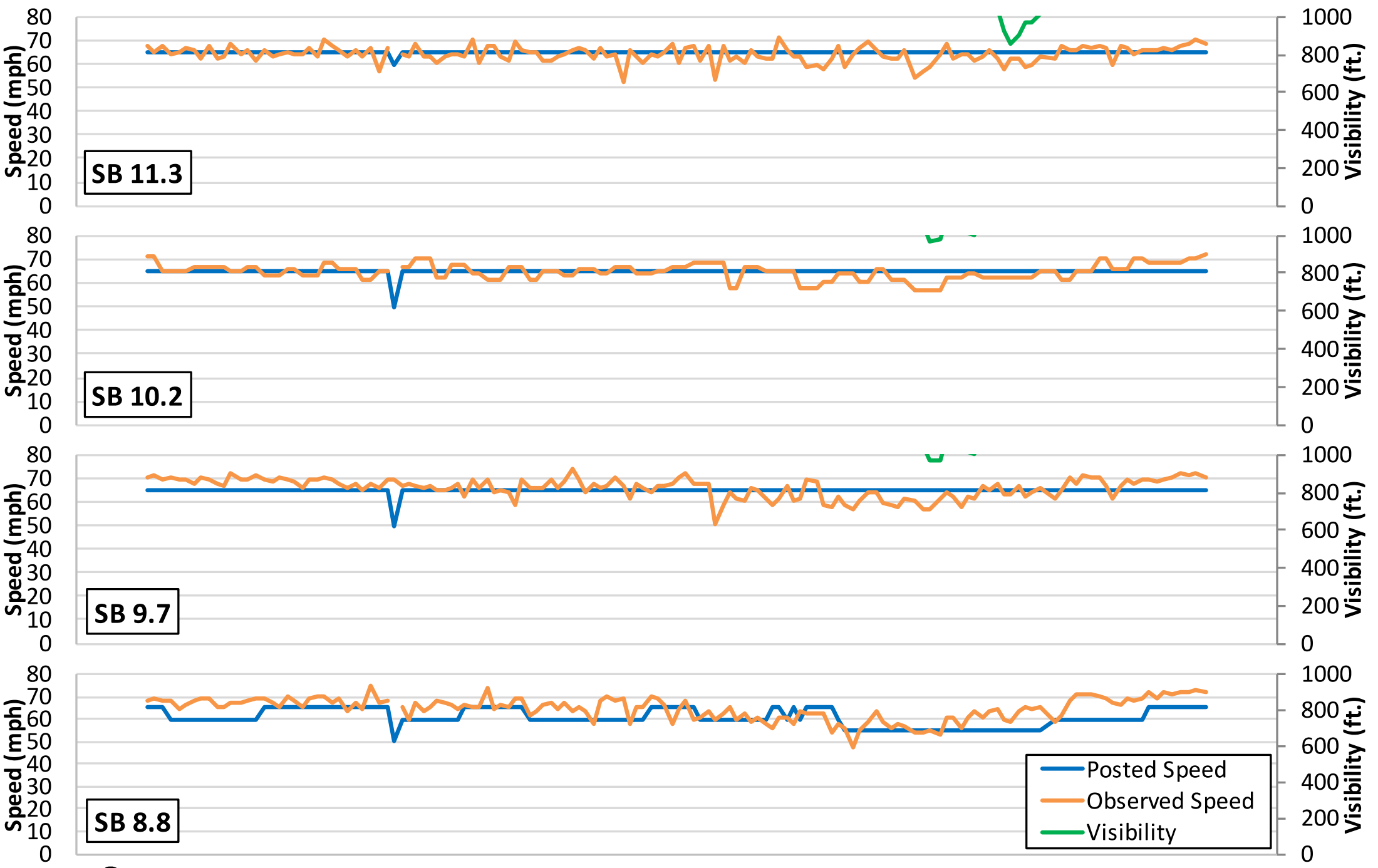

q ơ क人

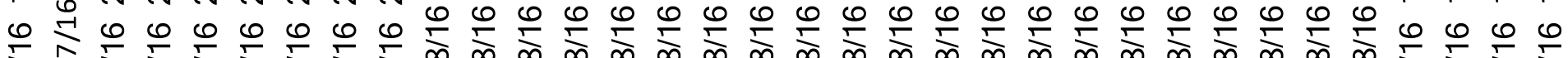

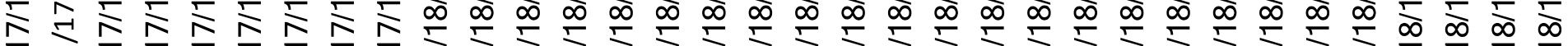

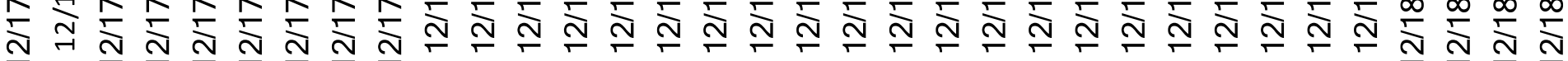




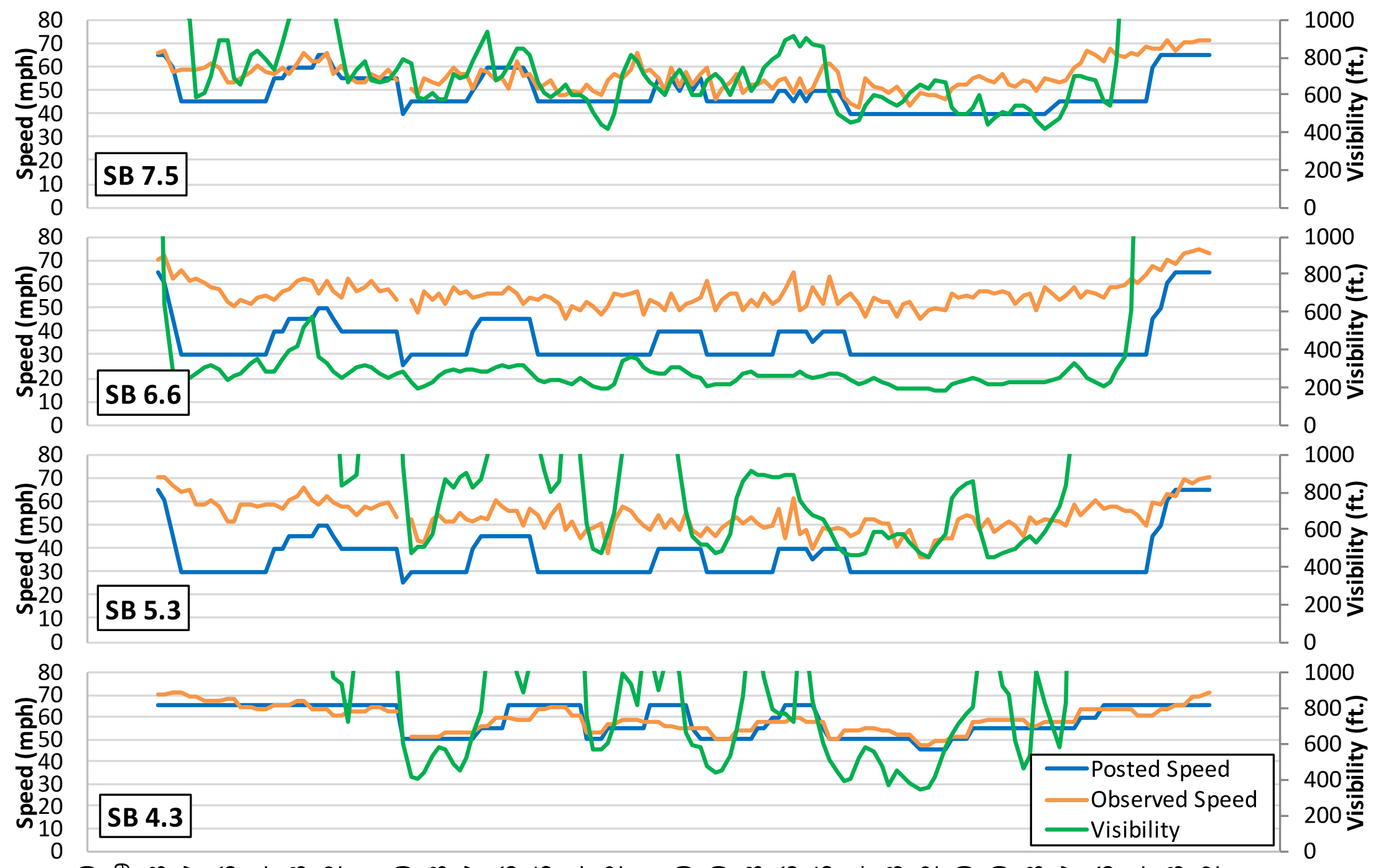

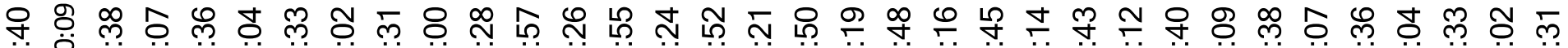
\%

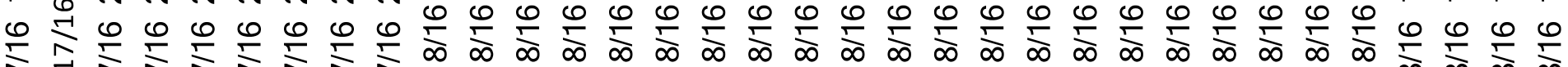

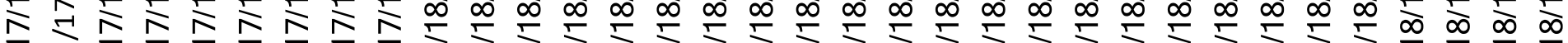

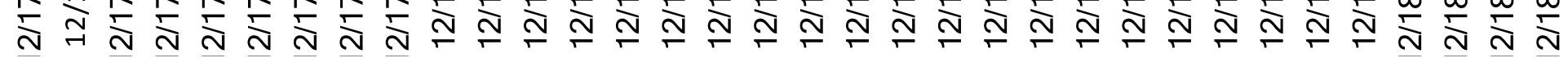



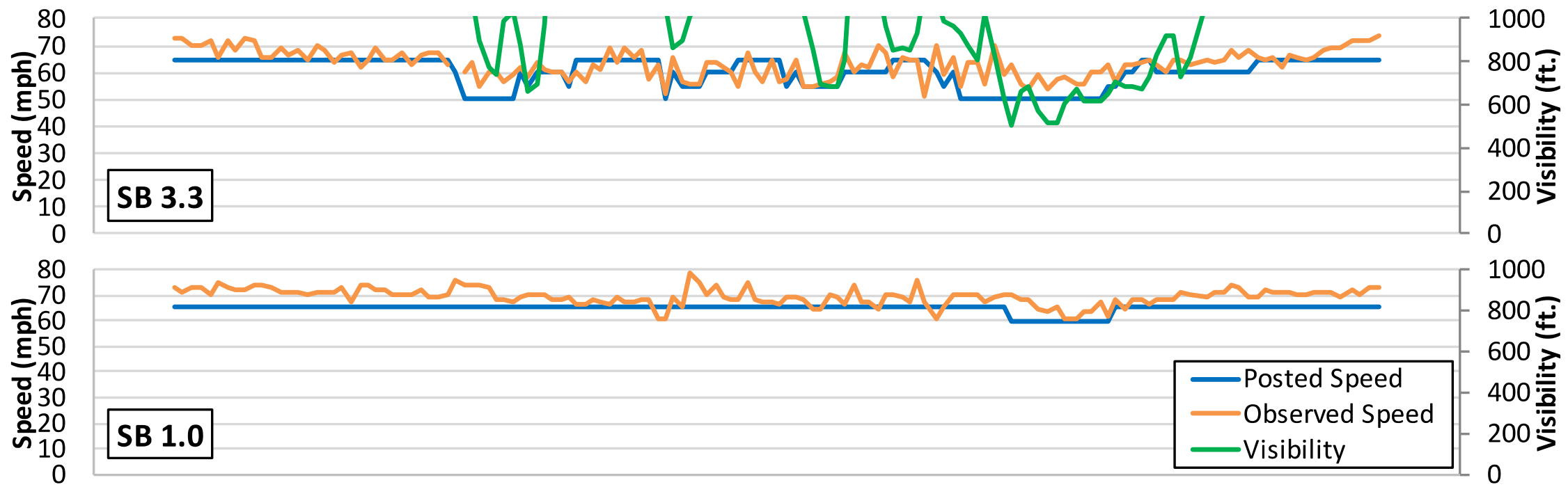

웡

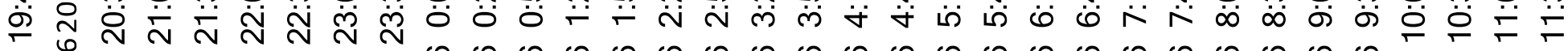

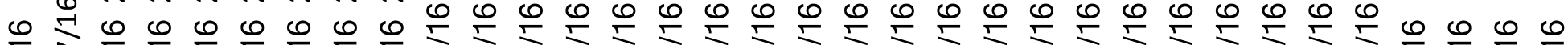

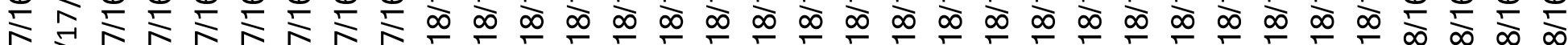

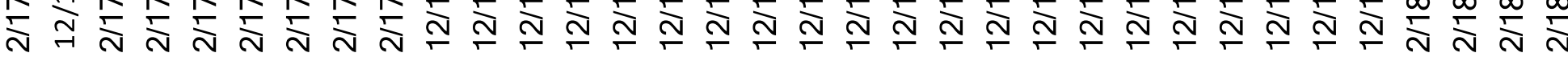
Figure $13 \overline{\text { SB Speeds Over Time }}$ 


\subsubsection{Speed Choice}

\subsubsection{Before-After Evaluation at MP 4.4}

Table 15 compares mean speeds and standard deviations by visibility range for the before and after periods. Although the aggregation rate for both periods differ, the number of intervals for both periods are given to establish the number of observations to make these conclusions. Note that the number of intervals available for visibilities greater than $645 \mathrm{ft}$. in the before period is substantially great than in the after period. In the after period, visibilities greater than $645 \mathrm{ft}$. were only recorded if there was fog elsewhere on the mountain. Hypothesis testing at a confidence interval $\alpha=0.05$ showed that all mean speeds showed reductions across every visibility range available in the after period. For every, visibility range available mean speed reductions of 2-5 mph were seen. At a $95 \%$ confidence interval, there were also reductions of standard deviation across all visibility ranges available. Reductions in speed and variance suggest the safety has improved after the VSL has been activated. Though, no periods of visibilities below $250 \mathrm{ft}$. were recorded in the after period, if the trend continues reductions could be expected for lower visibilities as well. These reductions point toward the overall positive impact by the VSL system. 


\begin{tabular}{|c|c|c|c|c|c|c|c|c|c|}
\hline \multirow[b]{2}{*}{$\begin{array}{c}\text { Visibility } \\
\text { Bin (ft.) }\end{array}$} & \multirow[b]{2}{*}{$\begin{array}{l}\text { SSD } \\
\text { Safe } \\
\text { Speed } \\
\text { (mph) }\end{array}$} & \multicolumn{3}{|c|}{ Before } & \multicolumn{3}{|c|}{ After } & \multicolumn{2}{|c|}{ p-values } \\
\hline & & $\begin{array}{l}\text { No. of } \\
\text { Intervals } \\
\text { (10 min } \\
\text { intervals) }\end{array}$ & $\begin{array}{l}\text { Mean } \\
\text { Speed } \\
\text { (mph) }\end{array}$ & $\begin{array}{c}\text { Standard } \\
\text { Deviation } \\
\text { (mph) }\end{array}$ & $\begin{array}{l}\text { No. of } \\
\text { Intervals } \\
\text { (5 min } \\
\text { intervals) }\end{array}$ & $\begin{array}{l}\text { Mean } \\
\text { Speed } \\
\text { (mph) }\end{array}$ & $\begin{array}{c}\text { Standard } \\
\text { Deviation } \\
\text { (mph) }\end{array}$ & Mean & Variance \\
\hline$>645$ & 65 & 69307 & 67.07 & 7.31 & 5158 & 64.34 & 5.41 & 0.000 & 0.000 \\
\hline $495-645$ & $55-65$ & 513 & 59.88 & 8.45 & 526 & 55.12 & 6.33 & 0.000 & 0.000 \\
\hline $360-495$ & $45-55$ & 524 & 56.63 & 9.03 & 561 & 51.83 & 5.40 & 0.000 & 0.000 \\
\hline $250-360$ & $35-45$ & 297 & 52.43 & 8.83 & 73 & 50.49 & 5.04 & 0.018 & 0.000 \\
\hline $155-250$ & $25-35$ & 22 & 49.75 & 7.96 & 0 & - & - & - & - \\
\hline$<155$ & $<25$ & 0 & - & - & 0 & - & - & - & - \\
\hline
\end{tabular}

The model building sought to explain the trends in speeds as a function of visibility and additional variables discussed in the Methodology chapter. Of the several different types of speed choice models attempted, the combined before-after model at MP 4.4 was found to be most useful for understanding the changes in speeds as a result of the VSL system.

Models were developed using data that was commonly available across both the before and after periods. For the after period, posted speed limit and the interaction of posted speed limit and visibility were found to be the best predictors of speed. For the before period the only value for posted speed limit was the base posted speed of $65 \mathrm{mph}$. Although these models yielded high $\mathrm{R}^{2}$ values greater than 0.7 , these models were not useful in relating how speeds changed from before period.

The combined before-after model was best equipped to help understand how the VSL system affected SB driver speeds in the corridor. The results of the model building showed that posted speed limits (PSL) showed stronger correlations with observed mean speed than with visibility variables. However, since the pre-VSL activation period only had one posted speed limit of $65 \mathrm{mph}$ and posted speed limits in the post-activation period were highly correlated 
with visibility, the posted speed limit variable and interactions were dropped from model building. Unlike the McCann and Fontaine's original model and the VSL algorithm model, the day/night indicator variable did not appear as significant in the after data.

After comparing different variations of the models without variables that were highly correlated the model equation below was selected:

$$
\text { Speed }=67.236-\frac{4242.723}{V i s}-2518.621 * \frac{V S L}{V i s}
$$

Where:

Speed $=$ Mean speed per time interval $(\mathrm{mph})$

Vis $=$ Visibility distance (feet)

VSL = indicator variable, with 1 indicating VSL is active and 0 VSL is inactive.

Table 16 shows that all model parameters were highly significant. With the exception of the day/night variable, the magnitude of the constant and the coefficient of the inverse visibility variable found in this model are similar to that found in McCann and Fontaine's original model and the VSL algorithm model. The greatest departure from these models is the inclusion the indicator variable that VSL indicator variable that indicates that there is no longer as big of a difference between daytime and nighttime speeds as much as there is a difference between pre-VSL and post-VSL speeds. Although the adjusted $R^{2}$ value was only 0.32 , this is similar to earlier efforts used to define the VSL algorithm for previous models (6). The data in the after period appears more varied about the model fit than in the before period. The smaller aggregation intervals in the after period (6 minutes versus 10 minutes) may contribute to the noise seen in the after period that weaken the $\mathrm{R}^{2}$ values. This model implies that when active, the presence of the VSL produces and additional $60 \%$ reduction in speeds over what would 
have occurred based on visibility alone, showing that the VSL does in fact positively affect driver speed reductions.

Table 16 Before-After Model Parameters

\begin{tabular}{|l|l|l|l|l|}
\hline \multirow{2}{*}{ Model Elements } & \multicolumn{2}{c|}{ Coefficients } & \multirow{2}{*}{ t-statistic } & \multirow{2}{*}{ p-value } \\
\cline { 2 - 4 } & Unstandardized & Standardized & & \\
\hline Constant & 67.235978 & & 149.382 & .000 \\
\hline Inverse Visibility & -4242.722554 & -0.367 & -22.578 & .000 \\
\hline VSL $\times$ Inverse Visibility & -2518.621476 & -0.439 & -27.069 & .000 \\
\hline
\end{tabular}

Figure 14 shows the observed mean speeds during reduced visibility conditions before and after VSL activation at milepost 4.4 southbound. Although observed mean speeds are somewhat noisy as a function of visibility, a downward trend in mean speeds as visibilities decrease can be seen for both the pre- and post- VSL conditions at milepost 4.4. Figure 14b shows that speeds have generally shifted lower for comparable visibilities in the after period, indicating the VSL is having a positive effect. The SSD safe speed line drawn for reference also suggests that speeds in the post VSL activation period align more closely to the safe speeds for a given available visibility. Figure $14 \mathrm{c}$ also shows the general trend in post-VSL activation average speeds falls below the VSL Algorithm model, which may suggest that VSL algorithm can be further refined to align mean speeds more closely to SSD safe speeds. 

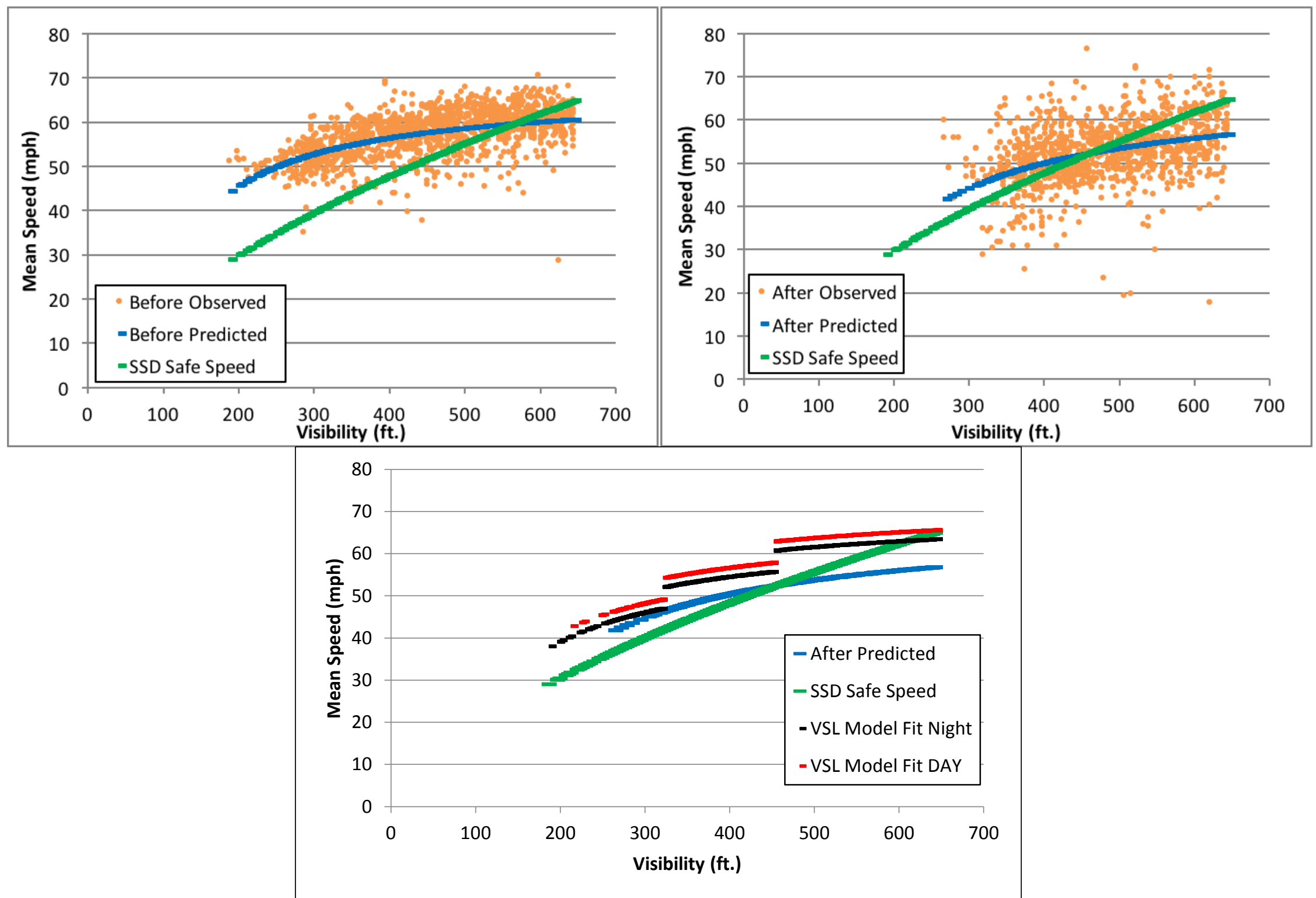

Figure 14 Observed mean speeds a) before and b) after VSL activation at MP 4.4. c) After Speeds Model with VSL algorithm model for reference. 


\subsubsection{Speed Changes During Fog Along Corridor}

Table 17, Table 18, Table 19, and Table 20 provide a summary of how observed speeds differ for various posted speeds summarizing observed mean speeds, count of intervals posted, differences between the posted speed and observed mean speed, and standard deviations of observed speeds vary by mile marker and posted speed along the corridor. In the absence of individual speed data to show compliance, differentials between observed and posted speeds were included to provide a surrogate picture of compliance. Table 19 is color coded to visualize the degree of compliance, with green showing high relative compliance and red showing large non-compliance based on the differential between posted and observed speeds.

Entering the corridor from the north, at every posted speed limit, mean observed speeds exceed the posted speeds, with differences increasing to the highest levels at MP 6.6, after which downstream speeds start to decrease to speeds below those entering corridor. This may suggest that drivers do not follow the reduced speed as closely until they enter the actual fog zone. The reaction to the VSL speeds seems more pronounced right before exiting the thick of the fog zone and after which drivers resume their regular speeds. In general, the difference in observed speeds and posted speeds increases with decreasing posted speed at every mile post, especially at posted speeds below $50 \mathrm{mph}$. However, with this apparent delayed reaction to fog, and compliance with lower limits improves past MP 5.3. This implies that drivers will not immediately reduce speeds upon seeing the VSLs, and that they must experience some reduced visibility before altering speeds.

In Table 17 the speeds in bold are not significantly different from the posted speed limit at a $95 \%$ confidence. With a few exceptions, all mean speeds are greater than the posted 
speeds. Excluding posted speeds of $50 \mathrm{mph}$, for the first couple miles entering the corridor, the average speeds tend to be no more than $5 \mathrm{mph}$ over the posted speed limits. When posted speeds are below $50 \mathrm{mph}$, for the first couple miles the average speeds tend to be about 10 mph higher than posted speeds. As drivers traverse the worst fog zone between mile posts 7.5 and 4.4 , the difference between means speeds and posted speeds increases to almost $10 \mathrm{mph}$ above the posted speed limits, and even more so for posted speeds below $50 \mathrm{mph}$. After exiting the fog zone, compliance seems to improve even for posted speeds below 50 mph as means speeds return to being within $6 \mathrm{mph}$ of the posted speed, with a few exceptions at the lowest posted speeds limit that are still within $10 \mathrm{mph}$ of the posted speed. Though speeds are still higher than posted, the VSL does seem to have a positive effect on reducing speeds based on model results and table summary.

Table 17 Observed mean speeds by posted speed limit

\begin{tabular}{|c|c|c|c|c|c|c|c|c|c|c|}
\hline \multicolumn{2}{|c|}{ Location (Mile Post) } & \multicolumn{7}{c|}{ Posted Speed Limit } & & \\
\hline VSL & $\begin{array}{c}\text { RWIS } \\
\text { Station }\end{array}$ & $\begin{array}{c}\text { Downstream } \\
\text { Speed } \\
\text { Sensor }\end{array}$ & $\mathbf{6 5}$ & $\mathbf{6 0}$ & $\mathbf{5 5}$ & $\mathbf{5 0}$ & $\mathbf{4 5}$ & $\mathbf{4 0}$ & $\mathbf{3 5}$ & $\mathbf{3 0}$ \\
\hline 11.6 & 11.3 & 11.3 & $\mathbf{6 5 . 0}$ & 64.8 & 57.0 & 59.0 & 57.4 & - & - & - \\
\hline 10.2 & 9.6 & 9.7 & 67.6 & 62.5 & 63.5 & 59.4 & - & - & - & - \\
\hline 9.5 & 9.0 & 8.8 & 68.0 & 64.7 & 59.2 & 57.9 & 49.5 & - & - & - \\
\hline 8.1 & 7.3 & 7.5 & 65.7 & 62.4 & 60.7 & 56.4 & 56.3 & 50.3 & - & 42.1 \\
\hline 7.2 & 6.6 & 6.6 & 69.1 & 67.2 & 62.6 & 62.2 & 58.6 & 57.5 & 57.3 & 52.9 \\
\hline 5.6 & 5.3 & 5.3 & 66.0 & 65.5 & 59.8 & 60.2 & 55.8 & 55.3 & 52.2 & 51.3 \\
\hline 4.5 & 4.4 & 4.4 & 65.1 & 62.7 & 58.5 & 55.6 & 49.9 & 48.1 & 41.4 & - \\
\hline 4.5 & 4.4 & 4.3 & 65.5 & 63.3 & 58.5 & 55.1 & 48.8 & 45.8 & 40.3 & - \\
\hline 3.4 & 3.1 & 3.3 & 67.9 & 64.8 & 58.5 & 57.1 & 50.6 & 49.6 & - & - \\
\hline 1.8 & 1.0 & 1.0 & 68.4 & 64.7 & - & - & - & - & - & - \\
\hline
\end{tabular}


Table 18 Count of observations by posted speed limit

\begin{tabular}{|c|c|c|c|c|c|c|c|c|c|c|}
\hline \multicolumn{3}{|c|}{ Location (Mile Post) } & \multicolumn{8}{|c|}{ Posted Speed Limit } \\
\hline VSL & $\begin{array}{c}\text { RWIS } \\
\text { Station }\end{array}$ & $\begin{array}{c}\text { Downstream } \\
\text { Speed } \\
\text { Sensor }\end{array}$ & 65 & 60 & 55 & 50 & 45 & 40 & 35 & 30 \\
\hline 11.6 & 11.3 & 11.3 & 6209 & 45 & 23 & 28 & 10 & - & - & - \\
\hline 10.2 & 9.7 & 9.7 & 6153 & 92 & 18 & 29 & - & - & - & - \\
\hline 9.5 & 8.8 & 8.8 & 4625 & 1403 & 142 & 31 & 54 & - & - & - \\
\hline 8.1 & 7.5 & 7.5 & 3498 & 429 & 577 & 248 & 1368 & 132 & - & 56 \\
\hline 7.2 & 6.6 & 6.6 & 1924 & 649 & 178 & 1029 & 384 & 621 & 24 & 1508 \\
\hline 5.6 & 5.3 & 5.3 & 1949 & 561 & 191 & 1072 & 388 & 619 & 24 & 1510 \\
\hline 4.5 & 4.4 & 4.4 & 3130 & 242 & 304 & 427 & 199 & 38 & 12 & - \\
\hline 4.5 & 4.3 & 4.3 & 4173 & 452 & 442 & 763 & 356 & 66 & 21 & - \\
\hline 3.4 & 3.3 & 3.3 & 4450 & 765 & 297 & 688 & 86 & 26 & - & - \\
\hline 1.8 & 1.0 & 1.0 & 6204 & 100 & - & - & - & - & - & - \\
\hline
\end{tabular}

Table 19 Difference from Posted Speeds by Posted Speed

\begin{tabular}{|c|c|c|c|c|c|c|c|c|c|c|}
\hline \multicolumn{9}{|c|}{ Location (Mile Post) } & \multicolumn{7}{c|}{ Posted Speed Limit } \\
\hline VSL & $\begin{array}{c}\text { RWIS } \\
\text { Station }\end{array}$ & $\begin{array}{c}\text { Downstream } \\
\text { Speed } \\
\text { Sensor }\end{array}$ & $\mathbf{6 5}$ & $\mathbf{6 0}$ & $\mathbf{5 5}$ & $\mathbf{5 0}$ & $\mathbf{4 5}$ & $\mathbf{4 0}$ & $\mathbf{3 5}$ & $\mathbf{3 0}$ \\
\hline 11.6 & 11.3 & 11.3 & 0.0 & 4.8 & 2.0 & 9.0 & 12.4 & - & - & - \\
\hline 10.2 & 9.7 & 9.7 & 2.6 & 2.5 & 8.5 & 9.4 & - & - & - & - \\
\hline 9.5 & 8.8 & 8.8 & 3.0 & 4.7 & 4.2 & 7.9 & 4.5 & - & - & - \\
\hline 8.1 & 7.5 & 7.5 & 0.7 & 2.4 & 5.7 & 6.4 & 11.3 & 10.3 & - & 12.1 \\
\hline 7.2 & 6.6 & 6.6 & 4.1 & 7.2 & 7.6 & 12.2 & 13.6 & 17.5 & 22.3 & 22.9 \\
\hline 5.6 & 5.3 & 5.3 & 1.0 & 5.5 & 4.8 & 10.2 & 10.8 & 15.3 & 17.2 & 21.3 \\
\hline 4.5 & 4.4 & 4.4 & 0.1 & 2.7 & 3.5 & 5.6 & 4.9 & 8.1 & 6.4 & - \\
\hline 4.5 & 4.3 & 4.3 & 0.5 & 3.3 & 3.5 & 5.1 & 3.8 & 5.8 & 5.3 & - \\
\hline 3.4 & 3.3 & 3.3 & 2.9 & 4.8 & 3.5 & 7.1 & 5.6 & 9.6 & - & - \\
\hline 1.8 & 1.0 & 1.0 & 3.4 & 4.7 & - & - & - & - & - & - \\
\hline
\end{tabular}


Table 20 Standard Deviations by posted Speed Limit

\begin{tabular}{|c|c|c|c|c|c|c|c|c|c|c|}
\hline \multicolumn{2}{|c|}{ Location (Mile Post) } & \multicolumn{7}{c|}{ Posted Speed Limit } & & \\
\hline VSL & $\begin{array}{c}\text { RWIS } \\
\text { Station }\end{array}$ & $\begin{array}{c}\text { Downstream } \\
\text { Speed } \\
\text { Sensor }\end{array}$ & $\mathbf{6 5}$ & $\mathbf{6 0}$ & $\mathbf{5 5}$ & $\mathbf{5 0}$ & $\mathbf{4 5}$ & $\mathbf{4 0}$ & $\mathbf{3 5}$ & $\mathbf{3 0}$ \\
\hline 11.6 & 11.3 & 11.3 & 5.4 & 2.8 & 1.5 & 6.6 & 9.3 & - & - & - \\
\hline 10.2 & 9.7 & 9.7 & 4.8 & 12.0 & 4.0 & 12.5 & - & - & - & - \\
\hline 9.5 & 8.8 & 8.8 & 6.0 & 6.2 & 5.7 & 10.4 & 17.5 & - & - & - \\
\hline 8.1 & 7.5 & 7.5 & 5.5 & 5.5 & 4.4 & 4.7 & 5.8 & 5.8 & - & 13.7 \\
\hline 7.2 & 6.6 & 6.6 & 6.8 & 4.5 & 8.7 & 6.1 & 6.4 & 6.0 & 6.5 & 7.1 \\
\hline 5.6 & 5.3 & 5.3 & 4.7 & 3.4 & 3.4 & 5.2 & 5.8 & 6.2 & 14.1 & 6.5 \\
\hline 4.5 & 4.4 & 4.4 & 3.7 & 2.5 & 2.9 & 3.6 & 3.3 & 5.9 & 8.9 & - \\
\hline 4.5 & 4.3 & 4.3 & 4.6 & 4.0 & 3.5 & 4.2 & 3.3 & 5.6 & 7.6 & - \\
\hline 3.4 & 3.3 & 3.3 & 4.6 & 3.6 & 3.4 & 5.2 & 4.4 & 7.4 & - & - \\
\hline 1.8 & 1.0 & 1.0 & 2.8 & 3.5 & - & - & - & - & - & - \\
\hline
\end{tabular}

5.2.5 Crash Analysis

\subsubsection{Crash Frequency and Characteristics}

Crash analysis for 2015, the year prior to VSL activation, was performed. Although McCann and Fontaine had already performed a 5-year crash analysis with 2010-2014 data, this 2015 had some new data available to help validate previous findings. For this year, out of the 108 crash reports retrieved, 5 crashes were coded as fog but only 4 were found to occur during low visibility conditions. One crash was an injury crash, and 3 were PDOs. One crash involved 1 vehicle, 2 involved 2, and the fourth involved 3+. Two were rear-end crashes, one was a sideswipe same direction, and the fourth was a non-collision. Overall, however, the addition of 2015 data to the 2010-2014 average minimally shifted average values, making it a fairly representative year of crash characteristics for pre-VSL activation. Updated crash characteristics 
for the 2010-2015 period are shown below in Table 21, Table 23, and Table 25. Appendix C includes all 2015 charts used to update tables.

Crash analysis for the after period was limited to a 11 months of crash data from October 2016 to August 2017. Out of 89 crashes that occurred in the corridor in this time, 12 were reported to have occurred during times when VSL was active. There were 6 crash reports that had weather condition types labeled as fog, one of which occurred outside of a VSL activation time. After matching visibility with corresponding times and location of these crashes, only two crashes appeared to have actually occurred in conditions where visibilities were less than $645 \mathrm{ft}$. These two crashes occurred on 12/26/2016 when visibilities were between 155-200 ft. during a 54-hour event, one of the longest continuous VSL activations to date. Of these crashes, the first was an injury crash and involved 6 vehicles, including a tractor trailer. The second crash was only a property damage crash which reported that vehicles "were stopped in traffic due to dense fog and a separate crash ahead" when a rear-end crash occurred. This crash and secondary crash are the common types expected in reduced visibility conditions, but given that these two are the only ones that were coded as fog and matched low visibility may be an indication in that the VSL has been influential in reducing the frequency of crashes. Crash characteristics for the after period are summarized in Table 22, Table 24, and Table 26. 


\begin{tabular}{|l|r|r|r|r|r|r|r|r|c|}
\hline \multirow{2}{*}{ Visibility Bin } & \multicolumn{2}{|c|}{ Fatal } & \multicolumn{2}{|c|}{ Injury } & \multicolumn{2}{c|}{$\begin{array}{c}\text { Fatal + } \\
\text { Injury }\end{array}$} & \multicolumn{2}{c|}{$\begin{array}{c}\text { Property } \\
\text { Damage Only }\end{array}$} & Total \\
\hline 1. $>645$ & 9 & $2 \%$ & 124 & $22 \%$ & 133 & $23 \%$ & 433 & $77 \%$ & 566 \\
\hline All Low Visibility & 5 & $8 \%$ & 24 & $39 \%$ & 29 & $47 \%$ & 33 & $53 \%$ & 62 \\
\hline $2.495-645$ & 2 & $20 \%$ & 4 & $40 \%$ & 6 & $60 \%$ & 4 & $40 \%$ & 10 \\
\hline $3.360-495$ & 0 & $0 \%$ & 2 & $29 \%$ & 2 & $29 \%$ & 5 & $71 \%$ & 7 \\
\hline $4.250-360$ & 1 & $14 \%$ & 3 & $43 \%$ & 4 & $57 \%$ & 3 & $43 \%$ & 7 \\
\hline 5. $155-250$ & 2 & $5 \%$ & 15 & $41 \%$ & 17 & $46 \%$ & 20 & $54 \%$ & 37 \\
\hline $6 .<155$ & 0 & $0 \%$ & 0 & $0 \%$ & 0 & $0 \%$ & 1 & $100 \%$ & 1 \\
\hline ERROR, NO VISIBILITY READING & 0 & $0 \%$ & 2 & $50 \%$ & 2 & $50 \%$ & 2 & $50 \%$ & 4 \\
\hline All Conditions & 14 & $2 \%$ & 150 & $24 \%$ & 164 & $26 \%$ & 468 & $74 \%$ & 632 \\
\hline
\end{tabular}

Table 22 Crash Severity by Visibility Bin, October 2016-August 2017

\begin{tabular}{|l|r|r|r|r|r|r|r|r|c|}
\hline \multirow{2}{*}{ Visibility Bin } & \multicolumn{2}{|c|}{ Fatal } & \multicolumn{2}{c|}{$\begin{array}{c}\text { Fatal }+ \\
\text { Injury }\end{array}$} & \multicolumn{2}{c|}{$\begin{array}{c}\text { Property } \\
\text { Injury }\end{array}$} & \multicolumn{2}{c|}{ Damage Only } & Total \\
\hline 1. $>645$ & 1 & $1 \%$ & 20 & $23 \%$ & 21 & $24 \%$ & 66 & $76 \%$ & 87 \\
\hline All Low Visibility & 0 & $0 \%$ & 1 & $50 \%$ & 1 & $50 \%$ & 1 & $50 \%$ & 2 \\
\hline $2.495-645$ & 0 & $0 \%$ & 0 & $0 \%$ & 0 & $0 \%$ & 0 & $0 \%$ & 0 \\
\hline $3.360-495$ & 0 & $0 \%$ & 0 & $0 \%$ & 0 & $0 \%$ & 0 & $0 \%$ & 0 \\
\hline $4.250-360$ & 0 & $0 \%$ & 0 & $0 \%$ & 0 & $0 \%$ & 0 & $0 \%$ & 0 \\
\hline 5. $155-250$ & 0 & $0 \%$ & 1 & $50 \%$ & 1 & $50 \%$ & 1 & $50 \%$ & 2 \\
\hline 6. $<155$ & 0 & $0 \%$ & 0 & $0 \%$ & 0 & $0 \%$ & 0 & $0 \%$ & 0 \\
\hline ERROR, NO VISIBILITY READING & 0 & $0 \%$ & 0 & $0 \%$ & 0 & $0 \%$ & 0 & $0 \%$ & 0 \\
\hline All Conditions & 1 & $1 \%$ & 21 & $24 \%$ & 22 & $25 \%$ & 67 & $75 \%$ & 89 \\
\hline
\end{tabular}

Table 23 Number of Vehicles Involved by Visibility Bin, updated with 2015, 2010-2015

\begin{tabular}{|l|r|r|r|r|r|r|r|}
\hline Visibility Bin & \multicolumn{2}{|c|}{1} & \multicolumn{2}{|c|}{2} & \multicolumn{2}{|c|}{$3+$} & Total \\
\hline 1. $>645$ & 302 & $53 \%$ & 209 & $37 \%$ & 55 & $10 \%$ & 566 \\
\hline All Low Visibility & 6 & $10 \%$ & 29 & $47 \%$ & 27 & $44 \%$ & 62 \\
\hline $2.495-645$ & 2 & $20 \%$ & 5 & $50 \%$ & 3 & $30 \%$ & 10 \\
\hline $3.360-495$ & 2 & $29 \%$ & 4 & $57 \%$ & 1 & $14 \%$ & 7 \\
\hline $4.250-360$ & 0 & $0 \%$ & 1 & $14 \%$ & 6 & $86 \%$ & 7 \\
\hline $5.155-250$ & 1 & $3 \%$ & 19 & $51 \%$ & 17 & $46 \%$ & 37 \\
\hline $6 .<155$ & 1 & $100 \%$ & 0 & $0 \%$ & 0 & $0 \%$ & 1 \\
\hline ERROR, NO VISIBILITY READING & 2 & $50 \%$ & 2 & $50 \%$ & 0 & $0 \%$ & 4 \\
\hline All Conditions & 310 & $49 \%$ & 240 & $38 \%$ & 82 & $13 \%$ & 632 \\
\hline
\end{tabular}


Table 24 Number of Vehicles Involved by Visibility Bin, October 2016-August 2017

\begin{tabular}{|l|r|r|r|r|r|r|r|}
\hline Visibility Bin & \multicolumn{2}{|c|}{1} & \multicolumn{2}{|c|}{2} & \multicolumn{2}{|c|}{$3+$} & \multicolumn{1}{l|}{ Total } \\
\hline $1 .>645$ & 37 & $43 \%$ & 39 & $45 \%$ & 11 & $13 \%$ & 87 \\
\hline All Low Visibility & 0 & $0 \%$ & 0 & $0 \%$ & 2 & $100 \%$ & 2 \\
\hline $2.495-645$ & 0 & $0 \%$ & 0 & $0 \%$ & 0 & $0 \%$ & 0 \\
\hline $3.360-495$ & 0 & $0 \%$ & 0 & $0 \%$ & 0 & $0 \%$ & 0 \\
\hline $4.250-360$ & 0 & $0 \%$ & 0 & $0 \%$ & 0 & $0 \%$ & 0 \\
\hline $5.155-250$ & 0 & $0 \%$ & 0 & $0 \%$ & 2 & $100 \%$ & 2 \\
\hline $6 .<155$ & 0 & $0 \%$ & 0 & $0 \%$ & 0 & $0 \%$ & 0 \\
\hline ERROR, NO VISIBILITY READING & 0 & $0 \%$ & 0 & $0 \%$ & 0 & $0 \%$ & 0 \\
\hline All Conditions & 37 & $42 \%$ & 39 & $44 \%$ & 13 & $15 \%$ & 89 \\
\hline
\end{tabular}

Table 25 Crash Type by Visibility Bin, updated to include 2015, 2010-2015

\begin{tabular}{|c|c|c|c|c|c|c|c|c|c|c|c|}
\hline \multirow{2}{*}{$\frac{\text { Visibility Bin }}{1 .>645}$} & \multicolumn{2}{|c|}{ Rear End } & \multicolumn{2}{|c|}{$\begin{array}{c}\text { Fixed } \\
\text { Object- Off } \\
\text { Road }\end{array}$} & \multicolumn{2}{|c|}{ Angle } & \multicolumn{2}{|c|}{$\begin{array}{l}\text { SideSwipe } \\
\text { - Same } \\
\text { Direction } \\
\end{array}$} & \multicolumn{2}{|c|}{ Other } & \multirow{2}{*}{$\frac{\text { Total }}{566}$} \\
\hline & 138 & $24 \%$ & 213 & $38 \%$ & 30 & $5 \%$ & 59 & $10 \%$ & 126 & $22 \%$ & \\
\hline All Low Visibility & 39 & $63 \%$ & 3 & $5 \%$ & 10 & $16 \%$ & 7 & $11 \%$ & 3 & $5 \%$ & 62 \\
\hline 2. $495-645$ & 4 & $40 \%$ & 1 & $10 \%$ & 4 & $40 \%$ & 0 & $0 \%$ & 1 & $10 \%$ & 10 \\
\hline 3. $360-495$ & 2 & $29 \%$ & 0 & $0 \%$ & 1 & $14 \%$ & 2 & $29 \%$ & 2 & $29 \%$ & 7 \\
\hline 4. $250-360$ & 7 & $100 \%$ & 0 & $0 \%$ & 0 & $0 \%$ & 0 & $0 \%$ & 0 & $0 \%$ & 7 \\
\hline 5. $155-250$ & 26 & $70 \%$ & 1 & $3 \%$ & 5 & $14 \%$ & 5 & $14 \%$ & 0 & $0 \%$ & 37 \\
\hline $6 .<155$ & 0 & $0 \%$ & 1 & $100 \%$ & 0 & $0 \%$ & 0 & $0 \%$ & 0 & $0 \%$ & 1 \\
\hline $\begin{array}{l}\text { ERROR, NO VISIBILITY } \\
\text { READING }\end{array}$ & 1 & $25 \%$ & 3 & $75 \%$ & 0 & $0 \%$ & 0 & $0 \%$ & 0 & $0 \%$ & 4 \\
\hline All Conditions & 178 & $28 \%$ & 219 & $35 \%$ & 40 & $6 \%$ & 66 & $10 \%$ & 129 & $20 \%$ & 632 \\
\hline
\end{tabular}

Table 26 Crash Type by Visibility Bin, October 2016- August 2017

\begin{tabular}{|c|c|c|c|c|c|c|c|c|c|c|c|}
\hline \multirow{2}{*}{$\frac{\text { Visibility Bin }}{1 .>645}$} & \multicolumn{2}{|c|}{ Rear End } & \multicolumn{2}{|c|}{$\begin{array}{c}\text { Fixed } \\
\text { Object- Off } \\
\text { Road }\end{array}$} & \multicolumn{2}{|c|}{ Angle } & \multicolumn{2}{|c|}{$\begin{array}{l}\text { SideSwipe } \\
\text { - Same } \\
\text { Direction }\end{array}$} & \multicolumn{2}{|c|}{ Other } & \multirow{2}{*}{$\begin{array}{r}\text { Total } \\
87\end{array}$} \\
\hline & 29 & $33 \%$ & 28 & $32 \%$ & 2 & $2 \%$ & 16 & $18 \%$ & 12 & $14 \%$ & \\
\hline All Low Visibility & 2 & $100 \%$ & 0 & $0 \%$ & 0 & $0 \%$ & 0 & $0 \%$ & 0 & $0 \%$ & 2 \\
\hline 2. $495-645$ & 0 & $0 \%$ & 0 & $0 \%$ & 0 & $0 \%$ & 0 & $0 \%$ & 0 & $0 \%$ & 0 \\
\hline 3. 360-495 & 0 & $0 \%$ & 0 & $0 \%$ & 0 & $0 \%$ & 0 & $0 \%$ & 0 & $0 \%$ & 0 \\
\hline 4. $250-360$ & 0 & $0 \%$ & 0 & $0 \%$ & 0 & $0 \%$ & 0 & $0 \%$ & 0 & $0 \%$ & 0 \\
\hline 5. $155-250$ & 2 & $100 \%$ & 0 & $0 \%$ & 0 & $0 \%$ & 0 & $0 \%$ & 0 & $0 \%$ & 2 \\
\hline 6. $<155$ & 0 & $0 \%$ & 0 & $0 \%$ & 0 & $0 \%$ & 0 & $0 \%$ & 0 & $0 \%$ & 0 \\
\hline $\begin{array}{l}\text { ERROR, NO VISIBILITY } \\
\text { READING }\end{array}$ & 0 & $0 \%$ & 0 & $0 \%$ & 0 & $0 \%$ & 0 & $0 \%$ & 0 & $0 \%$ & 0 \\
\hline All Conditions & 31 & $35 \%$ & 28 & $31 \%$ & 2 & $2 \%$ & 16 & $18 \%$ & 12 & $13 \%$ & 89 \\
\hline
\end{tabular}


Comparing Table 21 and Table 22, crash severity by visibility bin during low visibility conditions show about an even split between fatal and injury crashes and PDOs in both the before and after periods. Although proportions are similar, the low frequency in the after period as compared to the 10 crashes per year average in the before conditions suggest reductions in overall frequency. Crash severity by visibility bin for clear conditions show crash severity percentages in the after period remained within $\pm 1 \%$ of the before period indicating that overall conditions in the after period are characteristic of corridor. Thus, changes observed for low visibility conditions must be related to the activation of VSL system.

Percentages of crashes with different number of vehicles involved during low visibility conditions in Table 23 and Table 24 show that in the before period $44 \%$ of crashes involved $3+$ vehicles versus $100 \%$ of crashes in the after period. Similarly, a shift in crash type to all rear-end crashes in the after period also occurred. Given that only two crashes occurred in the after period during low visibility, it is difficult to draw conclusions from this data.

\subsubsection{Crash Rates}

Crash rates were updated for 2015 with continuous count data and new crash rates were developed for the after period. Table 27 provides updated crash rates by visibility for the now including 2015 period. In 2015, there were 10\% missing visibility data. The 2015 crash rates for all visibility conditions of 47.1 and 58.5 crashes per 100 million VMT for NB and SB, respectively, are lower than for the 2010-2014 average. When combined these rates lower the overall average, the new 2010-2015 average drops from 63 and 74 crashes per 100 million VMT to 49.3 and 58.8 crashes per 100 million VMT for NB and SB, respectively. The crash rates for all low visibility conditions also show rates of the same magnitude as those found as those of 
2010-2014, with updated values of 181 and 854 crashes per 100 million VMT for low visibility conditions for the NB and SB directions respectively.

Table 28 provides crash rates for the after period. Since all times outside VSL activations are considered clear conditions, there are less missing variables. For the individual 155-200 $\mathrm{ft}$. visibility bin that the two crashes were found in, the crash rate of 2226.6 crashes per 100 million VMT is nearly as large as the $2010-2015$ crash rate for the same bin of 2779.7 crashes per 100 million VMT. However, for the All Low Visibilities crash rate is lower in the post-VSL period than 2010-2015, dropping from 854.1 to 366.8 crashes per 100 million VMT. The overall crash rates for combined directions remain consistent in about 59 crashes per 100 million VMT, but crash rate per direction shifts. While as expected the crash rate for southbound direction lowered to 48.7 , the northbound direction saw an increase in crashes to 72.3 crashes per 100 million VMT.

The reduction of crash rate during low visibility conditions agrees with the notion of increased safety first indicated in the crash characteristics discussion. Considering VMTs and exposure to low visibility conditions, this reduction can be interpreted to mean that without the VSL system 2.3 times more crashes can be expected for every 100 VMT travel under low visibility conditions. Thus if results are transferrable, for VSL systems for low visibility conditions implemented in corridors with larger AADTs, longer corridor lengths, or with more severe fog exposure, greater reduction in frequency of crashes could be expected.

The primary limitation of this crash rate calculation lies within the police reporting. Due to the varied spatiotemporal nature of fog, should time and location in the be inaccurate, crashes cannot be correctly matched to appropriate visibility reading. Though having 
continuous volume data is an advantage over the crash rates from 2010-2014, the visibility readings come at a different rate and are matched assuming linear relationship between visibility readings and visibility stations. The interval between visibility readings are close enough in time and stations in the most fog prone are close enough together that this assumption is not expected to be of major concern.

Table 27 Updated 2010-2015 Crash Rates

\begin{tabular}{|l|c|c|c|c|c|c|r|r|r|}
\hline & \multicolumn{10}{|c|}{ Number of Crashes } & \multicolumn{3}{|c|}{ Crash Rate } & \multicolumn{3}{|c|}{$\%$ of Total VMT } \\
\cline { 2 - 13 } & North & South & Both & North & South & Both & North & South & Both \\
\hline$>645$ & 278 & 288 & 566 & 52.9 & 56.4 & 54.6 & $45 \%$ & $44 \%$ & $89 \%$ \\
\hline ALL LOW VISIBILITY & 12 & 54 & 66 & 181.0 & 854.1 & 509.5 & $0.57 \%$ & $0.54 \%$ & $1.11 \%$ \\
\hline $495-645$ & 0 & 10 & 10 & 0.0 & 619.9 & 302.8 & $0.14 \%$ & $0.14 \%$ & $0.28 \%$ \\
\hline $360-495$ & 2 & 5 & 7 & 107.4 & 281.6 & 192.4 & $0.16 \%$ & $0.15 \%$ & $0.31 \%$ \\
\hline $250-360$ & 1 & 6 & 7 & 60.0 & 375.7 & 214.4 & $0.14 \%$ & $0.14 \%$ & $0.28 \%$ \\
\hline $155-250$ & 6 & 31 & 37 & 514.3 & 2795.7 & 1626.0 & $0.10 \%$ & $0.09 \%$ & $0.19 \%$ \\
\hline$<155$ & 1 & 0 & 1 & 409.1 & 0.0 & 211.7 & $0.02 \%$ & $0.02 \%$ & $0.04 \%$ \\
\hline Error/No Reading & 2 & 2 & 4 & 3.5 & 3.1 & 3.3 & $4.83 \%$ & $5.51 \%$ & $10.34 \%$ \\
\hline ALL VISIBILITY & 290 & 342 & 632 & 49.3 & 58.8 & 54.0 & $50 \%$ & $50 \%$ & $100 \%$ \\
\hline
\end{tabular}

Table 28 Crash Rates October 2016- August 2017

\begin{tabular}{|l|c|c|c|c|c|c|r|r|r|}
\hline \multicolumn{7}{|c|}{ Oct 2016- Aug 2017 } \\
\hline \multirow{2}{*}{ Visibility Bin } & \multicolumn{2}{|c|}{ Number of Crashes } & \multicolumn{3}{|c|}{ Crash Rate } & \multicolumn{3}{c|}{$\%$ of Total VMT } \\
\cline { 2 - 11 } & North & South & Both & North & South & Both & North & South & Both \\
\hline$>645$ & 55 & 33 & 88 & 75.7 & 45.4 & 60.6 & $48 \%$ & $48 \%$ & $96 \%$ \\
\hline ALL LOW VISIBILITY & 0 & 2 & 2 & 0.0 & 366.8 & 165.2 & $0.44 \%$ & $0.36 \%$ & $0.80 \%$ \\
\hline $495-645$ & 0 & 0 & 0 & 0.0 & 0.0 & 0.0 & $0.11 \%$ & $0.12 \%$ & $0.23 \%$ \\
\hline $360-495$ & 0 & 0 & 0 & 0.0 & 0.0 & 0.0 & $0.12 \%$ & $0.10 \%$ & $0.22 \%$ \\
\hline $250-360$ & 0 & 0 & 0 & 0.0 & 0.0 & 0.0 & $0.12 \%$ & $0.08 \%$ & $0.19 \%$ \\
\hline $155-250$ & 0 & 2 & 2 & 0.0 & 2226.6 & 885.7 & $0.09 \%$ & $0.06 \%$ & $0.15 \%$ \\
\hline$<155$ & 0 & 0 & 0 & 0.0 & 0.0 & 0.0 & $0.00 \%$ & $0.00 \%$ & $0.00 \%$ \\
\hline Error/No Reading & 0 & 0 & 0 & 0.0 & 0.0 & 0.0 & $1.78 \%$ & $1.86 \%$ & $3.64 \%$ \\
\hline ALL VISIBILITY & 55 & 35 & 90 & 72.3 & 46.0 & 59.2 & $50 \%$ & $50 \%$ & $100 \%$ \\
\hline
\end{tabular}




\subsection{SUMMARY OF RESULTS}

Overall, with the introduction of the VSL, positive effects have been seen in driver speeds and limited insights into crash characteristics. Before-after analysis at one site along the corridor, showed statistically significant reductions in speeds across all visibility ranges of approximately 2 to $5 \mathrm{mph}$ for every range. Reductions in variance across all visibility ranges suggest that safety has improved. Speed models reconfirmed speed is inversely correlated with visibility and that the VSL has had a role in further reducing speeds. Though $R^{2}$ values are not as strong as the models before, there is a trend in decreasing speeds visibility and the speeds postVSL activation adhere more closely SSD safe speeds.

Exploring speeds throughout the corridor post-VSL activation also showed reductions in speed with reduced posted speed limits. While observed speeds varied by location and posted speed throughout the corridor, a general trend arises where drivers do not appear to comply as strongly with reduced speeds until they experience fog. There appears to be a delayed reaction to VSL until drivers traverse fog and see the present need for reduced speeds. Additionally, though speeds do decrease with decreasing posted speeds, compliance decreases as posted speed limits are reduced.

Crash analysis for the year immediately prior to VSL resulted in similar crash characteristics as in the previous years. Crash analysis for the post-VSL data showed signs of improvement. The only two crashes that were matched to fog conditions, occurred back-toback during a fog event within 3 months of first activation. Though this contributed to the crash rate, the southbound crash rate for all low visibility conditions was cut by more than half and the overall crash rate decreased to less than 45.4 crashes per 100 million VMT. More 
interestingly crash rates for all low visibility conditions in the SB direction were reduced 2.3 times. Taking exposure into consideration, this figure alone suggests the system has been successful in improving safety.

\subsection{VSL ALGORITHM ASSESSMENT}

The positive initial results from this analysis beg the question if compliance can be further improved. It is possible that the VSL control algorithm could be modified to attain better results. Currently, the VSL algorithm uses a step-adjusted model fit of pre-VSL observed speeds to generate proposed VSLs and smooths speeds throughout the corridor subject to a step range where successive VSL signs cannot decrease by more than $15 \mathrm{mph}$. The VSL step-adjusted model fit set as was an intermediate step between previously observed speeds and SSD safe speeds due to a concern that simply posting SSD safe speeds would not adequately alter driver behavior and instead would further increase speed variance and interactions between vehicles under low visibilities. The $15 \mathrm{mph}$ step range between VSL signs was chosen over $10 \mathrm{mph}$ as it was thought to ensure the message remained credible to the motorists (Kimley-Horn, I-77 Variable Speed Limit: Methodology for Establishing Variable Speed Limits, 2015). The analysis has shown, however, that the trend line for mean observed speeds falls below SSD safe speeds until about $50 \mathrm{mph}$ and is consistently below the VSL step-adjusted model fit for the available visibilities. To improve these promising initial findings, compliance could be improved by changing some of the VSL algorithm parameters.

It appears drivers do not sense the need to slow down until they encounter the fog and by then difference in observed and posted speeds is too great to slow down to posted speeds. By the time drivers have slowed enough, posted speeds raise back up but by now drivers have 
slowed down enough to maintain more constant speeds. Based on this apparent delayed reaction to VSL until drivers encounter the fog, the key to achieving increased compliance across the whole corridor may lie in improving compliance prior to worst fog area. One way to do so is by changing the step range between VSL signs. Lowering the step range to $10 \mathrm{mph}$ would cause to lower the speeds well in advance of actual fog. Though the concern of credibility is still present, perhaps having a more seeing a more gradual decrease in speed will give drivers time to really consider taking heed of the speed limits rather than encountering a more sudden drop in speeds. For example, from 60 to 45 to $30 \mathrm{mph}$ from MPs 9.0 to 8.1 to 7.3 to could instead 60 to 50 to 40 to 30 starting at MP 10.2 instead. This may lead to decreased compliance in the entering region but improved compliance in the worst fog region where it matters most. However, unless VSL signs are closer this may not be a viable option given the distance between VSL signs would cause speed reductions to need to be posted far upstream. An intermediate route to maintain credibility but have step ranges that more readily adjust to declining conditions is to have variable step ranges depending on severity of fog. Should fog conditions warrant the lowest VSLs of $30 \mathrm{mph}$, step ranges of $10 \mathrm{mph}$ begin to gradually decrease far in advance but for reduced visibilities were a step range of $15 \mathrm{mph}$ could still adequately decrease posted speeds, the step range remain at $15 \mathrm{mph}$.

Another possible way to improve the model is readjust the steps to follow VSL more closely. Currently the model has a $5 \mathrm{mph}$ decrease from the model fit when SSD safe speeds equal 50 and a $10 \mathrm{mph}$ decrease from model fit when SSD Safe speeds equal $40 \mathrm{mph}$. One close alternate could be to have an additional step and shift step boundaries, so instead of stepping down $5 \mathrm{mph}$ starting SSD safe speeds of $50 \mathrm{mph}$, start the shift at $55 \mathrm{mph}$, with additional 5 
mph reductions at SSD safe speeds of 45 and 35. Figure 15 depicts this adjusted model. This adjusted model fit would follow yield speeds much closer to SSD safe speeds and at lower visibilities would yield speeds closer to the observed mean speeds in the post-VSL period. Seeing that average observed speeds are falling below the current VSL step-adjusted model, this proposed readjusted model should continue to have observed speeds lower if not equal to the model fit.

Though likely unfeasible at this stage of system deployment, perhaps having more densely distributed VSL signs may achieve the improve compliance desired. System evaluation of CalTrans' FDWS with its VSLS spaced $1 / 4$ mile apart would shed light on how effective this is. Apart from changes to the physical system, improved compliance in the system will likely have to involve VSL algorithm modifications.

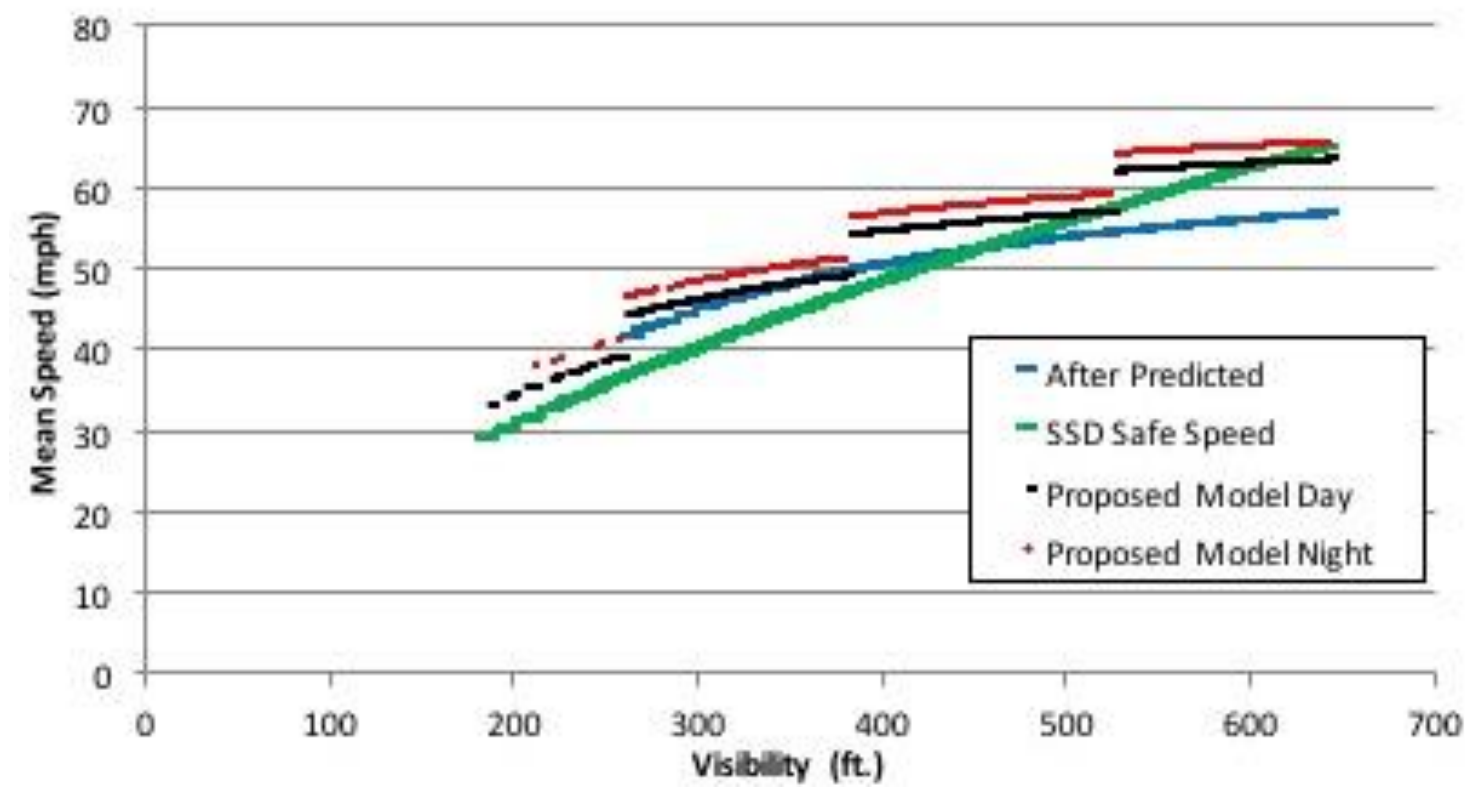

Figure 15 Proposed Modification to VSL 


\section{CHAPTER 6: CONCLUSIONS AND RECOMMENDATIONS}

\subsection{CONCLUSIONS AND DISCUSSION}

\subsubsection{Driver Speed Choice}

Before-after analysis at a single site showed statistically significant reductions in speeds of $5 \mathrm{mph}$ and standard deviations of $1-2 \mathrm{mph}$ for reduced visibilities of $250-645 \mathrm{ft}$. While ideally a before-after comparison at all locations throughout the corridor would show a clearer picture of how speeds changed as a result of the VSLs, having data for the southbound location at the edge of the worst fog area gives an indication of how drivers may have reacted at the rest of the locations. Though speeds are still higher than SSD safe speeds at MP 4.4 , the combination of reduced speeds and reduced variances imply increased safety in the corridor. Regression models related speeds as function of visibility showing that when VSL is active, visibility's influence to decrease speeds increased by $60 \%$. The development of a model similar to McCann and Fontaine's suggests that incorporating the driver behavior model into the VSL algorithm had an effect on compliance. There were no periods of reduced visibilities below 250 $\mathrm{ft}$. to speak of safety at the periods of worst visibility, but trend lines suggest improvements in those visibilities are likely.

Due to limitations in the way data were reported, compliance figures could not be determined. However, a surrogate measure of compliance could be inferred from the differentials in observed and posted speeds. Analysis of speeds along the corridor revealed an apparent lag in reaction to the VSLs, with drivers continuing to travel above the posted speed limit until they were amid the fog and could visually confirm the need for reduced speeds. Upon 
entering the corridor, differences in observed mean speeds and posted speeds were within 10 $\mathrm{mph}$ and increased to as much as $23 \mathrm{mph}$ over the posted speeds in the thick of the fog, until leveling out again and returning to between within $10 \mathrm{mph}$ of posted speeds. Understanding what causes this delay in compliance will be key to knowing how achieve higher compliances. Additionally, analysis of speed along corridor also revealed that at the lowest posted speeds compliance decreases. This is seen more prominently with posted speed under $50 \mathrm{mph}$ between mileposts 7.3 and 4.4. If greater compliance can be achieved upstream the worst fog zone, it is possible that compliance in the lower speed limits can also be improved.

Overall, reductions in means speeds are an indication that the VSL is achieving its desired effect and could be modified to maximize results. There is an apparent lack of response to VSLs until drivers can visually confirm the need for slower speeds, however.

\subsubsection{Crash Analysis}

The 11 months' worth of crash data is not sufficient enough to make definitive claims as to the system's effectiveness in improving safety by reducing the overall frequency and severity of crashes. However, given that the only fog-related crashes occurred early in the system's activation lifetime and that these event were correlated, suggests the reductions in crash rates are indicative of the improved safety under the system. It is possible that with the system in place the severity and number of vehicles involved in these multi-vehicle crashes was minimized. The crash rate of all low visibility bins for the southbound direction of 366.8 crashes per 100 million VMT, while still greater during reduced visibilities than in clear conditions, is less than half of the crash rate of 854 crashes per 100 million VMT seen for the years $2010-2015$. If 
not the frequency alone, the crash rates for the post-VSL period for low visibilities indicate that safety has improved in a tangible way.

\subsection{RECOMMENDATIONS}

Based on this study several recommendations can be made:

1. Pursue modifications to VSL control algorithm. The methodology for the VSL control algorithm allows for modifications as the operators see fit. Now that almost a full year of VSL operations has passed, these initial findings indicate that the VSL algorithm could be altered to see improved compliances. Considering alternate step ranges between successive VSL signs or even step ranges that vary by fog severity may trade off compliance entering the corridor for improved compliance in fog zone. Alternatively, the step ranges of the VSL model fit could be altered to more closely reflect SSD safe speeds by shifting step boundaries and adding one more step.

2. Decrease distances between VSL devices in future deployments. Although not necessarily applicable for this system, more closely spaced together VSL signs may be part of the answer to understand the lag in speed reductions before entering fog zones. Agencies looking to implement similar systems should consider densely placing VSL signs to give greater advanced warning, if feasible within budget. The spatial variance of fog prompts RWIS stations to be as densely spaced as possible, also. If an existing system already has static (signage and lane departure) countermeasures implemented as I-77 did and traffic conditions are similar, then the addition of a VSL system is likely to have positive results. 
3. Reevaluate safety analysis in future. This study was limited to the first year of operations of the system. As time elapses and more data accumulates, regression to the mean bias will adjust for extreme scenarios that may have taken place and larger sample sizes will give more weight to analysis results. If less aggregated data is available for future studies, more conclusive measures can be derived. A follow-up evaluation will confirm if early emerged trends continue.

\subsection{FUTURE RESEARCH}

The positive initial findings of the effectiveness of the I-77 VSLs suggest that the system has been successful in influencing driver behavior. Of greatest concern for future research is understanding why the lag in speed reductions prior to entering the fog zone. Investigating how to better reduce speeds in advance of the densest fog zones to achieve greater compliance would be most beneficial to the system. Modifications to VSL algorithm may shed light into this issue.

Since the southbound direction was found to be of greater concern during low visibility conditions, this analysis focused mainly on the effects of the system on driver speeds and behavior on it. Future research would also entail analyzing how the system affected the northbound direction and additional investigation as to the increased crash rates for this direction.

Although this project applies to one particular implementation of a low visibility activated VSL system, the benefits observed at this site may serve as a reference for other 
agencies contemplating alternatives for fog mitigation. Compliance figures based on individual vehicle speed data would be needed if recommendations are to be made on this.

With the advent of connected vehicle (CV) technology, other methods to achieve speed harmonization could affect the value of a system like this. If the connected vehicles need only communicate with each other, the risks associated with limited visibilities would be lessened since vehicles would know others' positions and speeds and real time visibility readings at ground level. Should connected vehicles be communicating with infrastructure that sets the speed limits, compliance is expected to increase. CVs themselves could be used as probes providing visibility reading at ground level throughout the entirety of corridor. The more CVs in the corridor the more accurate the speed recommendations. However, assuming not all vehicles in the corridor are connected, VSL signage would still be required. Depending on how non-CV compliance in the corridor is, recommended speeds would still have to be closer to observed speeds and not just SSD speeds, as variances are prone to more potential conflicts which could be riskier than just non-compliance. Future research in this area could involve simulating driver speeds based on current/proposed VSL algorithms. Benefits of connected vehicle environments versus infrastructure based approaches are emerging research areas. 


\section{REFERENCES}

1. Hamilton, B., B. Tefft, L. Arnold, and J. Grabowski. Hidden Highways: Fog and Traffic Crashes on America's Roads. Washington, D.C., 2014.

2. Abdel-Aty, M., A.-A. Ekram, and H. Huang. A Study on Visibiity Obstruction Related Crashes Due to Fog and Smoke. Lisbon, 2010.

3. Lynn, C., C. Schreiner, and R. Campbell. Reducing Fog-Related Crashes on The Afton and Fancy Gap Mountain Sections of I-64 and I-77 in Virginia. Charlottesville, VA, 2002.

4. McDonald, C. Active Traffic and Safety Management System for Interstate 77 in Virginia. July 2015.

5. URS. Concept of Operations for the I-77 Corridor at Fancy Gap. 2012.

6. McCann, K., and M. D.P.E.P.D. Fontaine. Investigation of Driver Speed Choice and Crash Characteristics During Low Visibility Events. Charlottesville, VA, 2016.

7. Snowden, R. J., N. Stimpson, and R. A. Ruddle. Speed Perception Fogs Up As Visibility Drops. Nature, 1998, p. 450.

8. Brooks, J. O., M. C. Crisler, N. Klein, R. Goodenough, R. W. Beeco, C. Guirl, P. J. Tyler, A. Hilpert, Y. Miller, J. Grygier, B. Burroughs, A. Martin, R. Ray, C. Palmer, and C. Beck. Speed Choice and Driving Performance in SImulated Foggy Conditions. Accident Analysis and Prevention, 2011, pp. 698-705.

9. Liang, W. L., M. Kyte, F. Kitchener, and P. Shannon. Effect of Environmental Factors on Driver Speed: A Case Study. Transportation Research Record, 1998.

10. MacCarley, A. Evaluation of Caltrans District 10 Automated Warning System: Year Two Progress Report. 1999.

11. Goodwin, L. Best Practices for Road Weather Management, Version 2.0. Washington, DC, 2003.

12. MacCarley, C.A., C. Ackles, and T. Watts. Highway Traffic Response to Dynamic Fod Warning and Speed Advisory Messages. Transportation Research Record: Journal of the Transportation Research Board, 2006, pp. 95-104.

13. Final Report, Instrumentation and Evaluation of District 10 CalTrans Automated Warning System (CAWS). San Luis Obispo, California, 2005.

14. Traffic Control in Adverse Weather. ITS Decision, 2005. http://fresno.ts.odu.edu/newitsd/ ITS_Serv_Tech/weather_app/weather_applications_weather_traffic_control_report5.html.

15. Kyte, M., P. Shannon, and F. Kitchener. Idaho Storm Warning System Operational Test. 2000.

16. Murphy, R., R. Swick, and G. Guevara. Best Practices for Road Weather Management, Version 3.0. 
Washington DC, 2012.

17. Liu, J. Fog Detection and Warning System. January 30, 2013.

18. Balke, K., P. Songchitruksa, H. Liu, R. Brydia, D. Jasek, and R. Benz. Concept For Managing Freeway Operations During Weather Events. 2007.

19. Abdek-Aty, M., M. Ahmed, J. Lee, Q. Shi, and M. Abuzwidah. Synthesis of Visibility Detection Systems. Orlando, 2012.

20. Gimmestad, G. Development of a Prototype Development of a Prototype Adverse Visibility Warning Adverse Visibility Warning and Control System for and Control System for Operational Evaluation Operational Evaluation. 2004.

21. Perrin, J., P. T. Martin, and B. Coleman. Testing the Adverse Visibility Information System Evaluation (ADVISE) - Safer Driving in Fog. 2000.

22. Kimley-Horn. Synthesis of Practice for Weather-Related Variable Speed Limit Systems in the United States. 2014.

23. Olson, C. S., J. Peters, and J. Crain. Oregon DOT Weather-Responsive Active Traffic Management. in Joint Western/Midwestern District ITE Annual Meeting, 2014.

24. Han, C., J. Luk, V. Pyta, and P. Cairney. Best Practice for Variable Speed Limits: Literature Review. 2009.

25. Robinson, M. Examples of Variable Speed Limit Applications. in TRB 79th Annual Meeting, 2000.

26. California Center for Innovative Transportation. Weather Applications - Traffic Control in Adverse Weather. ITS Decision, 2005. http://fresno.ts.odu.edu/newitsd/ITS_Serv_Tech/weather_app/ weather_applications_weather_traffic_control_report.html.

27. Kimley-Horn. I-77 Variable Speed Limit Standard Operating Procedures. 2015.

28. Kimley-Horn. I-77 Variable Speed Limit: Methodology for Establishing Variable Speed Limits. 2015. 


\title{
APPENDICES
}

\section{APPENDIX A: PUBLICATIONS \& PRESENTATIONS}

\author{
Presentations \\ "Effectiveness of I-77 Fancy Gap Variable Speed Limits", ITSVA/VASITE Joint Conference, \\ Richmond, VA, 2017. \\ "Impact of a Visibility Based Variable Speed Limit on Driver Speeds", SHPE National Conference, \\ Kansas City MO, 2017. \\ "Impact of a Variable Speed Limit System on Driver Speeds During Low Visibility Conditions", \\ Accepted for Poster Presentation, Publication Decision Pending. TRB Annual Meeting, \\ Washington D.C., 2018.
}




\section{APPENDIX B: EXCERPTS FROM MCCANN \& FONTAINE}

Table 5. Crash Severity by Visibility Bin, 2010-2014

\begin{tabular}{|l|c|c|c|c|c|c|c|c|c|}
\hline \multicolumn{1}{|c|}{ Visibility Bin } & \multicolumn{2}{|c|}{ Fatal } & \multicolumn{2}{c|}{ Injury } & \multicolumn{3}{c|}{ Fatal + Injury } & Property Damage Only & Total \\
\hline$>645 \mathrm{ft}, 65 \mathrm{mph}$ & 9 & $2 \%$ & 105 & $23 \%$ & 114 & $25 \%$ & 348 & $75 \%$ & 462 \\
\hline All Low Visibility & 5 & $9 \%$ & 23 & $40 \%$ & 28 & $48 \%$ & 30 & $52 \%$ & 58 \\
\hline $495-645 \mathrm{ft}, 55 \mathrm{mph}$ & 2 & $20 \%$ & 4 & $40 \%$ & 6 & $60 \%$ & 4 & $40 \%$ & 10 \\
\hline $360-495 \mathrm{ft}, 45 \mathrm{mph}$ & 0 & $0 \%$ & 2 & $40 \%$ & 2 & $40 \%$ & 3 & $60 \%$ & 5 \\
\hline $250-360 \mathrm{ft}, 35 \mathrm{mph}$ & 1 & $20 \%$ & 2 & $40 \%$ & 3 & $60 \%$ & 2 & $40 \%$ & 5 \\
\hline $155-250,25 \mathrm{mph}$ & 2 & $5 \%$ & 15 & $41 \%$ & 17 & $46 \%$ & 20 & $54 \%$ & 37 \\
\hline$<155 \mathrm{ft},<25 \mathrm{mph}$ & 0 & $0 \%$ & 0 & $0 \%$ & 0 & $0 \%$ & 1 & $100 \%$ & 1 \\
\hline Error, no visibility information & 0 & $0 \%$ & 2 & $50 \%$ & 2 & $50 \%$ & 2 & $50 \%$ & 4 \\
\hline All Conditions & 14 & $3 \%$ & 130 & $25 \%$ & 144 & $27 \%$ & 380 & $73 \%$ & 524 \\
\hline
\end{tabular}

Table 6. Number of Vehicles Involved in Crashes by Visibility Bin, 2010-2014

\begin{tabular}{|c|c|c|c|c|c|c|c|}
\hline \multirow{3}{*}{$\frac{\text { Visibility Bin }}{>645 \mathrm{ft}, 65 \mathrm{mph}}$} & \multicolumn{6}{|c|}{ Number of Vehicles Involved in Crash } & \multirow{3}{*}{$\frac{\text { Total }}{462}$} \\
\hline & \multicolumn{2}{|c|}{1} & \multicolumn{2}{|c|}{2} & \multicolumn{2}{|c|}{$3+$} & \\
\hline & 246 & $53 \%$ & 172 & $37 \%$ & 44 & $10 \%$ & \\
\hline All Low Visibility & 5 & $9 \%$ & 27 & $47 \%$ & 26 & $45 \%$ & 58 \\
\hline 495-645 ft, $55 \mathrm{mph}$ & 2 & $20 \%$ & 5 & $50 \%$ & 3 & $30 \%$ & 10 \\
\hline $360-495 \mathrm{ft}, 45 \mathrm{mph}$ & 1 & $20 \%$ & 3 & $60 \%$ & 1 & $20 \%$ & 5 \\
\hline $250-360 \mathrm{ft}, 35 \mathrm{mph}$ & 0 & $0 \%$ & 0 & $0 \%$ & 5 & $100 \%$ & 5 \\
\hline $155-25025 \mathrm{mph}$ & 1 & $3 \%$ & 19 & $51 \%$ & 17 & $46 \%$ & 37 \\
\hline$<155 \mathrm{ft},<25 \mathrm{mph}$ & 1 & $100 \%$ & 0 & $0 \%$ & 0 & $0 \%$ & 1 \\
\hline Error, no visibility information & 2 & $50 \%$ & 2 & $50 \%$ & 0 & $0 \%$ & 4 \\
\hline All Conditions & 253 & $48 \%$ & 201 & $38 \%$ & 70 & $13 \%$ & 524 \\
\hline
\end{tabular}

Table 7. Crash Type by Visibility Bin, 2010-2014

\begin{tabular}{|c|c|c|c|c|c|c|c|c|c|c|c|}
\hline \multirow{2}{*}{$\frac{\text { Visibility Bin }}{>645 \mathrm{ft}, 65 \mathrm{mph}}$} & \multicolumn{2}{|c|}{ Rear End } & \multicolumn{2}{|c|}{$\begin{array}{c}\text { Fixed Object - } \\
\text { Off Road }\end{array}$} & \multicolumn{2}{|c|}{ Angle } & \multicolumn{2}{|c|}{$\begin{array}{c}\text { Sideswipe - } \\
\text { Same Direction }\end{array}$} & \multicolumn{2}{|c|}{ Other } & \multirow{2}{*}{$\frac{\text { Total }}{462}$} \\
\hline & 116 & $25 \%$ & 178 & $39 \%$ & 23 & $5 \%$ & 45 & $10 \%$ & 100 & $22 \%$ & \\
\hline All Low Visibility & 37 & $64 \%$ & 3 & $5 \%$ & 10 & $17 \%$ & 6 & $10 \%$ & 2 & $3 \%$ & 58 \\
\hline $495-645 \mathrm{ft}, 55 \mathrm{mph}$ & 4 & $40 \%$ & 1 & $10 \%$ & 4 & $40 \%$ & 0 & $0 \%$ & 1 & $10 \%$ & 10 \\
\hline $360-495 \mathrm{ft}, 45 \mathrm{mph}$ & 2 & $40 \%$ & 0 & $0 \%$ & 1 & $20 \%$ & 1 & $20 \%$ & 1 & $20 \%$ & 5 \\
\hline $250-360 \mathrm{ft}, 35 \mathrm{mph}$ & 5 & $100 \%$ & 0 & $0 \%$ & 0 & $0 \%$ & 0 & $0 \%$ & 0 & $0 \%$ & 5 \\
\hline $155-25025 \mathrm{mph}$ & 26 & $70 \%$ & 1 & $3 \%$ & 5 & $14 \%$ & 5 & $14 \%$ & 0 & $0 \%$ & 37 \\
\hline$<155 \mathrm{ft},<25 \mathrm{mph}$ & 0 & $0 \%$ & 1 & $100 \%$ & 0 & $0 \%$ & 0 & $0 \%$ & 0 & $0 \%$ & 1 \\
\hline Error, no visibility information & 1 & $25 \%$ & 3 & $75 \%$ & 0 & $0 \%$ & 0 & $0 \%$ & 0 & $0 \%$ & 4 \\
\hline All Conditions & 154 & $29 \%$ & 184 & $35 \%$ & 33 & $6 \%$ & 51 & $10 \%$ & 102 & $19 \%$ & 524 \\
\hline
\end{tabular}


Table 8. Crash Rate by Visibility Condition, 2010-2014

\begin{tabular}{|l|c|c|c|c|c|c|}
\hline \multirow{2}{*}{ Visibility Bin } & \multicolumn{3}{|c|}{ Number of Crashes } & \multicolumn{3}{c|}{ Crash Rates } \\
& \multicolumn{2}{|c|}{ Srashes per 100 Million VMT) } \\
& North & South & Both & North & South & Both \\
\hline$>645 \mathrm{ft}, 65 \mathrm{mph}$ & 231 & 231 & 462 & 66.8 & 69.1 & 67.9 \\
\hline All Low Visibility & 9 & 49 & 58 & 175.3 & 1000.5 & 578.1 \\
\hline $495-645 \mathrm{ft}$, 55 mph & 0 & 10 & 10 & 0.0 & 879.3 & 429.3 \\
\hline $360-495 \mathrm{ft}, 45 \mathrm{mph}$ & 1 & 4 & 5 & 73.3 & 307.0 & 187.4 \\
\hline $250-360 \mathrm{ft}, 35 \mathrm{mph}$ & 1 & 4 & 5 & 74.5 & 311.3 & 190.4 \\
\hline $155-25025 \mathrm{mph}$ & 6 & 31 & 37 & 591.5 & 3213.3 & 1869.6 \\
\hline$<155 \mathrm{ft}$, <25 mph & 1 & 0 & 1 & 448.7 & 0.0 & 232.4 \\
\hline No Visibility Information & 2 & 2 & 4 & 6.0 & 4.8 & 5.3 \\
\hline All Conditions & 242 & 282 & 524 & 63.0 & 74.0 & 68.5 \\
\hline
\end{tabular}

Table 9. I-77 Mean Speed by Visibility Bin

\begin{tabular}{|l|c|c|c|c|c|c|}
\hline \multirow{2}{*}{\multicolumn{1}{|c|}{ Visibility Bin }} & \multicolumn{6}{|c|}{ I-77 Southbound } \\
\cline { 2 - 7 } & \multicolumn{2}{|c|}{ MP 5.3 } & \multicolumn{2}{c|}{ MP 6.6 } & \multicolumn{2}{c|}{ MP 7.3 } \\
\cline { 2 - 7 } & $\mathbf{N}$ & $\begin{array}{c}\text { Speed } \\
(\mathbf{m p h})\end{array}$ & $\mathbf{N}$ & $\begin{array}{c}\text { Speed } \\
(\mathbf{m p h})\end{array}$ & $\mathbf{N}$ & $\begin{array}{c}\text { Speed } \\
(\mathbf{m p h})\end{array}$ \\
\hline$>645$ feet $(65 \mathrm{mph})$ & 445 & 68.6 & 1322 & 66.7 & 849 & 65.7 \\
\hline 495-645 feet $(55 \mathrm{mph})$ & 398 & 58.2 & 273 & 62.0 & 104 & 56.0 \\
\hline $360-495$ feet $(45 \mathrm{mph})$ & 480 & 55.8 & 448 & 61.0 & 98 & 51.6 \\
\hline 250-360 feet $(35 \mathrm{mph})$ & 189 & 49.6 & 729 & 57.6 & 22 & 49.9 \\
\hline $155-250$ feet $(25 \mathrm{mph})$ & 15 & 47.2 & 738 & 51.2 & 0 & - \\
\hline$<155$ feet $(<25 \mathrm{mph})$ & 0 & - & 9 & 44.3 & 0 & - \\
\hline
\end{tabular}

Table 10. I-77 Speed Differential between Lanes by Visibility Bin

\begin{tabular}{|l|c|c|c|c|c|c|}
\hline \multirow{2}{*}{ Visibility Bin } & \multicolumn{4}{|c|}{ I-77 Southbound } \\
\cline { 2 - 7 } & $\mathbf{N}$ & $\begin{array}{c}\text { MP 5.3 } \\
\text { Mean Speed } \\
\text { Differential } \\
(\mathbf{m p h})\end{array}$ & $\mathbf{N}$ & $\begin{array}{c}\text { MP 6.6 } \\
\text { Mean Speed } \\
\text { Differential } \\
(\mathbf{m p h})\end{array}$ & $\begin{array}{c}\text { MP 7.3 } \\
\text { Nean Speed } \\
\text { Differential } \\
\text { (mph) }\end{array}$ \\
\hline$>645$ feet (65 mph) & 443 & 3.15 & 1318 & 5.16 & 849 & 3.84 \\
\hline $495-645$ feet $(55 \mathrm{mph})$ & 397 & 3.21 & 270 & 7.39 & 104 & 4.92 \\
\hline $360-495$ feet $(45 \mathrm{mph})$ & 480 & 3.59 & 442 & 7.70 & 98 & 3.87 \\
\hline $250-360$ feet $(35 \mathrm{mph})$ & 187 & 3.36 & 715 & 7.22 & 22 & 3.14 \\
\hline $155-250$ feet $(25 \mathrm{mph})$ & 14 & 6.61 & 701 & 6.54 & 0 & - \\
\hline$<155$ feet $(<25 \mathrm{mph})$ & 0 & - & 2 & -1.10 & 0 & - \\
\hline
\end{tabular}

Table 11. I-77 Speed Profile Characteristics

\begin{tabular}{|c|c|c|c|c|c|c|c|c|c|}
\hline \multirow{2}{*}{ Visibility Bin } & \multirow{2}{*}{ SSD } & \multirow{2}{*}{$\mathbf{N}$} & \multirow{2}{*}{$\begin{array}{l}\text { Mean Speed } \\
(\mathrm{mph})\end{array}$} & \multirow{2}{*}{$\begin{array}{c}\text { Standard } \\
\text { Deviation } \\
(\mathrm{mph})\end{array}$} & \multirow{2}{*}{$\begin{array}{c}\text { Coefficient } \\
\text { of Variation }\end{array}$} & \multirow{2}{*}{$\begin{array}{l}\text { Pace } \\
\text { Speed }\end{array}$} & \multirow{2}{*}{$\begin{array}{c}\% \text { of Vehicles } \\
\text { Traveling in } \\
\text { Pace }\end{array}$} & \multicolumn{2}{|c|}{ Percent Vehicles } \\
\hline & & & & & & & & $>$ SSD & $>\mathrm{SSD}+10 \mathrm{mph}$ \\
\hline$>645$ feet & $65 \mathrm{mph}$ & 1322 & 66.7 & 8.70 & 0.13 & $65-75 \mathrm{mph}$ & $49 \%$ & $\mathrm{n} / \mathrm{a}$ & $\mathrm{n} / \mathrm{a}$ \\
\hline $495-645$ feet & $55 \mathrm{mph}$ & 250 & 61.7 & 9.37 & 0.16 & $60-70 \mathrm{mph}$ & $44 \%$ & $74 \%$ & $33 \%$ \\
\hline $360-495$ feet & $45 \mathrm{mph}$ & 404 & 60.7 & 9.11 & 0.15 & $60-70 \mathrm{mph}$ & $43 \%$ & $92 \%$ & $71 \%$ \\
\hline $250-360$ feet & $35 \mathrm{mph}$ & 683 & 57.5 & 8.99 & 0.16 & $55-65 \mathrm{mph}$ & $44 \%$ & $98 \%$ & $87 \%$ \\
\hline $155-250$ feet & $25 \mathrm{mph}$ & 737 & 51.2 & 9.09 & 0.18 & $50-60 \mathrm{mph}$ & $38 \%$ & $98 \%$ & $92 \%$ \\
\hline$<155$ feet & $<25 \mathrm{mph}$ & 9 & 44.3 & 9.39 & 0.22 & $45-55 \mathrm{mph}$ & $38 \%$ & $99 \%$ & $91 \%$ \\
\hline
\end{tabular}




\section{APPENDIX C: ADDITIONAL TABLES}

Updated 2015 charts

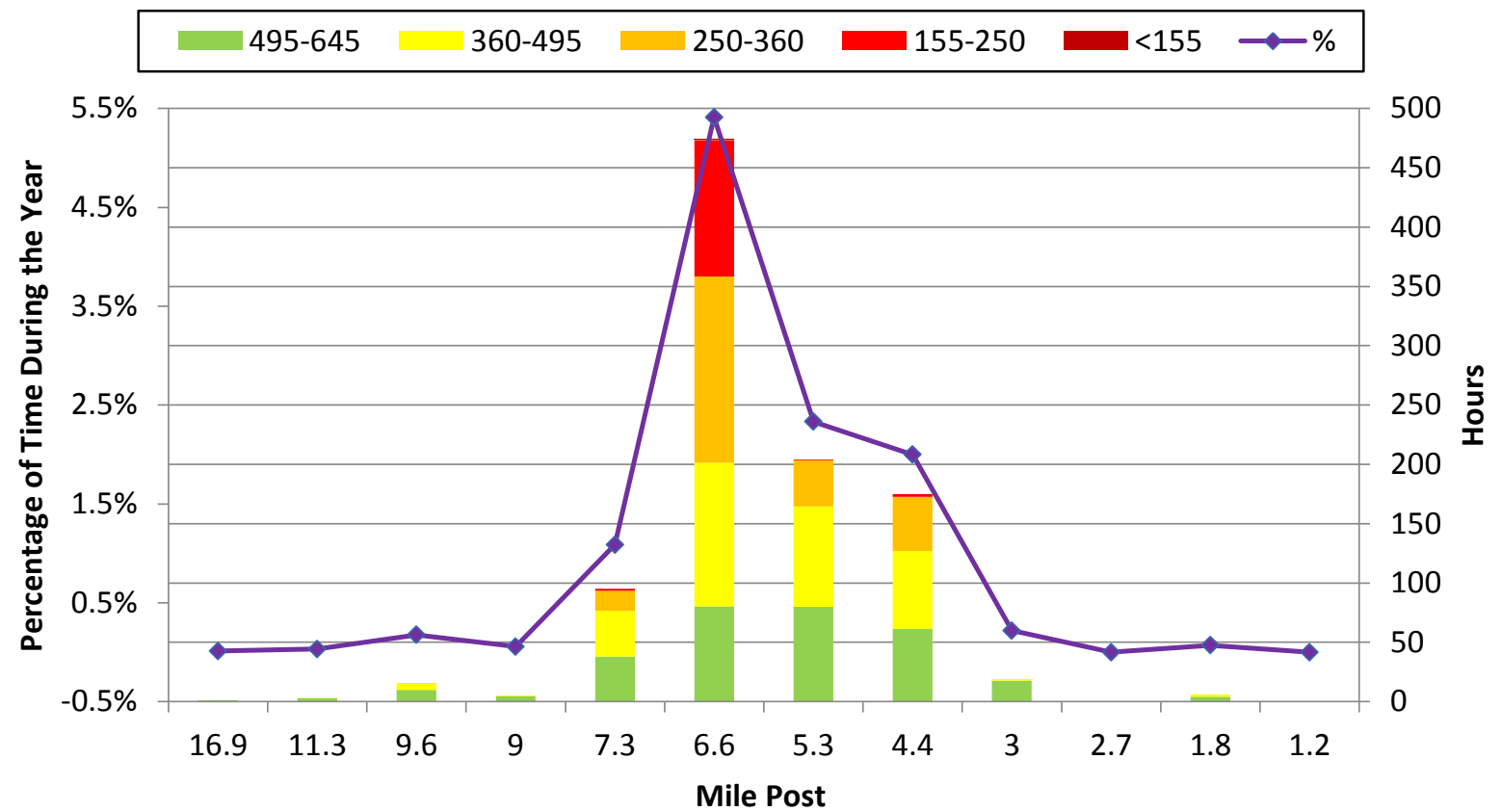

Figure 16 I-77 2015 Visibility Profile

Table 29 Crash Severity by Visibility Bin, 2015

\begin{tabular}{|c|c|c|c|c|c|c|c|c|c|}
\hline Visibility Bin & \multicolumn{2}{|c|}{ Fatal } & \multicolumn{2}{|c|}{ Injury } & \multicolumn{2}{|c|}{$\begin{array}{l}\text { Fatal + } \\
\text { Injury }\end{array}$} & \multicolumn{2}{|c|}{$\begin{array}{c}\text { Property } \\
\text { Damage Only }\end{array}$} & Total \\
\hline 1. $>645$ & 0 & $0 \%$ & 19 & $18 \%$ & 19 & $18 \%$ & 85 & $82 \%$ & 104 \\
\hline All Low Visibility & 0 & $0 \%$ & 1 & $25 \%$ & 1 & $25 \%$ & 3 & $75 \%$ & 4 \\
\hline 2. $495-645$ & 0 & $0 \%$ & 0 & $0 \%$ & 0 & $0 \%$ & 0 & $0 \%$ & 0 \\
\hline 3. $360-495$ & 0 & $0 \%$ & 0 & $0 \%$ & 0 & $0 \%$ & 2 & $100 \%$ & 2 \\
\hline 4. $250-360$ & 0 & $0 \%$ & 1 & $50 \%$ & 1 & $50 \%$ & 1 & $50 \%$ & 2 \\
\hline 5. $155-250$ & 0 & $0 \%$ & 0 & $0 \%$ & 0 & $0 \%$ & 0 & $0 \%$ & 0 \\
\hline $6 .<155$ & 0 & $0 \%$ & 0 & $0 \%$ & 0 & $0 \%$ & 0 & $0 \%$ & 0 \\
\hline $\begin{array}{l}\text { ERROR, NO VISIBILITY } \\
\text { READING }\end{array}$ & 0 & $0 \%$ & 0 & $0 \%$ & 0 & $0 \%$ & 0 & $0 \%$ & 0 \\
\hline All Conditions & 0 & $0 \%$ & 20 & $19 \%$ & 20 & $19 \%$ & 88 & $81 \%$ & 108 \\
\hline
\end{tabular}


Table 30 Number of Vehicles Involved by Visibility Bin, 2015

\begin{tabular}{|l|r|r|r|r|r|r|r|}
\hline Visibility Bin & \multicolumn{2}{|c|}{1} & \multicolumn{2}{|c|}{2} & \multicolumn{2}{|c|}{$3+$} & \multicolumn{1}{|c|}{ Total } \\
\hline 1. $>645$ & 56 & $54 \%$ & 37 & $36 \%$ & 11 & $11 \%$ & 104 \\
\hline All Low Visibility & 1 & $25 \%$ & 2 & $50 \%$ & 1 & $25 \%$ & 4 \\
\hline $2.495-645$ & 0 & $0 \%$ & 0 & $0 \%$ & 0 & $0 \%$ & 0 \\
\hline $3.360-495$ & 1 & $50 \%$ & 1 & $50 \%$ & 0 & $0 \%$ & 2 \\
\hline $4.250-360$ & 0 & $0 \%$ & 1 & $50 \%$ & 1 & $50 \%$ & 2 \\
\hline $5.155-250$ & 0 & $0 \%$ & 0 & $0 \%$ & 0 & $0 \%$ & 0 \\
\hline $6 .<155$ & 0 & $0 \%$ & 0 & $0 \%$ & 0 & $0 \%$ & 0 \\
\hline ERROR, NO VISIBILITY READING & 0 & $0 \%$ & 0 & $0 \%$ & 0 & $0 \%$ & 0 \\
\hline All Conditions & 57 & $53 \%$ & 39 & $36 \%$ & 12 & $11 \%$ & 108 \\
\hline
\end{tabular}

Table 31 Crash Type by Visibility Bin, 2015

\begin{tabular}{|c|c|c|c|c|c|c|c|c|c|c|c|}
\hline \multirow{2}{*}{$\frac{\text { Visibility Bin }}{1 .>645}$} & \multicolumn{2}{|c|}{ Rear End } & \multicolumn{2}{|c|}{$\begin{array}{c}\text { Fixed } \\
\text { Object- } \\
\text { Off Road }\end{array}$} & \multicolumn{2}{|c|}{ Angle } & \multicolumn{2}{|c|}{$\begin{array}{c}\text { SideSwipe - } \\
\text { Same } \\
\text { Direction }\end{array}$} & \multicolumn{2}{|c|}{ Other } & \multirow{2}{*}{$\frac{\text { Total }}{104}$} \\
\hline & 22 & $21 \%$ & 35 & $34 \%$ & 7 & $7 \%$ & 14 & $13 \%$ & 26 & $25 \%$ & \\
\hline All Low Visibility & 2 & $50 \%$ & 0 & $0 \%$ & 0 & $0 \%$ & 1 & $25 \%$ & 1 & $25 \%$ & 4 \\
\hline 2. $495-645$ & 0 & $0 \%$ & 0 & $0 \%$ & 0 & $0 \%$ & 0 & $0 \%$ & 0 & $0 \%$ & 0 \\
\hline 3. $360-495$ & 0 & $0 \%$ & 0 & $0 \%$ & 0 & $0 \%$ & 1 & $50 \%$ & 1 & $50 \%$ & 2 \\
\hline 4. $250-360$ & 2 & $100 \%$ & 0 & $0 \%$ & 0 & $0 \%$ & 0 & $0 \%$ & 0 & $0 \%$ & 2 \\
\hline 5. $155-250$ & 0 & $0 \%$ & 0 & $0 \%$ & 0 & $0 \%$ & 0 & $0 \%$ & 0 & $0 \%$ & 0 \\
\hline 6. $<155$ & 0 & $0 \%$ & 0 & $0 \%$ & 0 & $0 \%$ & 0 & $0 \%$ & 0 & $0 \%$ & 0 \\
\hline $\begin{array}{l}\text { ERROR, NO VISIBILITY } \\
\text { READING }\end{array}$ & 0 & $0 \%$ & 0 & $0 \%$ & 0 & $0 \%$ & 0 & $0 \%$ & 0 & $0 \%$ & 0 \\
\hline All Conditions & 24 & $22 \%$ & 35 & $32 \%$ & 7 & $6 \%$ & 15 & $14 \%$ & 27 & $25 \%$ & 108 \\
\hline
\end{tabular}

Table 322015 Crash Rates

\begin{tabular}{|l|c|c|c|c|c|c|r|r|r|}
\hline \multirow{2}{*}{ Visibility Bin } & \multicolumn{2}{|c|}{ Number of Crashes } & \multicolumn{4}{c|}{ Crash Rate } & \multicolumn{3}{c|}{ \% of Total VMT } \\
\cline { 2 - 11 } & North & South & Both & North & South & Both & North & South & Both \\
\hline$>645$ & 47 & 57 & 104 & 51.9 & 62.8 & 57.4 & $44 \%$ & $44 \%$ & $89 \%$ \\
\hline ALL LOW VISIBILITY & 1 & 3 & 4 & 127.5 & 393.0 & 258.4 & $0.38 \%$ & $0.37 \%$ & $0.76 \%$ \\
\hline $495-645$ & 0 & 0 & 0 & 0.0 & 0.0 & 0.0 & $0.12 \%$ & $0.12 \%$ & $0.24 \%$ \\
\hline $360-495$ & 1 & 1 & 2 & 384.8 & 398.9 & 391.8 & $0.13 \%$ & $0.12 \%$ & $0.25 \%$ \\
\hline $250-360$ & 0 & 2 & 2 & 0.0 & 1076.0 & 531.4 & $0.09 \%$ & $0.09 \%$ & $0.18 \%$ \\
\hline $155-250$ & 0 & 0 & 0 & 0.0 & 0.0 & 0.0 & $0.04 \%$ & $0.04 \%$ & $0.08 \%$ \\
\hline$<155$ & 0 & 0 & 0 & 0.0 & 0.0 & 0.0 & $0.00 \%$ & $0.00 \%$ & $0.00 \%$ \\
\hline Error/No Reading & 0 & 0 & 0 & 0.0 & 0.0 & 0.0 & $5.16 \%$ & $5.39 \%$ & $10.54 \%$ \\
\hline ALL VISIBILITY & 48 & 60 & 108 & 47.1 & 58.5 & 52.8 & $50 \%$ & $50 \%$ & $100 \%$ \\
\hline
\end{tabular}

